\title{
Analysis of the Air Voids within Superpave Gyratory Compacted Hot Mix Asphalt Specimens
}

Andrew Manuel Aguilar

Follow this and additional works at: https://researchrepository.wvu.edu/etd

\section{Recommended Citation}

Aguilar, Andrew Manuel, "Analysis of the Air Voids within Superpave Gyratory Compacted Hot Mix Asphalt Specimens" (2015). Graduate Theses, Dissertations, and Problem Reports. 5034.

https://researchrepository.wvu.edu/etd/5034

This Thesis is protected by copyright and/or related rights. It has been brought to you by the The Research Repository @ WVU with permission from the rights-holder(s). You are free to use this Thesis in any way that is permitted by the copyright and related rights legislation that applies to your use. For other uses you must obtain permission from the rights-holder(s) directly, unless additional rights are indicated by a Creative Commons license in the record and/ or on the work itself. This Thesis has been accepted for inclusion in WVU Graduate Theses, Dissertations, and Problem Reports collection by an authorized administrator of The Research Repository @ WVU. For more information, please contact researchrepository@mail.wvu.edu. 
Analysis of the Air Voids within Superpave Gyratory Compacted Hot Mix Asphalt Specimens

\title{
Andrew Manuel Aguilar
}

\author{
Thesis submitted to the \\ Benjamin M. Statler College of Engineering and Mineral Resources \\ at West Virginia University \\ in partial fulfillment of the requirements for the degree of
}

Master of Science In

Civil Engineering

Dr. John P. Zaniewski, Chair

Dr. Avinash Unnikrishnan

Dr. Yoojung Yoon

Department of Civil and Environmental Engineering

Morgantown, West Virginia

2015

Keywords: asphalt, Superpave, specific gravity, air voids, AMPT samples Copyright 2015 Andrew Manuel Aguilar 


\title{
Abstract \\ Analysis of the Air Voids within Superpave Gyratory \\ Compacted Hot Mix Asphalt Specimens
}

\begin{abstract}
Andrew Manuel Aguilar
The influence of mix design properties on the mechanical properties of Superpave hot mix asphalt samples has been researched by the state of West Virginia with the Asphalt Mixture Performance Tester (AMPT) since its acquisition in 2013. The dynamic modulus, flow number, and number of cycles to failure through uniaxial fatigue testing are all affected by the mix properties of the sample being tested. It has been a concern if samples prepared with the Superpave gyratory compactor (SGC) for testing with the AMPT have a uniform distribution of air voids within the sample.

Through review of literature the uniformity of air voids within a sample has been found to be a function of the mix properties of the samples, the equipment used to compact the sample, and the geometry of the sample. The compaction equipment and sample dimensions have been found to consistently have a significant effect on the uniformity of air voids within a sample. The effect of mix properties on the uniformity of air voids within a sample has been found to vary by mix design. The goal of this experiment was to determine if there is a significant difference in the air voids measured in the middle of Hot Mix Asphalt (HMA) samples in comparison to the air voids in the ends of the sample.
\end{abstract}

This thesis has found that the SGC prepared samples for AMPT dynamic modulus testing has produced samples with significantly greater air voids in the middle than the air voids at the ends of the specimen with a significance level of 0.05 . It was found that the measured air void difference in the middle and ends of the samples prepared with the SGC is not affected by the method of measuring the air voids or the sample's mix properties. From the results of this thesis it is recommended that samples are prepared by SGCs from manufacturers other than the Pine AFGC125X used in this research to verify that compacted samples with a non-uniform air void distribution is not unique to the SGC used in this study. It is also recommended that a heterogeneity index threshold be explored in order to distinguish samples that have an acceptable air void distribution for performance testing with the AMPT. 


\section{Acknowledgement}

First of all I would like to thank my advisor Dr. Zaniewski for helping me complete this research project as well as giving me constant lessons in the field of asphalt technology. I met Dr. Zaniewski in 2011 when he was a guest speaker for my materials class at Marshall University and at the time I had no idea how much of an impact he would have on my professional development. I would also like to thank my committee members, Dr. Yoon and Dr. Unnikrishnan, for all of their help in the completion of this thesis. Being surrounded by these great minds has helped build me into a better engineer.

Secondly, I would like to thank all of the graduate students in the asphalt technology program that helped me in the completion of this research topic. Frankie, Lara, Kyle, Justin, Steve, and Hadi; thank you for helping me whenever I needed your assistance whether it be in the asphalt lab or consultation on my research.

I would also like to thank my family and friends for all of their support and providing me with advice whenever necessary. Lastly, I would like to thank God for blessing me with this opportunity and surrounding me with the people at West Virginia University that have helped make this accomplishment possible. 


\section{Table of Contents}

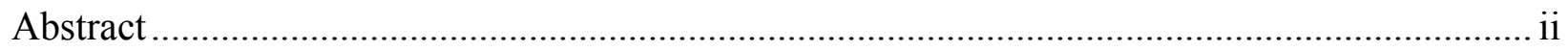

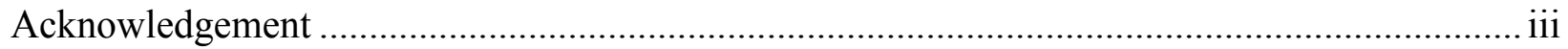

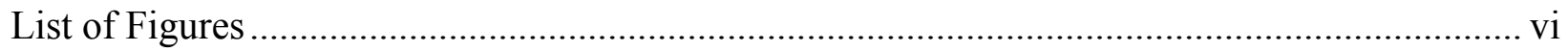

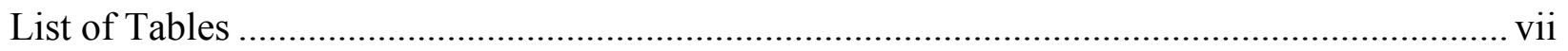

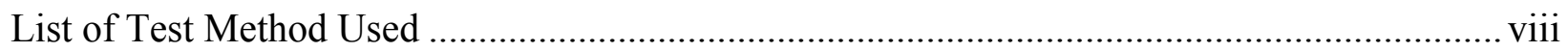

Chapter 1 Introduction ............................................................................................. 1

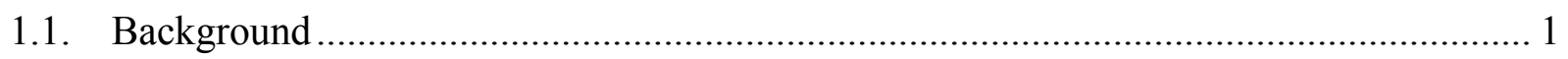

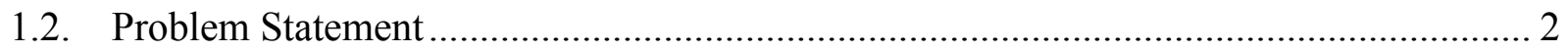

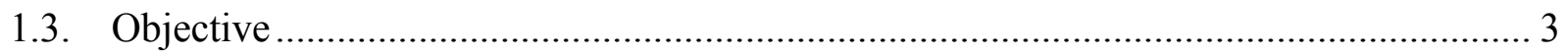

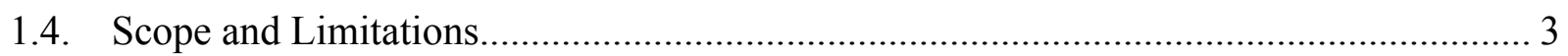

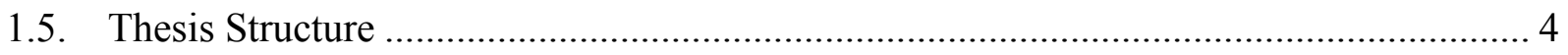

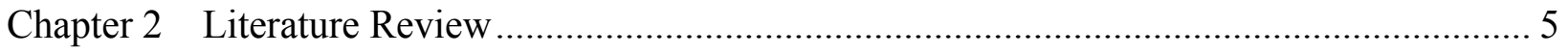

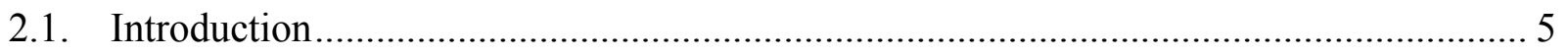

2.2. Specific Gravity and Air Voids of Asphalt Concrete ………………............................ 5

2.3. Theoretical Maximum Specific Gravity …………….................................................. 5

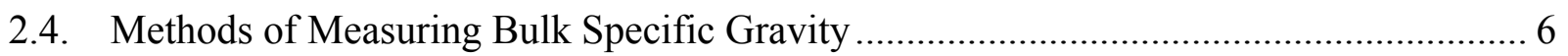

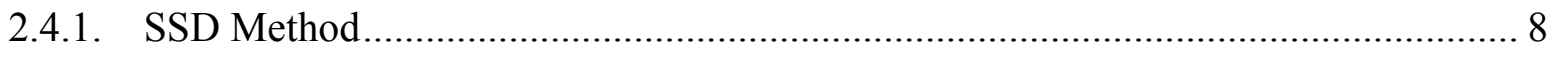

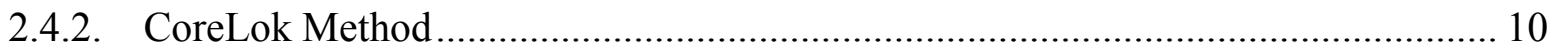

2.4.1. Dimensional Method.......................................................................................... 13

2.5. Superpave Gyratory Compactor ……………………............................................. 13

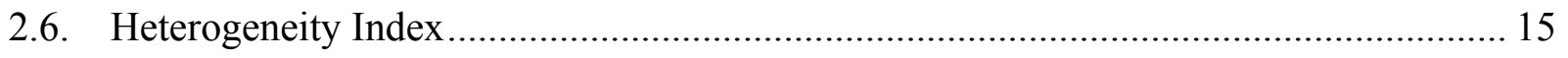

2.7. Evaluation of Heterogeneous Air Void Distribution in HMA Samples ......................... 15

2.8. AASHTO PP 60 Assessing Test Specimen Uniformity ................................................. 17 
2.9. Background of AMPT and Effect of Air Voids on Mechanical Properties of AMPT

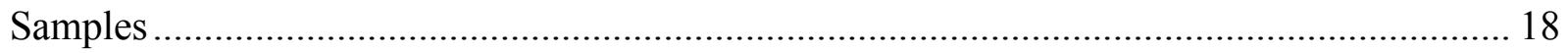

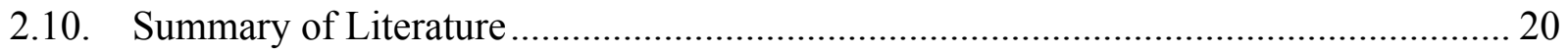

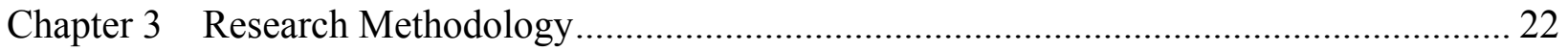

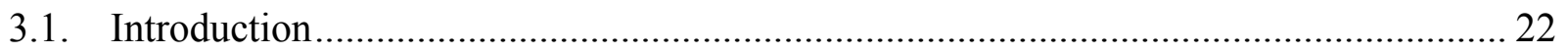

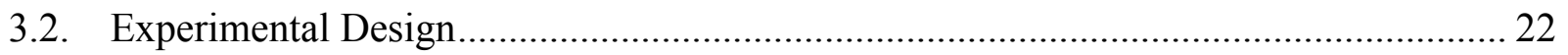

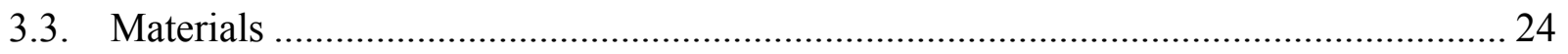

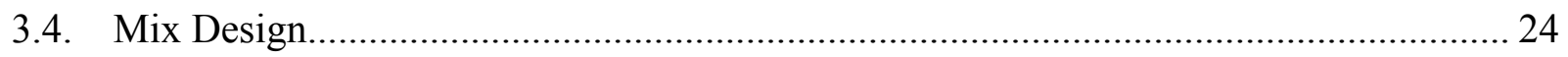

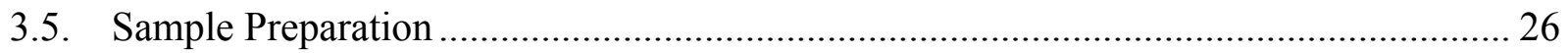

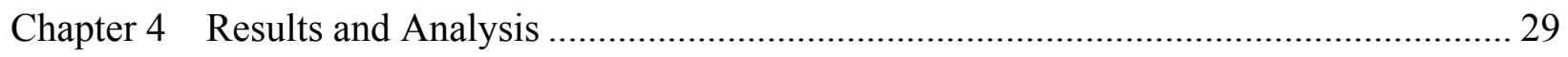

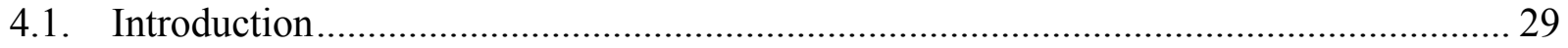

4.2. $\quad \mathrm{T}$ test of Air Voids Measured from Two $\mathrm{G}_{\mathrm{mb}}$ Methods .......................................... 30

4.3. ANOVA of Air Voids in Whole Sample ............................................................... 31

4.4. T test Comparing Air Voids in the Middle and Ends of Sample ................................ 32

4.5. Analysis of Air Voids within Sample ................................................................. 34

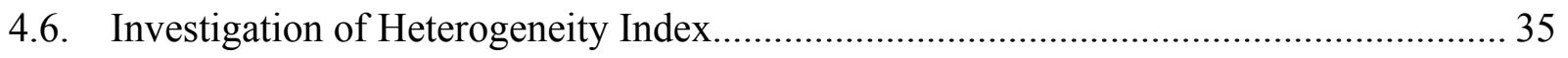

Chapter 5 Conclusions and Recommendations.............................................................. 37

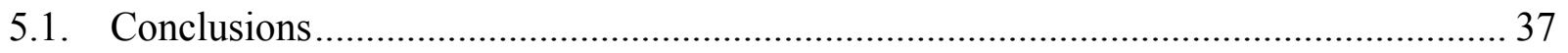

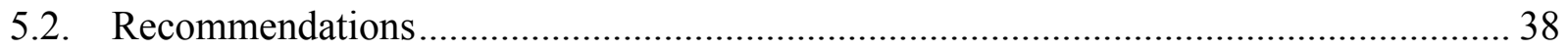

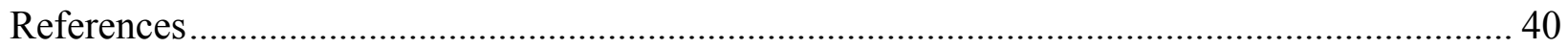

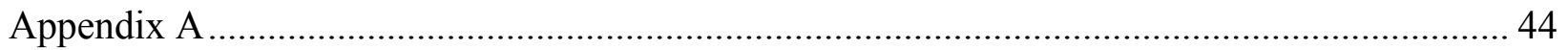

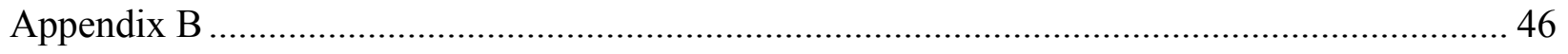

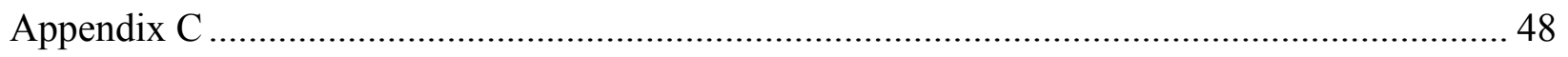

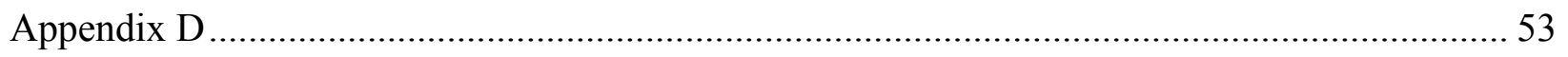

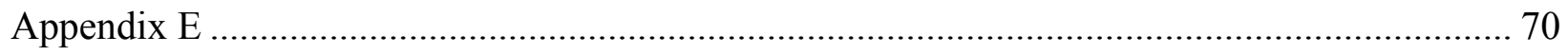




\section{List of Figures}

Figure 1 - Volumes Associated with Compacted HMA (Cooley, et al., 2002) ......................... 7

Figure 2 Illustration of Archimedes' Principle (Encyclopedia Brittanica, 2015) ........................ 8

Figure 3 Difference in Internal Air-Voids Structure of Coarse and Fine-Graded Mixes (Cooley,

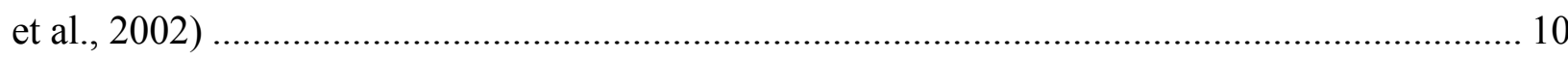

Figure 4 CoreLok Device (Pavement Interactive, 2011) .................................................. 11

Figure 5 Generic Superpave Gyratory Compactor (McGennis, et al., 1994) ........................... 14

Figure 6 Compaction Cone and Mold Effect on HMA (Thyagarajan, et al., 2010) .................. 16

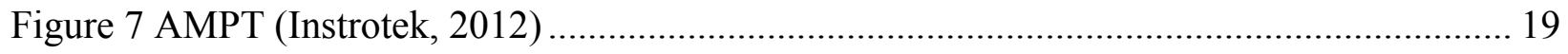

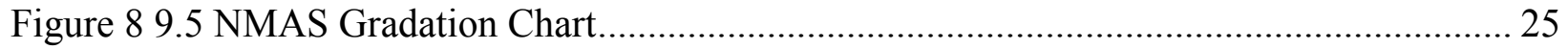

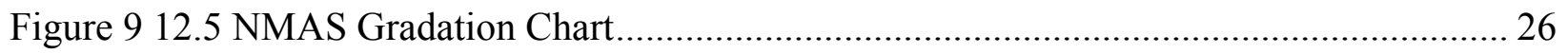

Figure 10 Boxplot Comparing CoreLok and Dimensional Method ........................................ 31

Figure 11 Boxplot Comparing Air Voids in the Middle and Ends of the Specimen Using

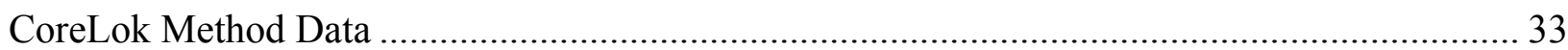

Figure 12 Boxplot Comparing Air Voids in the Middle and Ends of Specimen Using

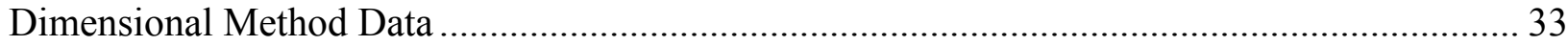




\section{List of Tables}

Table 1 Apparent Gravity of CoreLok Sample Bag (Instrotek, 2011) .................................... 12

Table 2 Summary of Experimental Factors .................................................................... 22

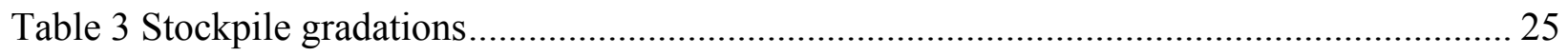

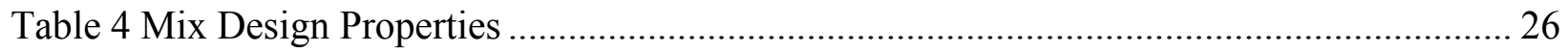

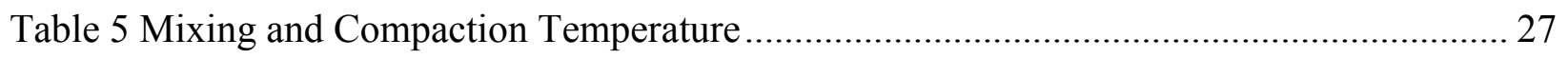

Table 6 Test Specimen Dimensional Tolerances in AASHTO PP 60 ................................... 27

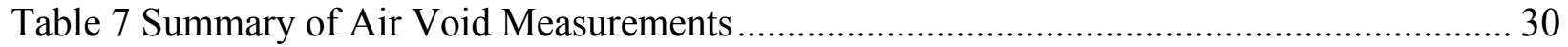

Table 8 Statistical Significance of $\mathrm{G}_{\mathrm{mb}}$ Method and Mix Properties on Air Voids .................... 32

Table 9 ANOVA of Air Voids within Sample Using CoreLok Data ....................................... 34

Table 10 ANOVA of Air Voids Within Sample Using Dimensional Data ............................... 35

Table 11 ANOVA of Heterogeneity Index and Mix Properties Using CoreLok Method Data ... 35

Table 12 ANOVA of Heterogeneity Index and Mix Properties Using Dimensional Method Data 


\section{List of Test Method Used}

1. AASHTO PP 60: Preparation of Cylindrical Performance Test Specimens Using the Superpave Gyratory Compactor. Washington, DC: American Association of State Highway and Transportation Officials, 2014.

2. AASHTO T 166: Bulk Specific Gravity of Compacted Hot Mix Asphalt (HMA) Using Saturated Surface-Dry Specimens. Washington, DC: American Association of State Highway and Transporation Officials, 2014.

3. AASHTO T 209: Theoretical Maximum Specific Gravity (Gmm) and Density of Hot Mix Asphalt (HMA). Washington, DC: American Association of State Highway and Transportation Officials, 2014.

4. AASHTO T 269: Percent of Air Voids in Compacted Dense and Open Asphalt Mixtures. Washington, DC: American Association of State Highway and Transportation Officials, 2014.

5. AASHTO T 312: Preparing and Determining the Density of Hot Mix Asphalt (HMA) by Means of the Superpave Gyratory Compactor. Washington, DC: American Association of State Highway Transportation Officials, 2014.

6. AASHTO T 331: Bulk Specific Gravity and Density of Compacted Hot Mix Asphalt (HMA) Using Automatic Vacuum Sealing Method. Washington, DC: American Association of State Highway and Transportation Officials, 2014.

7. ASTM D3549: Standard Test Method for Thickness or Height of Compacted Bituminous Paving Mixture Specimens. ASTM International, West Conshohocken, PA, 2011. 


\section{Chapter 1 Introduction}

\subsection{Background}

The amount of air voids in a Hot Mix Asphalt (HMA) mixture is one of the most important factors that affects the life of the pavement (Brown, et al., 2009). Numerous pavement distresses are directly related to the air voids. The air voids within the HMA layer of a pavement affects the pavement strength, fatigue life, durability, raveling, rutting and moisture damage susceptibility (Pavement Interactive, 2010). In order to estimate the performance of the HMA layer of pavements in the field, HMA samples are prepared in the laboratory with the most similar properties possible.

With the implementation of the Superpave Mix Design method, the Superpave Gyratory Compactor (SGC) was developed to prepare HMA samples with a similar compaction of HMA in the field. The SGC can compact samples to a $150 \mathrm{~mm}$ diameter and the height of the specimen can vary depending on the target height required for the test being performed. For mix design the target height is achieved by setting a number of gyrations to be applied by the SGC and using an appropriate amount of material to make samples that are $115 \pm 5 \mathrm{~mm}$ tall. Samples for other tests, such as the tensile-strength ratio test the SGC is set to use the number of gyrations needed to achieve a specific height. Generally these tests require a specific level of air voids. If the target air voids is not achieved, the mass of the sample must be adjusted and a new sample must be prepared.

In 2014, West Virginia University (WVU) Asphalt Technology Program began performance testing of HMA samples with the Asphalt Mixture Performance Tester (AMPT). This testing equipment requires compacting specimens with an initial height of 160 to $180 \mathrm{~mm}$ and diameter of $150 \mathrm{~mm}$. The samples are then sawn and cored to the dimensions required for testing with the AMPT. Since the sample height required for the AMPT specimens is much greater than the height of the samples the machine was designed to prepare there is a concern that the air void distribution within the sample may not be uniform.

The compaction energy that goes into HMA in the SGC is one factor that affects the volume of air voids in the compacted sample. If there is not a uniform distribution of the compaction 
energy then there will not be a uniform distribution of air voids within the sample. Testing specimens with a non-uniform air void distribution can cause a high variation in stresses and strains within a specimen thus affecting testing repeatability and eventually misrepresenting the material response (Tashman, et al., 2002). AASHTO PP 60:Preparation of Cylindrical Performance Test Specimens Using the Superpave Gyratory Compactor is the standard method for the preparation of samples that are used for AMPT testing. This method requires compacting samples to dimensions greater than is required for AMPT testing. The sample is then cut and cored to the dimensions required for AMPT test. In concept, removing the sides and ends of the compacted sample eliminates the side and end effects of the compacted sample resulting in a more uniform sample for the AMPT testing.

\subsection{Problem Statement}

The compaction of HMA is sensitive to the following (Copple, 1998):

- Aggregate gradation, shape, and surface texture.

- Asphalt binder content and grade.

- Construction practices, compaction temperature, and compaction equipment.

For laboratory prepared samples, these factors are accounted for in the mix design, preparation procedures specified in American Association of State Highway and Transportation Officials (AASHTO) test methods, and equipment available at the asphalt laboratory. How these factors and the interaction of these factors affect the air void distribution in HMA samples is of interest.

The specimen geometry for the AMPT samples was established through the study "Specimen Geometry and Aggregate Size Effects in Uniaxial Compression and Constant Height Shear Tests" (Witczak, et al., 2000). Testing with the AMPT uses linear variable differential transducers (LVDTs) to measure the deformation over the middle $70 \mathrm{~mm}$ of the AMPT specimens. Witczak et al. measured the sample's deformation over the middle portion of the sample equal to the diameter of the specimen. For his $100 \mathrm{~mm}$ diameter and $150 \mathrm{~mm}$ height specimens the LVDT gauge points were placed over the middle $100 \mathrm{~mm}$ of the specimen. First they measured the air voids in the entire sample and then they cut the middle $100 \mathrm{~mm}$ from the sample and measured the air voids of this section. They found that there was not a significant 
difference between the air voids. This conclusion suggested that the specimen geometry developed in their study produces samples with a uniform distribution of air voids within the sample. In 2010, Thyagarajan et al. used X-Ray Computed Tomography (CT) and Image Analysis Techniques to measure the air void distribution in samples with the same geometry and found the samples to have a non-uniform distribution of air voids.

\subsection{Objective}

With the implementation of AMPT testing at WVU it is desirable to know if the SGC is creating samples with the same air voids in the middle and ends of the sample. The objective of this project is to determine if AMPT samples prepared with the SGC have a uniform distribution of air voids within the sample. The air voids in the middle of the sample was measured and compared to the air voids on the ends of the sample.

\subsection{Scope and Limitations}

For this study samples were prepared in accordance with the method specified in AASHTO PP 60. Samples were prepared for AMPT dynamic modulus testing. Upon completion of compaction, sawing, and coring of the specimens the AMPT malfunctioned and was not available for testing. This resulted in a research topic change to evaluating the air voids within AMPT specimens. AASHTO PP 60 has a method in Appendix X2 for measuring the air void distribution where the ends are distinguished as either the top or bottom of the specimen. The protocol for the dynamic modulus testing does not require marking the compaction orientation of the samples. Since the orientation of the samples was not needed for AMPT testing the compaction orientation of the samples was not marked as is needed for the protocol of AASHTO PP 60 Appendix X2. It was decided that the samples could be used for testing the internal variation of the air voids by comparing the slices from the middle of the sample to the slices from the ends of the sample.

The three sections of the $150 \mathrm{~mm}$ sample were $48 \pm 2.5 \mathrm{~mm}$. This is because the thickness of the saw used to cut the $150 \mathrm{~mm}$ tall samples into three even sections was measured to be $2.5 \mathrm{~mm}$. The air voids was measured in the entire sample and in each of these three slices. 
Air voids of the samples prepared at WVU are measured using either the CoreLok or saturated surface dry (SSD) methods. Due to the exposure of aggregate faces after sawing and coring, the SSD method could give false readings due to the potential of the aggregates to absorb water. The CoreLok method, which vacuum seals the specimen in puncture resistant polymer bags was chosen as the alternative method. The dimensional method for determining the volume of the samples for computing the bulk specific gravity was also used for both the whole samples and the slices.

\subsection{Thesis Structure}

This thesis consists of five chapters. Chapter 1 is a summary of the research performed and presents the background information related to this thesis. Chapter 2 is a literature review of papers related to the thesis topic; including measurements of air voids, the principles of the Superpave Gyratory Compactor, causes of non-uniform distribution of air voids, and the relationship between AMPT testing and air voids. Chapter 3 presents the research methodology and an explanation of the experimental factors. Chapter 4 presents the results from the project that were organized and performed through the statistical analysis software RStudio. Chapter 5 presents the conclusions and recommendations from this thesis. 


\section{Chapter 2 Literature Review}

\subsection{Introduction}

This chapter covers the methods of measuring air voids in HMA laboratory samples and why these different methods result in different measurements for air voids. A background of the SGC equipment and recent literature on the air void distribution within HMA samples is evaluated. The heterogeneity index is introduced as a quantitative method for determining what mix properties affect the air void uniformity of samples produced with the SGC. Lastly, background information of AMPT testing and the effect of air voids on the mechanical properties of asphalt samples tested with the AMPT are presented.

\subsection{Specific Gravity and Air Voids of Asphalt Concrete}

Specific gravity is the ratio of a materials density to the density of water at a specified temperature (Pavement Interactive, 2011). The two properties needed to compute the air voids in a compacted HMA sample are the theoretical maximum specific gravity $\left(\mathrm{G}_{\mathrm{mm}}\right)$ of a HMA mix and the bulk specific gravity $\left(\mathrm{G}_{\mathrm{mb}}\right)$ of the compacted sample. The theoretical maximum specific gravity is the specific gravity of a mixture excluding air voids, and the bulk specific gravity is the specific gravity of a compacted sample. The percent air voids within a samples is computed by subtracting the ratio between the bulk and maximum specific gravity from one, Equation 1.

$$
\begin{gathered}
\% \text { Air Voids }=100 *\left(1-\frac{G_{m b}}{G_{m m}}\right) \\
G_{m b}=\text { bulk specific of the compacted mix } \\
G_{m m}=\text { theoretical maximum specific gravity of the mix }
\end{gathered}
$$

\subsection{Theoretical Maximum Specific Gravity}

The theoretical maximum specific gravity of a mix is measured in accordance with $A A S H T O$ T 209. Jim Rice of the Asphalt Institute developed the test so it is frequently called the Rice test (Mamlouk and Zaniewski, 2011). The method requires a loose mix to be prepared in accordance with AASHTO procedures and then the sample is cooled to the test temperature $\left(25^{\circ} \mathrm{C}\right)$. While the sample cools, the particles are separated to ensure none of the fine aggregate portions are 
larger than $1 / 4$ inch. The dry weight of the sample is measured, placed in a tarred vacuum bowl, and then the material is covered with water at $25^{\circ} \mathrm{C}$. A vacuum is applied to the bowl until the residual pressure reads $25 \pm 2.5 \mathrm{~mm} \mathrm{Hg}$ for $15 \pm 2 \mathrm{~min}$ to remove all air. The sample and tarred bowl is then submerged in water at $25^{\circ} \mathrm{C}$ and weighed. The theoretical maximum specific gravity is calculated using Equation 2.

$$
\begin{gathered}
G_{m m}=\frac{M_{s}}{M_{s}+M_{b s}-M_{b m s}} \\
M_{s}=\text { Dry Mass of Sample, } g \\
M_{b s}=\text { Mass of Vacuum Bowl Submerged, } g \\
M_{b m s}=\text { Mass of bowl and submerged sample in water, } g
\end{gathered}
$$

\section{Equation 2}

\subsection{Methods of Measuring Bulk Specific Gravity}

The bulk specific gravity is the specific gravity of the mix after compaction. There are several methods to measure the bulk specific gravity of compacted HMA. These can be categorized as water displacement, dimensional, and gamma/x-ray methods (Pavement Interactive, 2011). For the gamma/x-ray method is not commonly used so it will not be considered further in this research. For the dimensional method, the density of the material is used to calculate its specific gravity. The density of a sample is the mass of the sample divided by its volume. The mass of the sample is obtained by placing it on a scale. The measured volume of the sample varies based on the test method.

The volume of the sample can be measured by using water submersion or from the sample dimensions measured with calipers. Since each of these methods will measure a different volume for the sample, they lead to different values for the bulk specific gravity of the sample. This produces discrepancies in computed air voids amongst different bulk specific gravity methods. Figure 1 illustrates the volumes and air voids that are associated with a compacted HMA sample (Cooley, et al., 2002). 


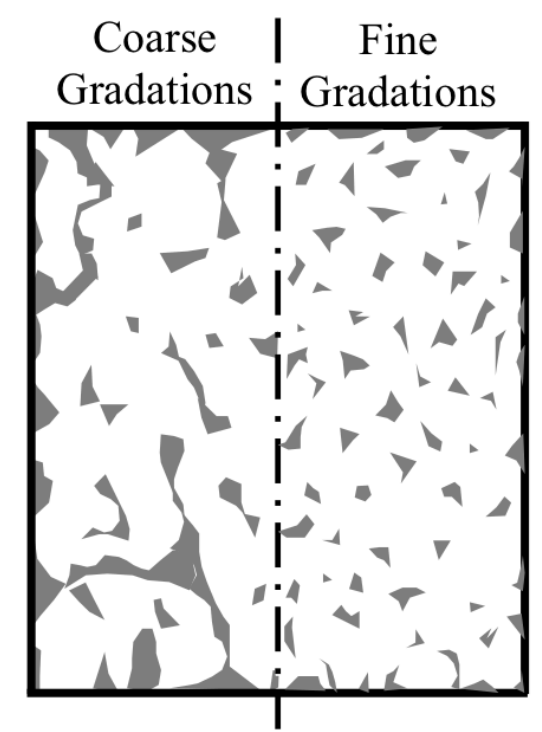

a) Gyratory Volume

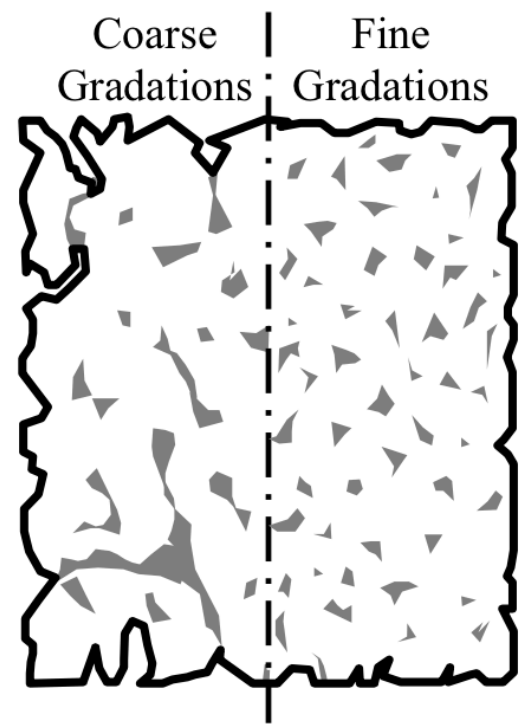

b) Apparent Volume
Coarse | Fine Gradations; Gradations

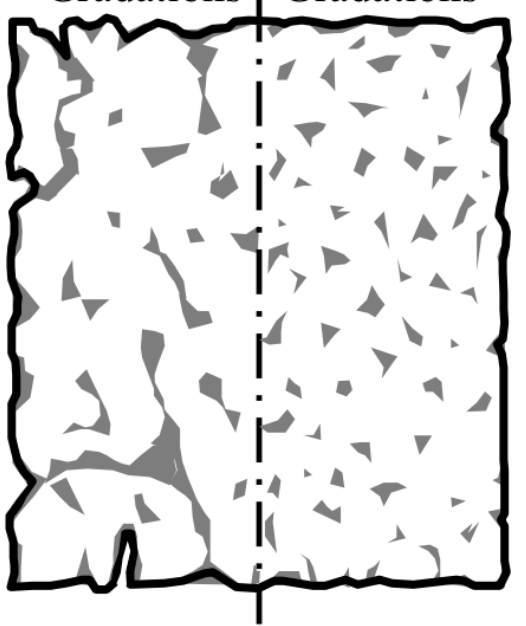

c) Bulk Volume

Figure 1 - Volumes Associated with Compacted HMA (Cooley, et al., 2002)

Figure 1 shows a side-by-side comparison of two compacted samples with two different NMAS and the same mass. Figure 1 a) shows the gyratory volume of a compacted sample. This volume is associated with the specific gravity obtained when using the dimensional procedure. It includes the air voids inaccessible to water, the voids accessible to water, and the surface irregularities. Figure 1 b) shows the apparent volume of the sample. This volume does not include the surface irregularities or the voids accessible to water but does include the voids that are inaccessible to water. Figure $1 \mathrm{c}$ ) shows the bulk volume of a compacted sample. This volume includes the voids that are and are not accessible by water within the sample but does not include surface irregularities. The density obtained from this volume corresponds with the bulk specific gravity measured from the SSD method.

Using different bulk specific gravity methods will lead to different computed air voids for the same sample. The gyratory volume considers the surface irregularities as internal air voids. Test methods such as the dimensional procedure that use the gyratory volume determines a bulk specific gravity that is less than the computed bulk specific gravity from other methods. This leads to an upper bound for the air void content of a sample. The SSD method measures the air voids of the sample using the bulk volume so the SSD bulk specific gravity is greater than other methods. This creates a lower bound for the air void content. Crouch et al. (2007) found that 
90\% of Tennessee Department of Transportation sample groups tested with the CoreLok method had air voids between these upper and lower bounds.

\subsubsection{SSD Method}

A standard test method for measuring the bulk specific gravity of a sample is the SSD method (West, et al., 2010). The SSD method for determining the bulk specific gravity of a sample uses Archimedes' principle to determine the volume of the sample. Archimedes' principle states that the volume of an irregularly shaped object can be determined by the mass of water displaced by the object (Crouch, et al., 2003). The volume of water displaced will be equal to the volume of the sample. Figure 2 illustrates this principle. The buoyant force acting on the sample in the water is equal to the mass of water displaced by a submerged sample. If the density of the water displaced is known, the volume of the sample can be obtained.
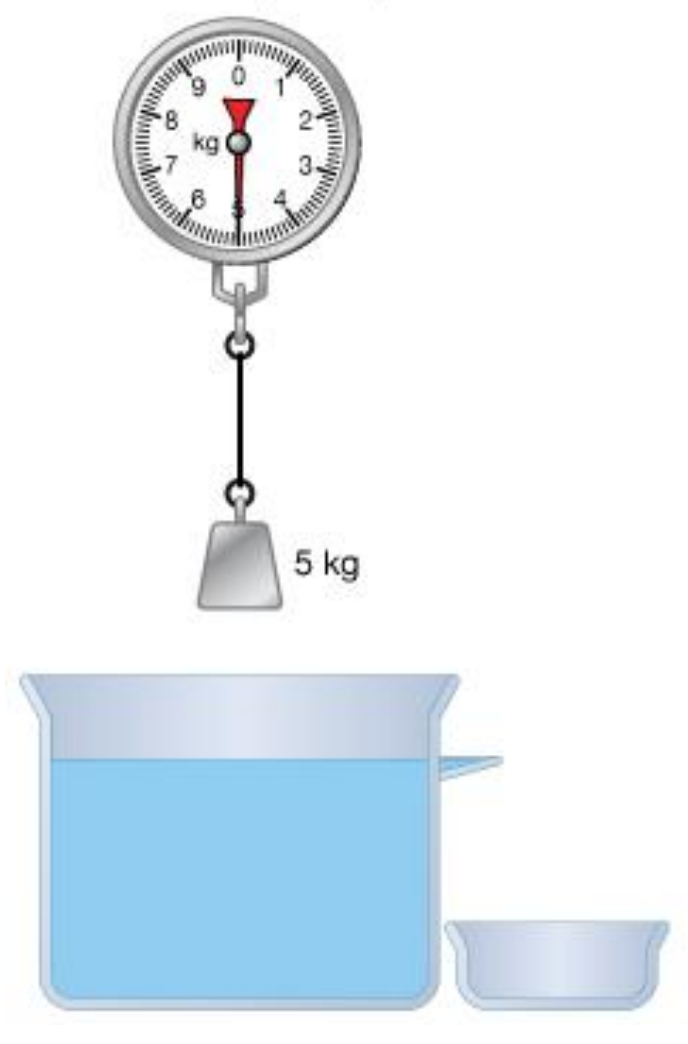

Figure 2 Illustration of Archimedes' Principle (Encyclopedia Brittanica, 2015)

The saturated surface dry condition of HMA is when water is removed from the surface of the sample without removing water from the surface voids (Mamlouk and Zaniewski, 2011). This is shown in Figure $1 \mathrm{c}$ ) where the surface of the sample is dry but the surface voids are saturated. 
According to Crouch et al. (2003), the mass of water displaced by a sample in the SSD condition is obtained by taking the difference between the mass of the sample in its SSD condition and the mass of the sample submerged in a water bath (Equation 3).

$$
\begin{gathered}
M_{w}=M_{m S S D}-M_{m s u b} \\
M_{w}=\text { mass of } \text { water displaced, } g \\
M_{m S S D}=\text { mass of specimen in SSD condition, } g \\
M_{m s u b}=\text { mass of specimen submerged in water, } g
\end{gathered}
$$

Equation 3

The mass of water displaced is converted to the volume of the sample by using the density of the water displaced. The density of the water is determined by using a thermometer to measure the temperature of the water bath. The volume of the sample is computed by dividing the mass of water displaced by the water's density (Crouch, et al., 2003). The density of the compacted sample is obtained by dividing the mass of the sample by the volume of the sample (Equation 4).

$$
\begin{gathered}
\rho_{\text {sample }}=\frac{M_{m}}{\left(\frac{M_{m S S D^{-M} m s u b}}{\rho_{w}}\right)} \\
\rho_{\text {samples }}=\text { density of the sample, } g / m l \\
M_{m}=\text { mass of the specimen in air, } g \\
\rho_{w}=\text { density of water at test temperature, } \mathrm{g} / \mathrm{ml} \mathbf{m}
\end{gathered}
$$

\section{Equation 4}

The specific gravity of a sample is the ratio of the density of the sample to the density of water at a specified temperature (Pavement Interactive, 2011). Therefore, the final calculation for the bulk specific gravity of the sample is simplified to Equation 5.

$$
G_{m b}=\frac{M_{S}}{M_{m S S D}-M_{m s u b}}
$$

Equation 5

Equation 5 is the same equation in AASHTO T 166 for determining the bulk specific gravity of compacted samples using the saturated surface dry method. AASHTO T 166 states to blot dry the sample, after submersion for 3 to 5 minutes, with a damp towel as quickly as possible, not to exceed 5 seconds. This procedure is done to eliminate water from the surface but should be performed quickly to prevent any loss of water from the voids. 
This method has been proven to be adequate for conventionally designed fine-graded mixes but can give erroneous results for coarse-graded mixes (Cooley, et al., 2002). As shown in Figure 3 a coarse and fine-grade mix can have the same overall air void volume but different sized voids. Coarse grade mixes have larger aggregate particles and the internal air voids can become interconnected to surface voids. This leads to water being able to quickly infiltrate the sample when submerged but also leads to water draining from the sample quickly when attempting to measure the mass in the SSD condition. If this water drains from the voids before the SSD mass is measured then the surface voids will not be taken into account when measuring the volume of the sample.

Coarse-Graded Mix

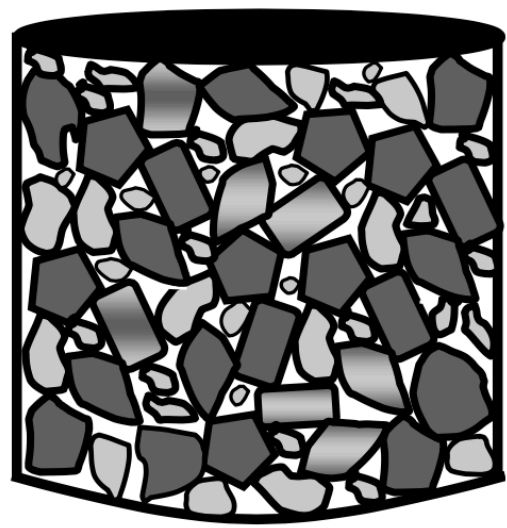

- Coarser Gradation

- Larger Sized Voids (more chance for inter-connected voids)
Fine-Graded Mix

Equal Air

Volumes

(\% Air Voids)

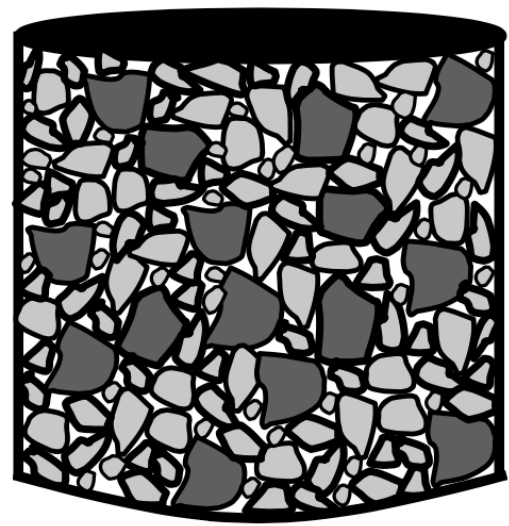

Figure 3 Difference in Internal Air-Voids Structure of Coarse and Fine-Graded Mixes (Cooley, et al., 2002)

\subsubsection{CoreLok Method}

The CoreLok method is relatively new in comparison to the two previous methods. This is a water displacement method because it utilizes Archimedes' principle. A sample is sealed inside of a plastic bag using a vacuum chamber (Figure 4) and then it is submerged into a water bath. By knowing the apparent gravity of the sample bag, the mass of the sample bag, the mass of the sample, and the submerged weight of the vacuum-sealed specimen, the bulk specific gravity of the sample can be calculated as shown in Equation 6. The apparent gravity of the sample bag is 
dependent upon the ratio between the mass of the sample and the mass of the bag. The table to obtain the apparent gravity of the sample bag is shown in Table 1.

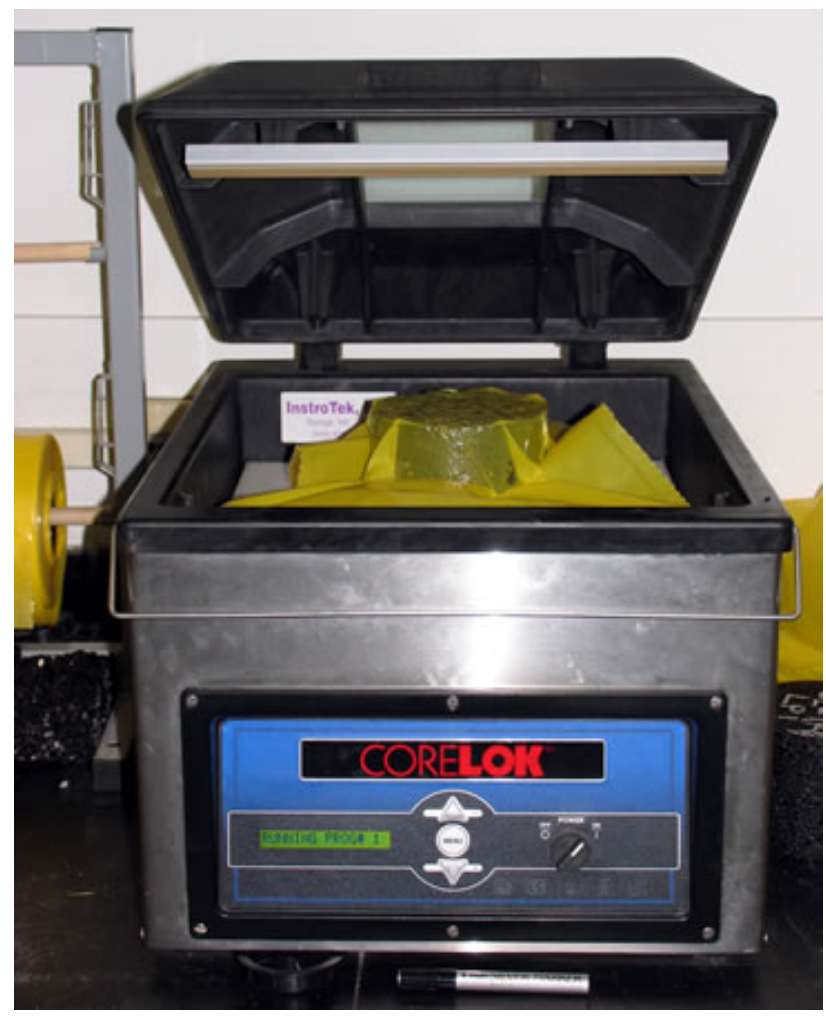

Figure 4 CoreLok Device (Pavement Interactive, 2011)

$$
\begin{gathered}
G_{m b}=\frac{M_{s}}{\left(\left(M_{b}+M_{s a}\right)-M_{s s}\right)-\frac{M_{b}}{G_{b a}}} \\
M_{b}=\text { Bag Mass, } g \\
M_{s a}=\text { Dry Sample Mass After Water Submersion, } g \\
M_{s s}=\text { Sealed Sample Mass in Water }, g \\
G_{b a}=\text { Bag Apparent Gravity } \\
M_{c}=\text { mass of dry core } \\
M_{b}=\text { mass of bag }
\end{gathered}
$$


Table 1 Apparent Gravity of CoreLok Sample Bag (Instrotek, 2011)

\begin{tabular}{|c|c|}
\hline \multicolumn{2}{|c|}{$\begin{array}{c}\text { Small Bag (10 X 14") Apparent Gravity } \\
-0.000566^{\star} R+0.8121\end{array}$} \\
\hline $\mathrm{R}=$ Ratio $\mathrm{M}_{d} / \mathrm{M}_{\mathrm{b}}$ & Apparent Gravity \\
\hline 10 & 0.806 \\
\hline 20 & 0.801 \\
\hline 30 & 0.795 \\
\hline 40 & 0.789 \\
\hline 50 & 0.784 \\
\hline 60 & 0.778 \\
\hline 70 & 0.773 \\
\hline 80 & 0.767 \\
\hline 90 & 0.761 \\
\hline 100 & 0.756 \\
\hline 110 & 0.750 \\
\hline 120 & 0.744 \\
\hline 130 & 0.739 \\
\hline 140 & 0.733 \\
\hline 150 & 0.727 \\
\hline 160 & 0.722 \\
\hline 170 & 0.716 \\
\hline 180 & 0.710 \\
\hline 190 & 0.705 \\
\hline 200 & 0.699 \\
\hline 210 & 0.693 \\
\hline 220 & 0.688 \\
\hline 230 & 0.682 \\
\hline 240 & 0.676 \\
\hline 250 & 0.671 \\
\hline 260 & 0.665 \\
\hline 270 & 0.659 \\
\hline 280 & 0.654 \\
\hline 290 & 0.648 \\
\hline 300 & 0.642 \\
\hline
\end{tabular}

The advantage of this method is that it is relatively simple and can test samples with high absorption. The disadvantage is that the bags are not reusable causing a reoccurring cost to the user (Williams, 2007). Another concern with the CoreLok method is a bridging effect the bag has over large surface voids (Sholar, et al., 2003). If a sample has large surface irregularities the bag may bridge over the irregularities leading to the same problem with the dimensional method where surface irregularities are considered as sample voids. This can cause an underestimation of the bulk specific gravity leading to an overestimation of the air voids (Sholar, et al., 2003).

Another common issue faced when measuring the bulk specific gravity with the CoreLok method is that the sample can puncture the bag when vacuum sealing the specimen (Cooley, et al., 2002). If this puncture is not noticed before the specimen is submerged into the water bath than water can infiltrate the bag making the test results erroneous. This is time consuming 
because the researcher then has to dry the sample again and costly because another bag will have to be used for one test specimen.

\subsubsection{Dimensional Method}

The height-diameter method or dimensional method is based on the standard specified in AASHTO T 269. The greatest advantage of this method is that it is extremely simple, quick, and inexpensive (Williams, 2007). This method is based on the gyratory volume shown in Figure 1 a) and thus leads to an overestimation of air voids of compacted samples because surface irregularities are included as sample air voids.

AASHTO T 269 requires measuring the diameter of the specimen at four locations and measuring the height per ASTM D 3549; which requires measuring the height at four quarter points on the periphery of the sample. Once the average diameter and average height are calculated the volume is computed by multiplying the height times the area of the sample. Once this volume is obtained and the mass of the sample is weighed, the density of the sample is obtained. The density of the sample is then divided by the density of water at $25^{\circ} \mathrm{C}$ $\left(0.99707 \mathrm{~g} / \mathrm{cm}^{3}\right)$, if the sample was measured at $25^{\circ} \mathrm{C}$, to obtain the specimen specific gravity.

\subsection{Superpave Gyratory Compactor}

The Superpave Gyratory Compactor (SGC) was created with the implementation of the Superpave Mix Design method under the Strategic Highway Research Program (Hall, et al., 2010). It is used to produce and compact specimens for determination of volumetric analysis and determination of mechanical properties (Solaimanian, et al., 1999).

The SGC consists of the following components:

- Frame, rotating base, and motor

- Loading ram and pressure control

- Height measuring and recording system

- Mold and base plate

Figure 5 shows a generic diagram of the SGC. A loading system applies a load to the loading ram, which applies a $600 \mathrm{kPa}$ compaction pressure to the specimen. A pressure gauge measures the ram pressure to ensure it remains constant throughout compaction. The SGC cylindrical wall 
and base plates at the top and bottom of the mold provide confinement of the material during the compaction process (Solaimanian, et al., 1999). The SGC rotates the specimen mold at $30 \pm .5$ gyrations per minute and tilts the specimen mold at an average internal angle of $1.16 \pm .02^{\circ}$ throughout compaction (AASHTO T312). The specimen height can be designated or a number of gyrations can be designated to apply to the material.

The specimens prepared with the SGC simulate the density, aggregate orientation, and structural characteristics obtained in the actual roadway when proper construction procedure is used in the placement of the paving mix (AASHTO T 312). The SGC was designed and developed to evaluate mix designs by creating samples with a $150 \mathrm{~mm}$ diameter and $115 \pm 5 \mathrm{~mm}$ height. For mix design samples are compacted to the design number of gyrations and then the volumetric properties are measured to determine if the samples meet the design criteria.

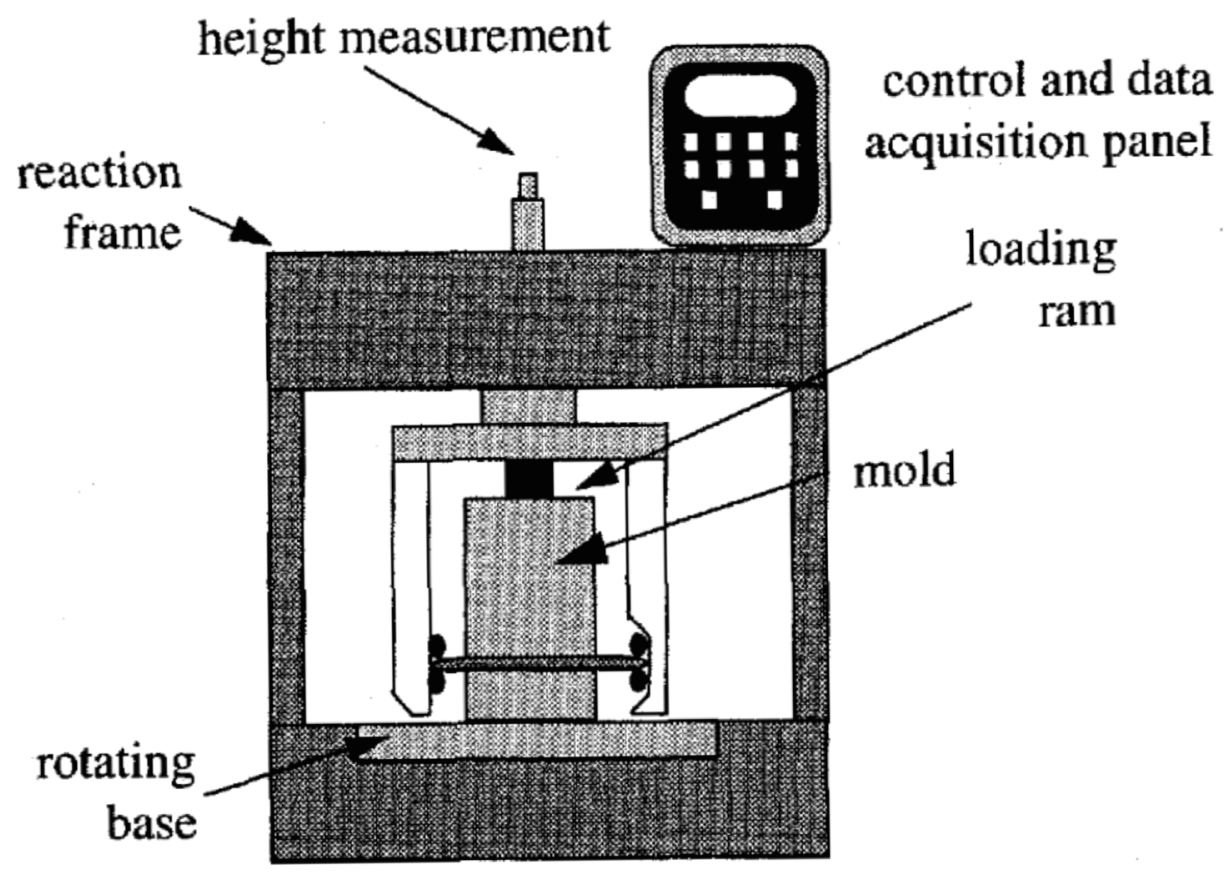

Figure 5 Generic Superpave Gyratory Compactor (McGennis, et al., 1994) 


\subsection{Heterogeneity Index}

One method to quantitatively analyze the air void distribution in HMA samples is through the heterogeneity index (HI) developed by Thyagarajan et al. (2010). The formula for the heterogeneity index is shown in Equation 7. They measured the distribution of air voids within the sample by using X-Ray Computed tomography and measuring the air voids every $0.2 \mathrm{~mm}$ along the height of the specimen.

$$
\begin{gathered}
H I=\frac{1}{N} \sum_{i=1}^{N} \operatorname{abs}\left(\frac{V_{i}-V_{\text {avg }}}{V_{\text {avg }}}\right) \\
H I=\text { Heterogeneity index } \\
N=\text { number of vertical layers } \\
V_{i}=\text { air void content of ith layer } \\
V_{\text {avg }}=\text { average air void content of entire sample }
\end{gathered}
$$

\section{Equation 7}

If a sample has a $\mathrm{HI}=0$ then the air void distribution in the sample is homogenous. If the sample has a HI closer to 1 then the air void distribution of the sample is very poor. The HI is useful because it allows the determination of what affect different experimental factors has on the air void distribution within HMA samples. The relative air void distribution within the samples were established but the authors concluded that samples with a homogenous air void distribution needed to be prepared in order to make any conclusion on recommended heterogeneity index values.

\subsection{Evaluation of Heterogeneous Air Void Distribution in HMA Samples}

One of the concerns with the hot mix asphalt samples for the AMPT is if the samples are receiving uniform compaction. It is postulated that the compaction energy going into a sample in the SGC follows the patterns shown in Figure 6 and the distribution of the compaction energy in the sample is dependent upon the specimen geometry (Thyagarajan, et al., 2010). The material at the top and bottom has high compaction energy but simultaneously high resistance due to the top and bottom plates. The compaction energy decreases until it reaches the tip of the cone. If 
the specimen is slender this cone will not interact with the compaction cone on the other end resulting in an area of the middle of the specimen with little to no compaction.

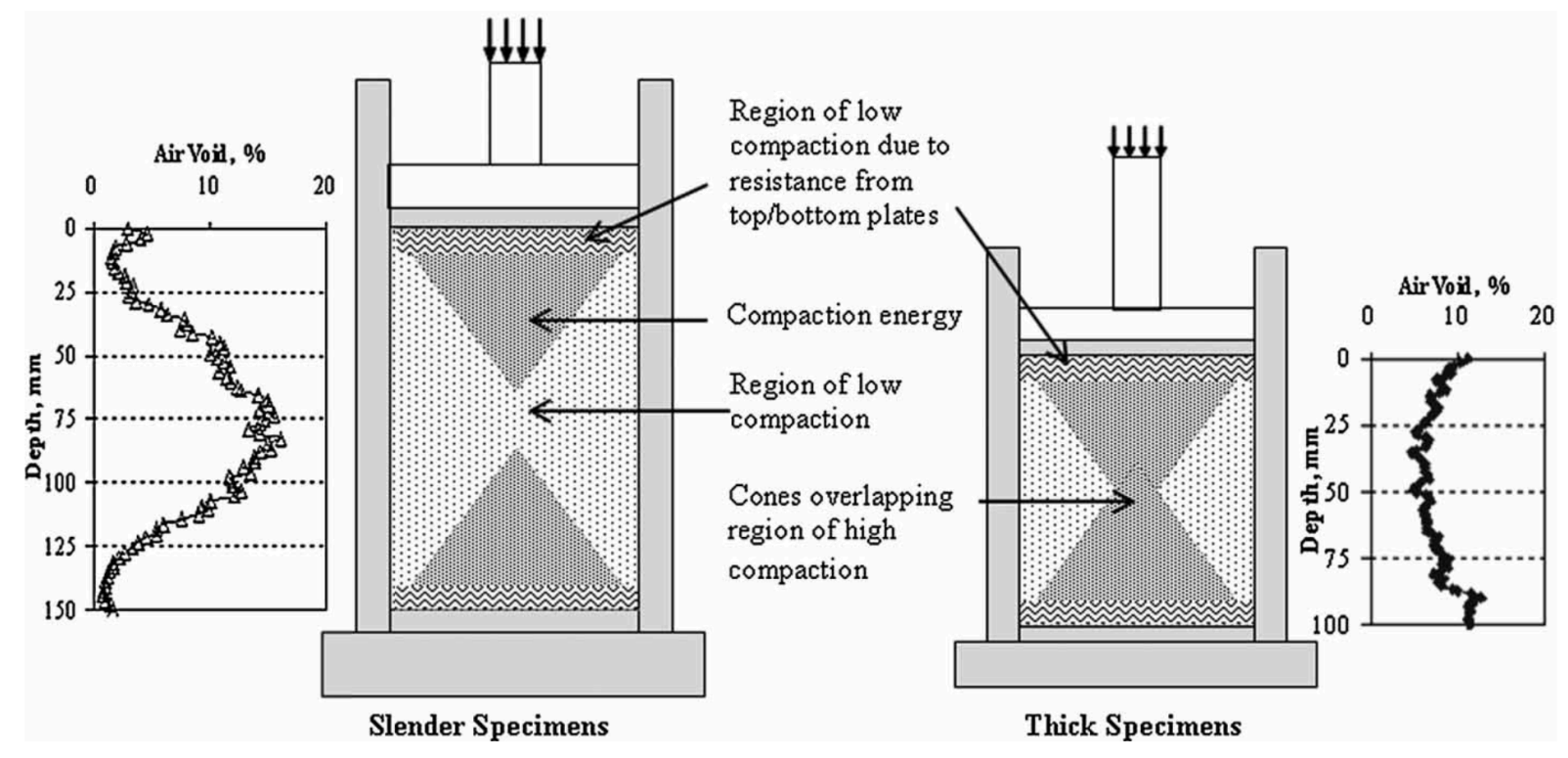

Figure 6 Compaction Cone and Mold Effect on HMA (Thyagarajan, et al., 2010)

Chen et al. (2013) performed a discrete element analysis on hot mix asphalt. Samples were compacted using a SGC simulation with a vertical pressure of $600 \mathrm{kPa}$, angle of gyration of $1.25^{\circ}$, and gyrations of 30 revolutions per minute. Their research found that their theoretical samples had significantly higher air voids near the mold boundaries due to an edge effect. It was also found that the height of the sample had a significant effect on the distribution of air voids within the sample in the vertical direction. The air void distribution in samples with heights of $100,120,140$, and $160 \mathrm{~mm}$ were computed. There was a strong correlation that as the theoretical specimen height increased the heterogeneous distribution of air voids increased as well regardless of specimen diameter.

Thyagarajan et al. (2010) used X-Ray Computed Tomography (CT) and Image Analysis Techniques to measure the air void distributions in laboratory compacted HMA samples. Samples were compacted with the SGC using 100 and $150 \mathrm{~mm}$ diameter molds. The samples compacted with the $100 \mathrm{~mm}$ mold were compacted to heights of 50, 100 and $150 \mathrm{~mm}$. Specimens made with the $150 \mathrm{~mm}$ mold were compacted to heights of 70,120 , and $170 \mathrm{~mm}$ and 
then cored to $100 \mathrm{~mm}$. Then the samples were cut evenly on each end to heights of 50,100, and $150 \mathrm{~mm}$. They found that decreasing the specimen height significantly reduces the heterogeneous distribution of air voids in the vertical direction but does the opposite in the lateral direction. They also found that samples had a significantly higher air void content near the mold's top and bottom platens. They found that sawing and coring significantly reduced the heterogeneous distribution of air voids but the higher air void content near the top and bottom plates was still present. Cutting $10 \mathrm{~mm}$ from the top and bottom of the sample was found to significantly reduce the heterogeneous air void distribution level in the vertical direction but it did not remove the lower air void content at the ends of the sample due to the edge effect. It was recommended that taller samples should be prepared so even more of the material could be removed from the top and bottom of the sample. They also measured the air void distribution of the sample before and after dynamic modulus testing and found no significant difference in the air void distribution.

Dubois et al. (2010) found the air void distribution in a sample was affected by compaction type, specimen dimension, and mix properties. The gyratory compactor and roller compactor were the two methods of compaction that were tested. However, these compaction types were not compared to each other. They found that sawn and cored specimen had significantly more uniform air voids than samples that were not sawn and cored. Sawing and coring removed the edge effects and allowed the middle of the specimen to be used for testing which has a more homogeneous air void distribution. Also, it was found the air void distribution was dependent on the HMA mix properties.

\subsection{AASHTO PP 60 Assessing Test Specimen Uniformity}

AASHTO PP 60 Appendix $\mathrm{X} 2$ has a procedure for analyzing the air void distribution in HMA samples. The protocol tests the significance of the difference in mean $\mathrm{G}_{\mathrm{mb}}$ between the top and bottom third of the specimen relative to the middle third. The procedure requires that three test specimens are prepared to a target air void content of 5.5 percent. The samples are then cut into three even slices, labeled as top, bottom, or middle, and then the bulk specific gravity of each

slice is determined. The mean and variance for the bulk specific gravity of the top, middle, and bottoms of the specimen are then averaged to perform a statistical analysis of the air void distribution. 
The null hypothesis is that the mean $G_{m b}$ of the top or bottom slice is equal to the mean $G_{m b}$ of the middle slice. The alternate hypothesis is that the mean $\mathrm{G}_{\mathrm{mb}}$ of the top or bottom slice is not equal to the mean $\mathrm{G}_{\mathrm{mb}}$ of the middle slice. The test statistic is computed by using Equation 8 .

$$
\begin{gathered}
t=\frac{\left(\bar{y}_{t, b}-\bar{y}_{m}\right)}{0.8165(s)} \\
t=\text { test statistic } \\
s=\sqrt{\frac{s_{t, b}^{2}+s_{m}^{2}}{2}} \\
\text { Equation } 8 \\
\bar{y}_{t, b}=\text { computed mean for the top or bottom slices } \\
\bar{y}_{m}=\text { computed mean for the middle slices } \\
s_{t, b}{ }^{2}=\text { the computed variance for the top or bottom slices } \\
s_{m}{ }^{2}=\text { the computed variance for the middle slices }
\end{gathered}
$$

\section{Equation 8}

The absolute value of the test statistic must be greater than 2.78 to reject the null hypothesis.

\subsection{Background of AMPT and Effect of Air Voids on Mechanical Properties of AMPT Samples}

The simple performance tester (SPT) was a result of a research project sponsored by the NCHRP to develop a practical and economical test method for use in routine Superpave mix designs (Bonaquist, et al., 2003). The SPT was designed to perform, dynamic modulus testing but after feedback from researchers throughout the county it was desired that the SPT be able to perform flow number and flow time testing, and testing at a variety of frequencies and temperatures. The SPT was the prototype development of the AMPT (Figure 7). It is a computer controlled hydraulic system that is used for the testing of asphalt samples at a variety of temperatures and load frequencies. It is also capable of performing confined and unconfined testing. The strain over the middle $70 \mathrm{~mm}$ of the specimen is measured using linear variable differential transducers (LVDTs). 


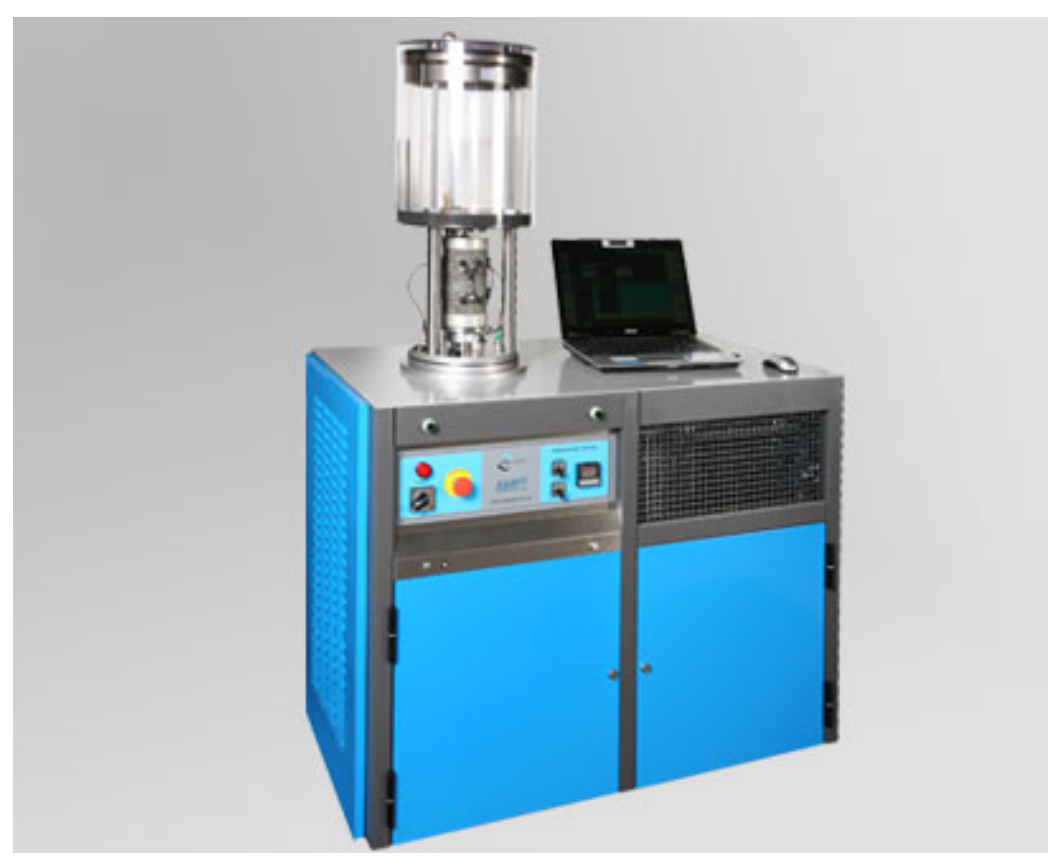

Figure 7 AMPT (Instrotek, 2012)

The AMPT tests asphalt concrete specimens prepared in accordance with AASHTO PP 60 to perform several tests including dynamic modulus and flow number. The results from dynamic modulus testing are a primary input for flexible pavement structural design in the "Mechanistic Empirical Pavement Design Guide" (MEPDG).

Witczak et al. (2000) performed rigorous specimen geometry testing in order to determine the specimen size and geometry for testing with the AMPT. Several specimen geometry, and mix design combinations were performed in order to determine the optimum specimen size for dynamic modulus, and flow number testing. It was concluded that $100 \mathrm{~mm}$ specimens cored from a $150 \mathrm{~mm}$ diameter gyratory compacted specimens having a final cut height of $150 \mathrm{~mm}$ will provide true and accurate material responses. A total of 144 samples, with the recommended specimen geometry and preparation procedures, were measured for air voids, sawed at the gauge mounting points in the middle $100 \mathrm{~mm}$ of the specimen, and then the air voids in the middle 100 $\mathrm{mm}$ of the sample was measured. Statistical analyses were conducted to determine if there was a significant difference between the overall specimen air voids and the air voids in the middle 100 $\mathrm{mm}$ of the specimen. The study concluded no significant difference between the air voids in the middle $100 \mathrm{~mm}$ of the sample and the measured air voids of the $150 \mathrm{~mm}$ tall sample. 
Yu and Shen (2012) performed dynamic modulus and flow number testing on Washington state asphalt mixes. The effect of air voids, asphalt binder, and aggregate gradation on the dynamic modulus was researched. It was found that samples with a higher air void content have a lower dynamic modulus in comparison to samples with a lower air void content. It was also found that samples with a higher air void content have a lower flow number in comparison to samples with a lower air void content.

Taylor and Tran (2013) performed an inter-laboratory study to determine the effect of air voids on dynamic modulus and flow number testing and if the $0.5 \%$ air void tolerance could be increased to $1.0 \%$ as suggested in NCHRP Project $09-29$. There were a total of 29 participating laboratories that were placed in three groups. Groups 1, 2, and 3 had target air void contents of 6 $\pm 0.5 \%, 7 \pm 0.5 \%$, and $8 \pm 0.5 \%$ respectively. It was found that air voids have a significant effect on both dynamic modulus and flow number. Over $50 \%$ of the variability of the dynamic modulus test data and $70 \%$ of the variability of flow number test data could be explained by the variability of the specimen air voids. It was found for dynamic modulus testing that an increase in air voids leads to a decrease in the dynamic modulus and a $1 \%$ increase of air voids leads to a flow number reduction of approximately 95 cycles. The repeatability of the data support the requirement of an air void tolerance of $0.5 \%$.

\subsection{Summary of Literature}

The methods for determining the air void content within a HMA sample fall into three categories; water displacement, dimensional, and gamma/x-rays. Each of these methods will give varying results for the air void content. The SSD method tends to overestimate the bulk specific gravity and underestimate the volume of air voids of compacted samples. The dimensional method tends to underestimate the bulk specific gravity and overestimate the volume of air voids of compacted samples, and the CoreLok method results in a volume of air voids in between this upper and lower bound.

The significant issues concerning the different definitions for determining the volume of the samples for the specific gravity calculations are related to the surface irregularities of compacted samples as shown on Figure 1. These irregularities should not be considered part of the volume of the sample for determining the specific gravity. However, once the compacted sample is sawn 
and cored to the dimensions of the AMPT samples the surface irregularities are removed. Any voids that are present on the surface of the AMPT samples are part of the void structure of the asphalt concrete. Hence, volume of the voids on cut faces should be included in the determination of the bulk specific gravity and air voids of the sample. No literature was found that addresses the issue of surface voids of samples that have been sawn and cored.

The SGC was developed with the implementation of the Superpave Mix Design. This device was created with the intent to simulate compaction of HMA in the field. However, the SGC has been shown to create samples with a non-uniform distribution of air voids for slender specimens. The air void of the specimens near the ends and outer edges has been shown to have significantly lower air void contents than the middle of the specimen. It is believed that the cause of this is because the compaction energy cones coming from the top and bottom of the specimen do not connect leaving a section of low compaction in the middle of the specimen. When the SGC specimen geometry was developed by Witczak et al. (2002) it was found that the computed air voids in the middle and entire sample were not significantly different.

The air voids within a sample has been found to have a significant effect on the mechanical properties of HMA samples being tested with the AMPT. The air voids have been found to have a direct correlation to the stiffness of a HMA sample. As the air voids increase the stiffness of the sample decreases. Therefore, it is important to maintain uniform air voids in the samples because of the strong effect they have on mechanical properties of HMA. 


\section{Chapter 3 Research Methodology}

\subsection{Introduction}

The objective of this research project was to determine if AMPT samples prepared with the SGC have a uniform distribution of air voids within the sample. It was also desired to determine if there was a significant difference amongst measured air voids depending on the method of measurement that was used. This chapter covers the experimental design, materials used, mix design of the HMA, and the sample preparation procedure to prepare the test samples.

\subsection{Experimental Design}

Table 2 is a summary of the experimental factors for the research performed for this thesis. The samples tested varied by binder type and aggregate gradation. The two aggregate gradations are 9.5 NMAS and 12.5 NMAS, and the three binder types are PG 70-22, PG 70-22 Polymer Modified (PM), and PG 76-22. Five samples were prepared for each NMAS-binder type combination resulting in a total of 30 samples.

Table 2 Summary of Experimental Factors

\begin{tabular}{lcl}
\hline Factor & \# of Levels & Levels \\
\hline NMAS & 2 & 9.5 NMAS \\
& & 12.5 NMAS \\
Binder Type & 3 & PG 70-22 \\
& PG 70-22 PM \\
& & PG 76-22 PM \\
Sample Type & 3 & Total \\
& & Middle \\
& & Ends \\
$\mathrm{G}_{\mathrm{mb}}$ Method & 2 & CoreLok \\
& & Dimensional \\
\hline
\end{tabular}

The samples were compacted using the SGC to a diameter of $150 \mathrm{~mm}$ and height of $180 \mathrm{~mm}$. The samples were sawn and cored to a diameter of $100 \mathrm{~mm}$ and height of $150 \mathrm{~mm}$. The air voids in the $150 \mathrm{~mm}$ tall samples were computed and then the samples were cut into three slices of approximately $48 \mathrm{~mm}$. The air voids were then measured for each of the $48 \pm 2.5 \mathrm{~mm}$ sections of 
the sample and each section was categorized as the middle or end portion of the sample. The bottom and top slices were considered end samples.

AASHTO PP 60 has a method in Appendix X2 for measuring test specimen air void uniformity where the top and bottom of the specimen are tracked rather than grouped as end samples. The samples used in this experiment were initially made for dynamic modulus testing with the AMPT. Upon completion of compaction, coring, and sawing of the samples the AMPT malfunctioned resulting in the machine to not be available. This resulted in the experimental design being changed to evaluating the air voids within AMPT specimens. AMPT dynamic modulus testing does not require marking the compaction orientation of the samples. Since the samples were initially made for AMPT testing the top and bottom of the specimens were not marked resulting in them being grouped as ends.

Each air void measurement was taken by using the CoreLok (AASHTO T 331) and dimensional method (AASHTO T 269). An attempt was made to measure the air voids using the SSD method but the absorption of the sample exceeded 2\%. AASHTO T 166 states that if the absorption of the sample exceeds $2 \%$ an alternative method such as the vacuum sealing method (CoreLok) or paraffin sealing method should be used.

All statistical tests for hypothesis testing were performed at a significance level of 0.05 . A Student $t$ test was performed to determine if there was a significant difference amongst the methods of measuring the bulk specific gravity of the specimen. Then an analysis of variance was performed to determine if any of the mix properties had an effect on the air void measurements by each bulk specific gravity method. Next a Student $t$ test was performed to determine if the air voids measured in the middle and ends of the specimen was different. Then an analysis of variance was performed to see if any of the mix properties or bulk specific gravity method had an effect on the difference in measured air voids between the middle and ends of the specimen. Lastly an analysis was performed with the heterogeneity index to determine if any of the experimental factors had an effect on the air void distribution within the HMA samples. 


\subsection{Materials}

The aggregate for the samples were limestone coarse and fine aggregate from Buckeye and Greer limestone quarries near Morgantown, WV. Both of these quarries are a part of Greer Industries, headquartered in Morgantown, WV. The PG 70-22 binder was supplied by Associated Asphalt Partners and the PG 70-22PM and PG 76-22 binders were provided by Marathon Petroleum Co.

\subsection{Mix Design}

The 9.5 NMAS and the 12.5 NMAS mixes were coarse graded designs based on job mix formulas (JMFs) prepared by Greer. A validation of the mixes was performed by Turner $\left(2015^{1}\right)$ and the percent binder was adjusted to the values shown in Table 4.

For the 9.5 NMAS mix, the aggregates consisted of:

- Buckeye \#8 limestone (45\%)

- Buckeye sand limestone (35\%)

- Greer sand limestone $(20 \%)$

For the 12.5 NMAS mix, the aggregates consisted of:

- $\quad$ Buckeye \#7 limestone (25\%)

- Buckeye \#8 limestone (20\%)

- Buckeye sand limestone (35\%)

- Greer sand limestone $(20 \%)$

The gradation for these stockpiles is shown in Table 3. The mix gradations are shown in Figure 8 and Figure 9 for the 9.5 and 12.5 NMAS mixes respectively.

\footnotetext{
${ }^{1}$ Turner, K., Evaluation of Asphalt Mixture Performance Tester and Testing Protocol, MSCE thesis, West Virginia University, Morgantown WV, 2015
} 
Table 3 Stockpile gradations

\begin{tabular}{|r|r|r|r|r|}
\hline & \multicolumn{4}{|c|}{ Percent Passing } \\
\hline Passing Sieve $(\mathrm{mm})$ & Buckeye 7's & Buckeye 8's & WVSand & Buckeye Sand \\
\hline 19 & 100 & 100 & 100 & 100 \\
\hline 12.5 & 76 & 100 & 100 & 100 \\
\hline 9.5 & 51 & 94 & 100 & 100 \\
\hline 4.75 & 7 & 21 & 91 & 97 \\
\hline 2.36 & 5 & 6 & 57 & 71 \\
\hline 1.18 & 4 & 4 & 33 & 43 \\
\hline 0.6 & 3 & 3 & 21 & 32 \\
\hline 0.3 & 2 & 3 & 13 & 21 \\
\hline 0.075 & 1.8 & 2.1 & 9.8 & 8 \\
\hline
\end{tabular}

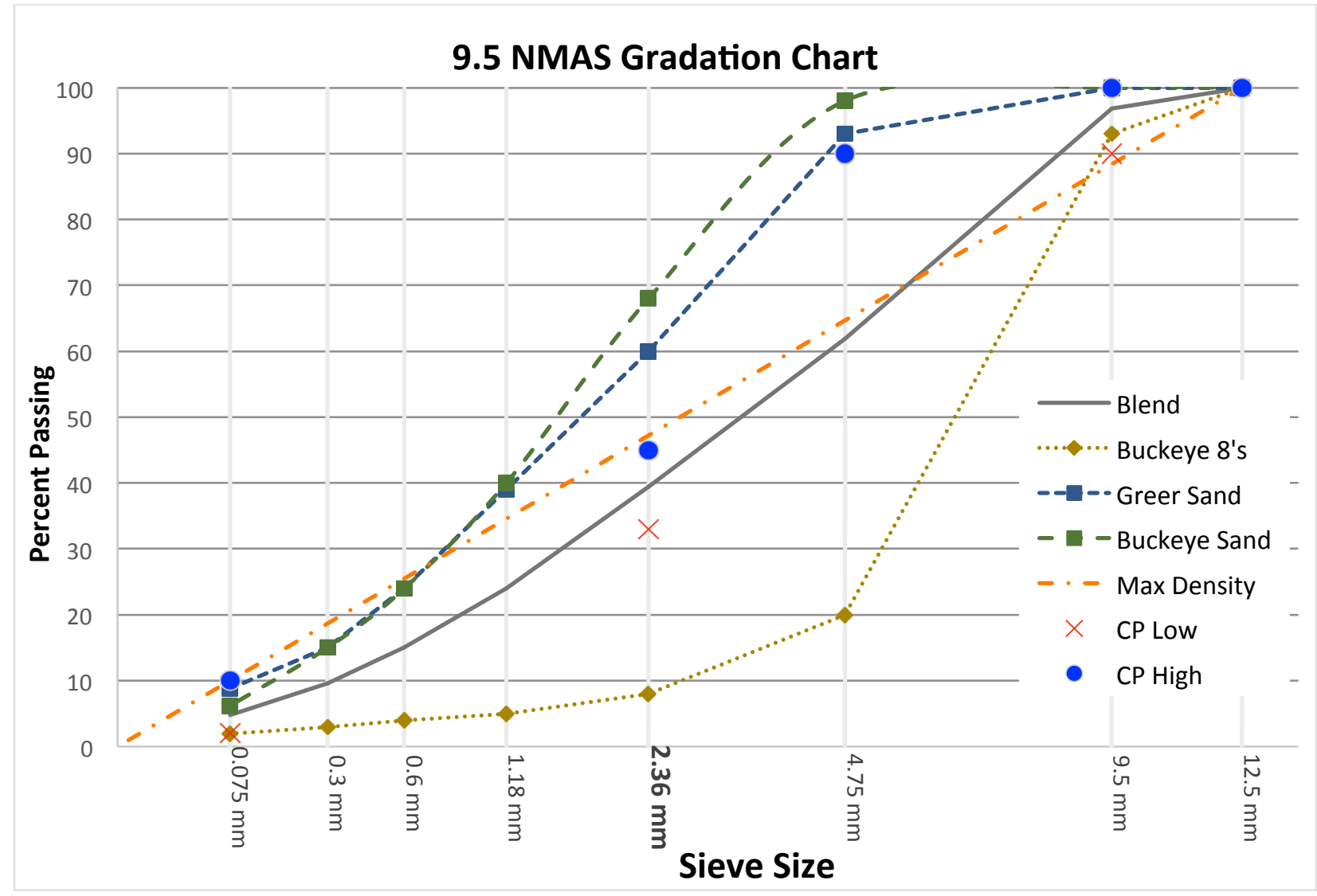

Figure 8 9.5 NMAS Gradation Chart 


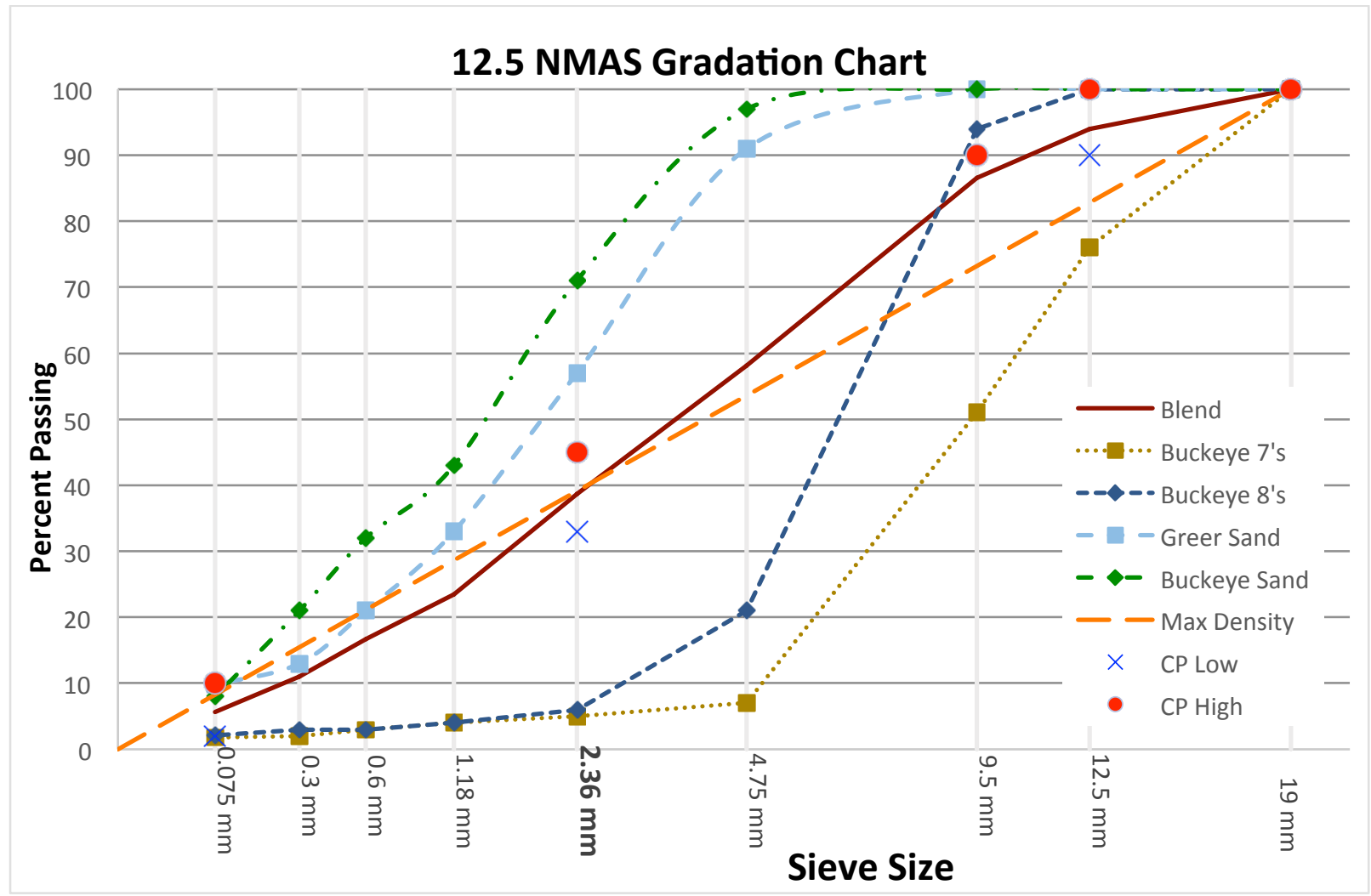

Figure 9 12.5 NMAS Gradation Chart

Table 4 Mix Design Properties

\begin{tabular}{|r|l|r|r|r|r|r|r|r|r|}
\hline \multicolumn{2}{|c|}{} & \multicolumn{2}{|c|}{ \%Binder } & \multicolumn{2}{|c|}{ \%Air Voids } & \multicolumn{2}{|c|}{ VMA } & \multicolumn{2}{|c|}{ VFA } \\
\hline NMAS & Binder & Target & Actual & Target & Actual & Target & Actual & Target & Actual \\
\hline 9.5 & PG 70-22 & 6.2 & 6.2 & 4 & 4.5 & 16 & 16.6 & $74-80$ & 75 \\
\hline 9.5 & PG 70-22 PM & 6.1 & 6.1 & 4 & 4 & 16 & 16.5 & $74-80$ & 76 \\
\hline 9.5 & PG 76-22 PM & 5.9 & 5.9 & 4 & 4 & 16 & 16.2 & $74-80$ & 76 \\
\hline 12.5 & PG 70-22 & 5.6 & 5.6 & 4 & 4.5 & 15 & 16.6 & $72-79$ & 75 \\
\hline 12.5 & PG 70-22 PM & 5.4 & 5.4 & 4 & 4 & 15 & 14.8 & $72-79$ & 74 \\
\hline 12.5 & PG 76-22 PM & 5.2 & 5.2 & 4 & 4 & 15 & 14.5 & $72-79$ & 73 \\
\hline
\end{tabular}

\subsection{Sample Preparation}

The samples were prepared in accordance with AASHTO T 312 and AASHTO PP 60-13. The mixing and compaction temperatures, Table 5, of the samples was dependent upon binder type. The mixture and compaction temperatures were established by the binder supplier and the 
average of the maximum and minimum temperatures were used for the mixing and compaction of the samples. Samples were compacted to a height of $180 \mathrm{~mm}$ and a diameter of $150 \mathrm{~mm}$. Samples were cored to a $100 \mathrm{~mm}$ diameter and sawed to a height of $150 \mathrm{~mm}$ by cutting $15 \mathrm{~mm}$ from the top and bottom of the sample. After sawing and coring, each sample was analyzed to determine if it meets the specimen dimensional tolerances shown in Table 6 , the requirements for samples prepared for AMPT testing. AASHTO PP 60 states that samples should be compacted to a minimum height of $160 \mathrm{~mm}$ and samples with acceptable properties have been made from specimens ranging in height from $160 \mathrm{~mm}$ to $180 \mathrm{~mm}$. Samples were compacted to $180 \mathrm{~mm}$ because this was the minimum height that samples could be sawed and still meet the end perpendicularity tolerance.

Table 5 Mixing and Compaction Temperature

\begin{tabular}{|c|c|c|c|c|}
\hline \multirow{2}{*}{ Binder Grade } & \multicolumn{2}{|c|}{ Mixture Temperature $\left({ }^{\circ} \mathrm{C}\right)$} & \multicolumn{2}{c|}{ Compaction Temperature $\left({ }^{\circ} \mathrm{C}\right)$} \\
\cline { 2 - 5 } & Minimum & Maximum & Minimum & Maximum \\
\hline PG 70-22 & 163 & 169 & 152 & 157 \\
\hline PG 70-22 PM & 165 & 171 & 146 & 163 \\
\hline PG 76-22 PM & 165 & 171 & 146 & 163 \\
\hline
\end{tabular}

Table 6 Test Specimen Dimensional Tolerances in AASHTO PP 60

\begin{tabular}{lc}
\hline \multicolumn{1}{c}{ Item } & Specification \\
\hline Average diamter & 98 to $104 \mathrm{~mm}$ \\
Standard deviation of diameter & $\leq 0.5 \mathrm{~mm}$ \\
Height & 147.5 to $152.5 \mathrm{~mm}$ \\
End flatness & $\leq 0.5 \mathrm{~mm}$ \\
End perpendicularity & $\leq 1.0 \mathrm{~mm}$ \\
\hline Diameter - measure 90 degrees apart & \\
Height - ASTM D3549 & \\
End Flatness - Place blad along end at three points 120 degrees apart use .5 mm wire to check. \\
End Perpendicularity - Place long end of specimen along blade use $1 \mathrm{~mm}$ wire, check at two points 90 degrees apart
\end{tabular}

The $\mathrm{G}_{\mathrm{mb}}$ of the $150 \mathrm{~mm}$ tall samples was measured before sawing to obtain the air voids of the entire sample using the CoreLok and dimensional methods. The samples for the measurement of the air voids in the middle and ends of the specimens were obtained by sawing the $150 \mathrm{~mm}$ tall sample in three equal sections. The middle and end specimens were approximately $48 \mathrm{~mm}$ 
because the thickness of the saw blade is $2.5 \mathrm{~mm}$. After sawing, the debris was removed from the sample with a damp cloth. Then the sample was air dried with a fan and dried to $0 \%$ moisture with the CoreDry machine. The $48 \mathrm{~mm}$ samples were then tested for air voids using the CoreLok and dimensional $\mathrm{G}_{\mathrm{mb}}$ methods. 


\section{Chapter 4 Results and Analysis}

\subsection{Introduction}

The program RStudio was used for all statistical analyses including:

1. A t test was performed to determine if there is a significant difference in the air void results for the CoreLok and dimensional methods of measuring the bulk specific gravity.

2. Illustratively compare the air voids between the two $\mathrm{G}_{\mathrm{mb}}$ methods using boxplots.

3. Determine if the mix properties has an effect on the air void measurements from each $\mathrm{G}_{\mathrm{mb}}$ method.

4. Determine if there is a significant difference in the air voids in the middle and ends of the sample.

5. Determine if the mix properties have a significant effect on the difference in air voids within the sample.

6. Determine if the heterogeneity index is a reliable method to determine if experimental factors have an effect on the distribution of air voids within a sample.

The data collected in this research are presented in the Appendix. Table 7 presents the resulting air voids for all samples. 
Table 7 Summary of Air Void Measurements

\begin{tabular}{|c|c|c|c|c|c|c|c|c|c|c|c|}
\hline & \multicolumn{10}{|c|}{ Air Void (\%) } \\
\hline & & \multicolumn{5}{|c|}{ Corelok } & \multicolumn{5}{|c|}{ Dimensional } \\
\hline NMAS & Binder & Whole & End & Middle & End & Het. Index & Whole & End & Middle & End & Het. Index \\
\hline 9.5 & $70-22$ & 6.97 & 7.40 & 7.250 & 6.62 & 0.04 & 7.63 & 7.65 & 8.13 & 7.79 & 0.02 \\
\hline 9.5 & $70-22$ & 7.10 & 7.67 & 8.108 & 6.27 & 0.10 & 7.63 & 7.78 & 9.31 & 7.30 & 0.10 \\
\hline 9.5 & $70-22$ & 7.25 & 7.07 & 8.458 & 6.91 & 0.09 & 8.00 & 7.61 & 9.35 & 7.75 & 0.09 \\
\hline 9.5 & $70-22$ & 7.44 & 6.50 & 9.040 & 7.16 & 0.13 & 8.27 & 7.49 & 9.85 & 8.42 & 0.10 \\
\hline 9.5 & $70-22$ & 7.09 & 6.50 & 7.824 & 7.20 & 0.06 & 7.64 & 7.21 & 8.61 & 7.99 & 0.06 \\
\hline 12.5 & $70-22$ & 7.01 & 7.33 & 7.476 & 6.54 & 0.05 & 7.59 & 7.89 & 8.47 & 7.89 & 0.03 \\
\hline 12.5 & $70-22$ & 7.00 & 6.30 & 7.673 & 7.31 & 0.07 & 7.74 & 6.76 & 8.88 & 8.47 & 0.11 \\
\hline 12.5 & $70-22$ & 6.81 & 5.91 & 7.080 & 7.18 & 0.08 & 7.22 & 6.53 & 8.02 & 8.14 & 0.09 \\
\hline 12.5 & $70-22$ & 7.24 & 7.12 & 8.016 & 6.72 & 0.07 & 7.78 & 8.19 & 8.93 & 7.60 & 0.06 \\
\hline 12.5 & $70-22$ & 6.80 & 7.03 & 7.279 & 6.86 & 0.02 & 7.56 & 7.43 & 8.21 & 7.71 & 0.04 \\
\hline 9.5 & $70-22 \mathrm{PM}$ & 7.32 & 7.54 & 9.056 & 6.99 & 0.10 & 8.24 & 7.82 & 9.73 & 7.69 & 0.10 \\
\hline 9.5 & $70-22 \mathrm{PM}$ & 6.93 & 6.04 & 8.211 & 6.56 & 0.12 & 7.50 & 6.87 & 9.31 & 8.05 & 0.10 \\
\hline 9.5 & $70-22 \mathrm{PM}$ & 6.72 & 7.34 & 7.193 & 5.92 & 0.09 & 6.12 & 7.79 & 8.04 & 7.06 & 0.05 \\
\hline 9.5 & $70-22 \mathrm{PM}$ & 7.03 & 6.22 & 8.505 & 6.85 & 0.12 & 7.83 & 6.51 & 9.34 & 8.17 & 0.12 \\
\hline 9.5 & $70-22 \mathrm{PM}$ & 8.08 & 8.25 & 8.615 & 7.55 & 0.05 & 8.86 & 9.16 & 9.42 & 8.45 & 0.04 \\
\hline 12.5 & $70-22 \mathrm{PM}$ & 7.09 & 6.61 & 8.405 & 6.68 & 0.11 & 7.75 & 7.38 & 9.01 & 7.65 & 0.08 \\
\hline 12.5 & 70-22PM & 7.18 & 7.13 & 8.513 & 6.12 & 0.12 & 7.75 & 7.85 & 9.43 & 7.39 & 0.10 \\
\hline 12.5 & $70-22 \mathrm{PM}$ & 7.22 & 7.82 & 7.757 & 6.65 & 0.07 & 7.82 & 8.16 & 8.71 & 7.26 & 0.07 \\
\hline 12.5 & $70-22 \mathrm{PM}$ & 6.78 & 7.03 & 7.598 & 6.50 & 0.05 & 7.45 & 7.23 & 8.39 & 7.20 & 0.07 \\
\hline 12.5 & 70-22PM & 7.01 & 6.64 & 7.496 & 7.13 & 0.04 & 7.66 & 7.37 & 8.09 & 8.04 & 0.04 \\
\hline 9.5 & 76-22 PM & 6.84 & 6.19 & 8.430 & 6.06 & 0.15 & 7.57 & 6.66 & 9.18 & 7.10 & 0.13 \\
\hline 9.5 & 76-22 PM & 7.08 & 6.33 & 8.096 & 6.81 & 0.10 & 7.60 & 5.83 & 9.01 & 7.56 & 0.15 \\
\hline 9.5 & 76-22 PM & 6.63 & 6.66 & 7.520 & 6.22 & 0.07 & 7.24 & 7.19 & 8.68 & 7.23 & 0.08 \\
\hline 9.5 & $76-22 \mathrm{PM}$ & 7.63 & 7.28 & 7.998 & 6.97 & 0.05 & 8.16 & 7.86 & 9.00 & 7.96 & 0.06 \\
\hline 9.5 & $76-22 \mathrm{PM}$ & 6.84 & 6.29 & 8.167 & 6.75 & 0.10 & 7.48 & 6.77 & 8.60 & 7.57 & 0.08 \\
\hline 12.5 & $76-22 \mathrm{PM}$ & 7.19 & 7.44 & 8.420 & 5.88 & 0.13 & 7.90 & 7.99 & 9.18 & 7.22 & 0.09 \\
\hline 12.5 & 76-22PM & 6.85 & 7.36 & 8.208 & 6.62 & 0.07 & 7.82 & 7.63 & 8.31 & 7.80 & 0.03 \\
\hline 12.5 & 76-22PM & 7.17 & 7.08 & 7.394 & 7.62 & 0.03 & 7.78 & 7.41 & 8.12 & 8.91 & 0.06 \\
\hline 12.5 & 76-22PM & 6.71 & 6.44 & 7.594 & 6.52 & 0.07 & 7.29 & 7.19 & 8.26 & 7.43 & 0.05 \\
\hline 12.5 & 76-22PM & 6.51 & 6.37 & 7.532 & 6.26 & 0.08 & 7.23 & 6.81 & 8.21 & 7.04 & 0.08 \\
\hline
\end{tabular}

\subsection{T test of Air Voids Measured from $T w o G_{m b}$ Methods}

In order to determine if there was a significant difference between the CoreLok and dimensional methods for measuring the air voids, a t test was performed with the data in RStudio. The null hypothesis is that the mean air voids from these two methods are equal and the alternate hypothesis is that the mean air voids from these two samples are not equal. The analysis was performed on a $95 \%$ confidence interval. It was found that the $\mathrm{p}$ value for this test was less than 0.05 , which means that the null hypothesis is rejected and the alternate hypothesis 
is accepted. The data indicates that the two methods produce significantly different measurements for the air voids for the entire sample. On average the dimensional method air voids $0.62 \%$ higher than the CoreLok method. Figure 10 shows a boxplot comparing the air void measurements for the two $G_{m b}$ methods. It is also shown in Figure 10 that the dimensional method is consistently higher than the CoreLok method.

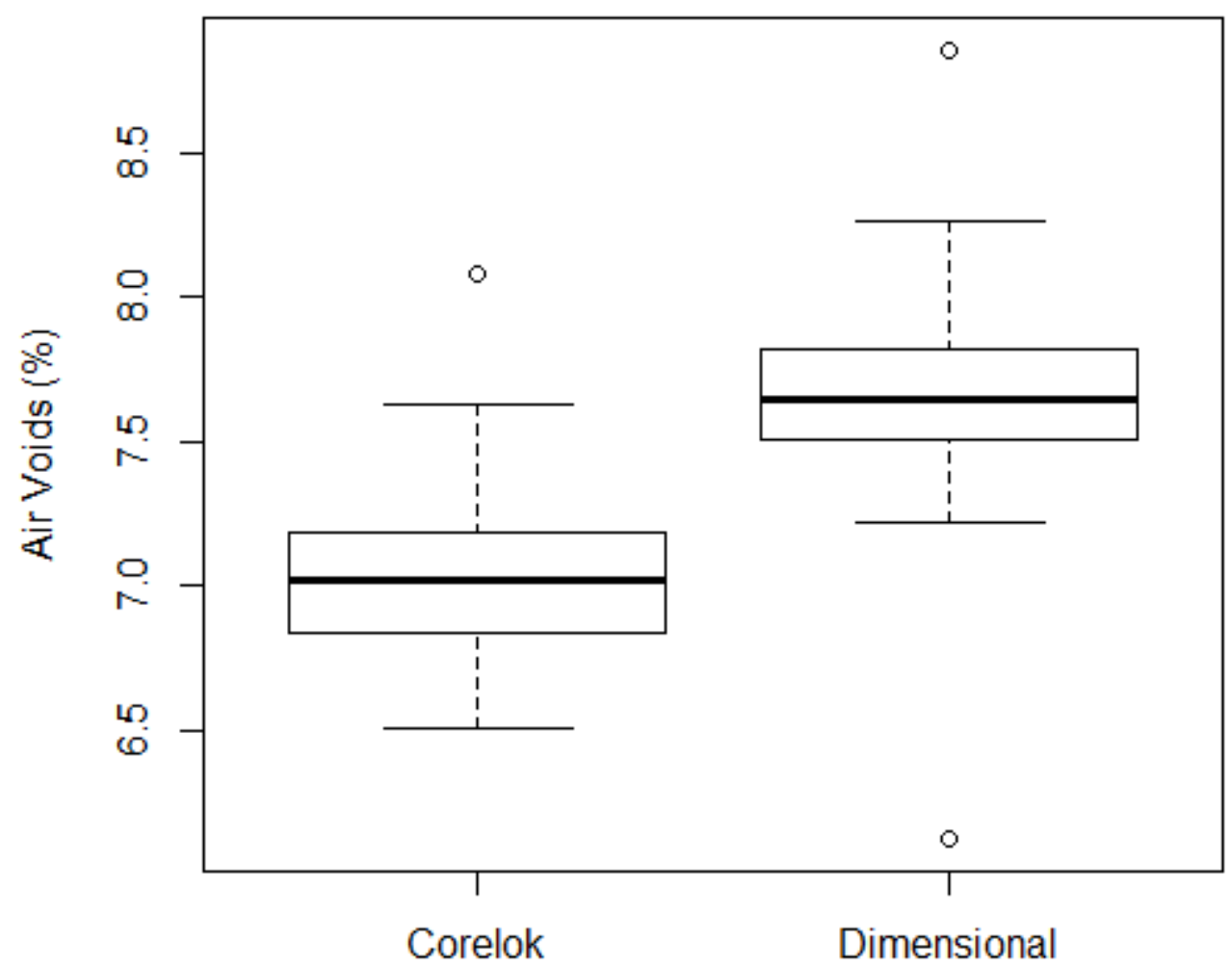

Figure 10 Boxplot Comparing CoreLok and Dimensional Method

\subsection{ANOVA of Air Voids in Whole Sample}

An ANOVA was performed on the air voids for the entire sample to determine if the mix properties had an effect on the measured air voids by each $\mathrm{G}_{\mathrm{mb}}$ method. Table 8 is a summary of the ANOVA performed. From the analysis it is confirmed that the means of the two methods for measuring the air voids are significantly different. It was also found that none of the mix properties or interaction of mix properties and the $\mathrm{G}_{\mathrm{mb}}$ methods have an effect on the measured air voids in the whole sample. 
Table 8 Statistical Significance of $G_{m b}$ Method and Mix Properties on Air Voids

\begin{tabular}{lcclll}
\hline Factor & Type & Levels & Values & \\
\hline Gmb Method & Fixed & 2 & Dimensional and Corelok & & \\
NMAS & Fixed & 2 & 9.5 NMAS, 12.5 NMAS & & \\
Binder & Fixed & 3 & PG 70-22, PG 70-22 PM, PG 76-22 PM & & \\
& & & & & \\
ANOVA for Air Voids & & & MS & F & P-value \\
Factor & DF & SS & 5.760 & 34.097 & $<.001 \mathrm{~S}$ \\
\hline Gmb Method & 1 & 5.760 & 0.111 & 0.658 & 0.522 \\
Binder & 2 & 0.222 & 0.242 & 1.432 & 0.237 \\
NMAS & 1 & 0.242 & 0.013 & 0.079 & 0.924 \\
Gmb Method x Binder & 2 & 0.027 & 0.015 & 0.089 & 0.767 \\
Gmb Method x NMAS & 1 & 0.026 & 0.039 & 0.229 & 0.796 \\
Binder x NMAS & 2 & 0.077 & 0.014 & 0.083 & 0.921 \\
Gmb Method x Binder x NMAS & 2 & 0.028 & 0.169 & & \\
Residuals & 48 & 8.108 & &
\end{tabular}

DF, degree of freedom; SS, sum of squares; MS, mean square (SS divided by DF); F, ratio of mean squares.

It is used to determine the $P$-value; $S$, factor is significant.

\subsection{T test Comparing Air Voids in the Middle and Ends of Sample}

A t test was performed to determine if there is a significant difference in the air voids in the middle of the sample and the air voids in the ends of the sample. A t test was performed with the data obtained from the CoreLok method and the data obtained from the dimensional method.

The null hypothesis is that the air voids in the middle of the sample is equal to the air voids in the ends of the specimen and the alternate hypothesis is the air voids in these two sections are not equal. The test was performed on a $95 \%$ confidence level. The $\mathrm{p}$ values for both tests were less than 0.05 resulting in the null hypothesis being rejected and the alternate hypothesis being accepted for the both the CoreLok and dimensional method data.

On average the air voids in the middle of the specimens were $1.15 \%$ greater than the air voids in the ends of the specimen for the CoreLok data. For the dimensional method data the average air voids in the middle of the specimens were $1.23 \%$ greater than the ends of the specimen.

Figure 11 and Figure 12 are boxplots comparing the air voids in the middle of the sample and the ends of the sample for the CoreLok and dimensional method data respectively. These figures show that the air void measurements in the middle of the sample are consistently higher than the air voids in the ends of the sample. 


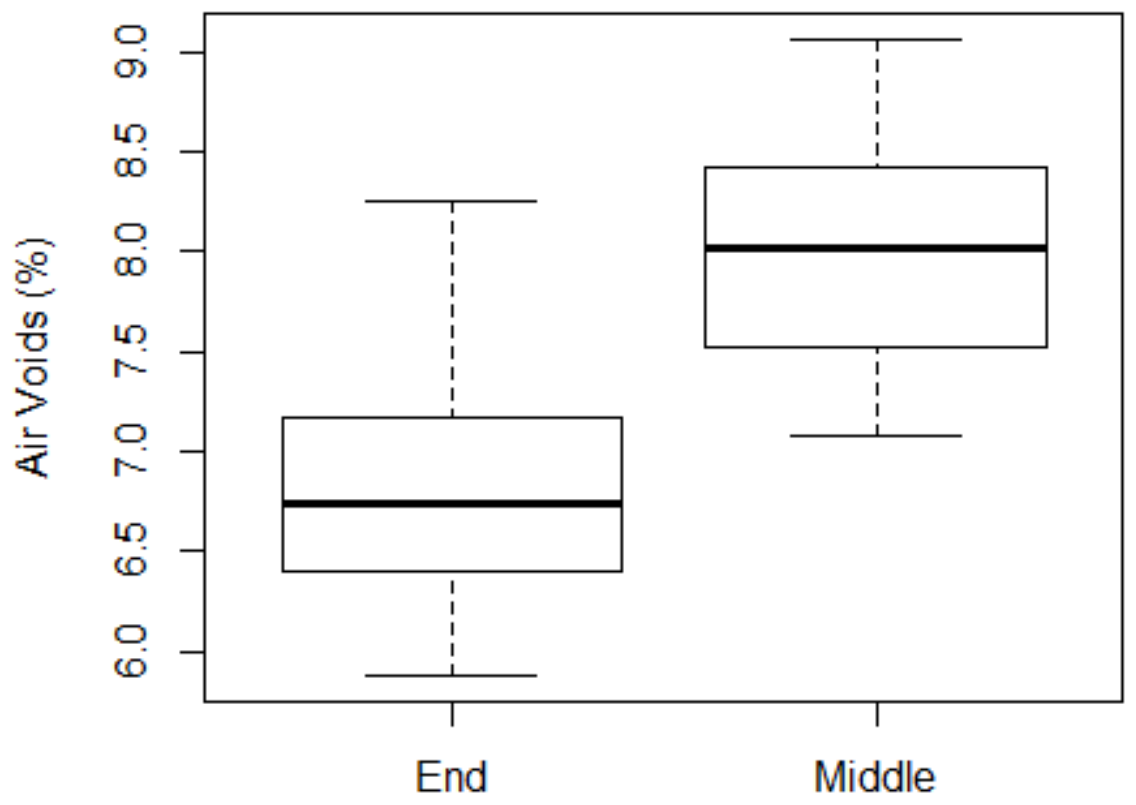

Figure 11 Boxplot Comparing Air Voids in the Middle and Ends of the Specimen Using CoreLok Method Data

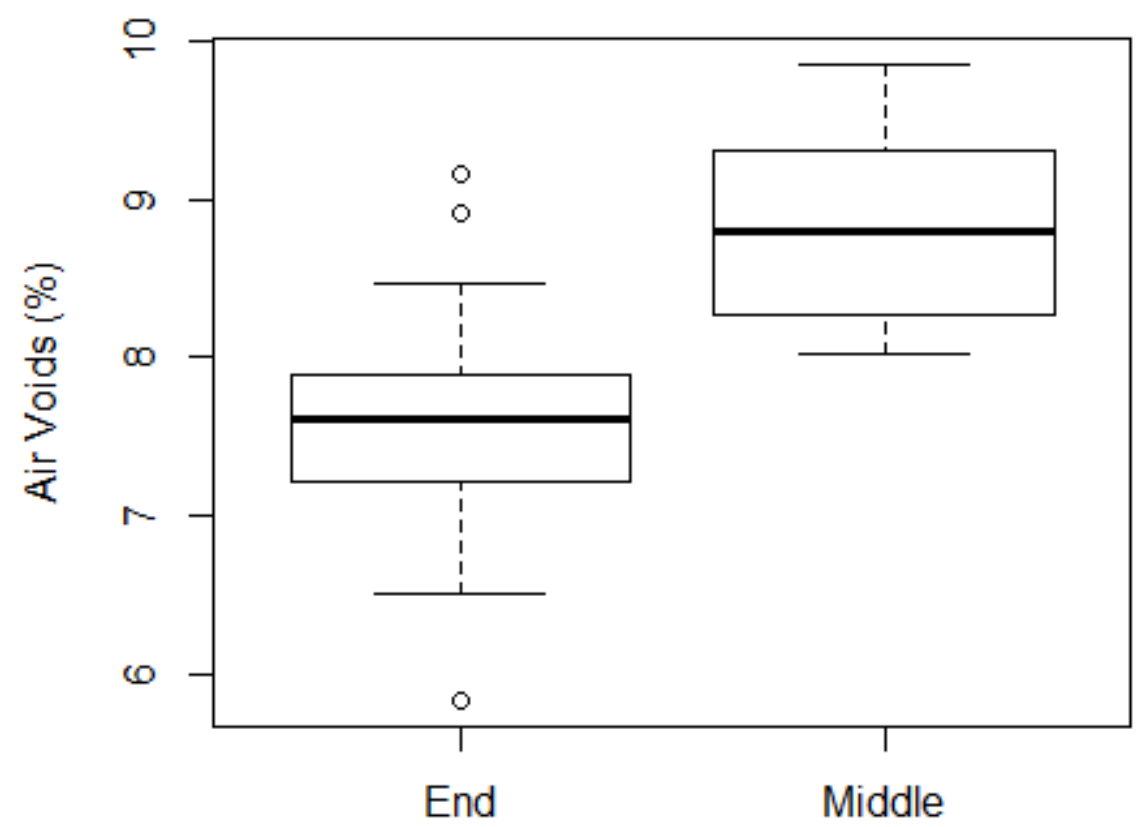

Figure 12 Boxplot Comparing Air Voids in the Middle and Ends of Specimen Using Dimensional Method Data 


\subsection{Analysis of Air Voids within Sample}

In order to determine if the mix properties had an effect on the variation of air voids in the middle and ends of the specimen an ANOVA was performed. This analysis is shown in Table 9 and Table 10 for the CoreLok and dimensional method data respectively. The data in Table 9 indicates that there is a significant difference in the air voids in the middle of the sample and the air voids on the ends of the sample. It also shows that none of the mix properties have an effect on the difference in air void measurements within the sample. The data in Table 10 also indicates that there is a significant difference in the air voids in the middle of the sample and the ends of the sample. However, the data obtained from the dimensional method found that the NMAS has an effect on the difference between the air voids in the middle of the sample and the ends of the sample.

Table 9 ANOVA of Air Voids within Sample Using CoreLok Data

\begin{tabular}{lccc}
\hline Factor & Type & Levels & Values \\
\hline Section & Fixed & 2 & End, Middle \\
NMAS & Fixed & 2 & 9.5 NMAS, 12.5 NMAS \\
Binder & Fixed & 3 & PG 70-22, PG 70-22 PM, PG 76-22 PM
\end{tabular}

ANOVA for Air Voids

\begin{tabular}{lccccc} 
Factor & DF & SS & MS & F & P-value \\
\hline Section & 1 & 26.866 & 26.866 & 96.361 & $<.001 \mathrm{~S}$ \\
NMAS & 1 & 0.393 & 0.393 & 1.411 & 0.239 \\
Binder & 2 & 0.687 & 0.344 & 1.232 & 0.297 \\
Section x NMAS & 1 & 0.819 & 0.819 & 2.937 & 0.091 \\
Section x Binder & 2 & 0.477 & 0.238 & 0.855 & 0.429 \\
NMAS x Binder & 2 & 0.463 & 0.231 & 0.830 & 0.440 \\
Section x NMAS x Binder & 2 & 0.059 & 0.03 & 0.106 & 0.900 \\
Residuals & 78 & 21.747 & 0.279 & & \\
\hline
\end{tabular}

DF, degree of freedom; SS, sum of squares; MS, mean square (SS divided by DF); F, ratio of mean squares.

It is used to determine the P-value; $\mathrm{S}$, factor is significant. 
Table 10 ANOVA of Air Voids Within Sample Using Dimensional Data

\begin{tabular}{|c|c|c|c|c|c|}
\hline Factor & Type & Levels & Values & & \\
\hline Section & Fixed & 2 & End, Middle & & \\
\hline NMAS & Fixed & 2 & 9.5 NMAS, 12.5 NMAS & & \\
\hline Binder & Fixed & 3 & PG 70-22, PG 70-22 PM, PG 76-22 PM & & \\
\hline \multicolumn{6}{|l|}{ ANOVA for Air Voids } \\
\hline Factor & DF & SS & MS & $\mathrm{F}$ & P-value \\
\hline Section & 1 & 30.176 & 30.176 & 37.109 & $<.001 \mathrm{~S}$ \\
\hline NMAS & 1 & 0.408 & 0.408 & 1.313 & 0.255 \\
\hline Binder & 2 & 1.539 & 0.769 & 2.476 & 0.091 \\
\hline Section $\times$ NMAS & 1 & 1.415 & 1.415 & 4.554 & $0.036 \mathrm{~S}$ \\
\hline Section x Binder & 2 & 0.175 & 0.088 & 0.282 & 0.755 \\
\hline NMAS x Binder & 2 & 0.576 & 0.288 & 0.926 & 0.400 \\
\hline Section $x$ NMAS $\times$ Binder & 2 & 0.311 & 0.156 & 0.501 & 0.608 \\
\hline Residuals & 78 & 24.238 & 0.311 & & \\
\hline
\end{tabular}

\subsection{Investigation of Heterogeneity Index}

The heterogeneity index for each sample was calculated by using Equation 7. It was desired to determine if this index could distinguish if experimental factors have significance on the air void distribution within a HMA sample. An ANOVA was performed on the heterogeneity index with the data from the CoreLok method as shown in Table 11 and the data from the dimensional method as shown in Table 12. The results found that none of the mix properties affected the air void distribution within the sample for the CoreLok and Dimensional method data.

Table 11 ANOVA of Heterogeneity Index and Mix Properties Using CoreLok Method Data

\begin{tabular}{llcl}
\hline Factor & Type & Levels & \multicolumn{1}{c}{ Values } \\
\hline NMAS & Fixed & 2 & 9.5 NMAS, 12.5 NMAS \\
Binder & Fixed & 3 & PG 70-22, PG 70-22 PM, PG 76-22 PM
\end{tabular}

ANOVA for Air Voids

\begin{tabular}{|c|c|c|c|c|c|}
\hline Factor & DF & SS & MS & $\mathrm{F}$ & P-value \\
\hline Binder & 1 & 0.003 & 0.0032 & 2.908 & 0.101 \\
\hline NMAS & 2 & 0.002 & 0.0008 & 0.69 & 0.511 \\
\hline Binder $x$ NMAS & 2 & 0.000 & 0.0001 & 0.048 & 0.953 \\
\hline Residuals & 24 & 0.026 & 0.0011 & & \\
\hline
\end{tabular}

DF, degree of freedom; SS, sum of squares; MS, mean square (SS divided by DF); F, ratio of mean squares.

It is used to determine the P-value; $\mathrm{S}$, factor is significant. 
Table 12 ANOVA of Heterogeneity Index and Mix Properties Using Dimensional Method Data

\begin{tabular}{lcccc}
\hline Factor & Type & Levels & Values \\
\hline NMAS & Fixed & 2 & 9.5 NMAS, 12.5 NMAS & \\
Binder & Fixed & 3 & PG 70-22, PG 70-22 PM, PG 76-22 PM & \\
ANOVA for Air Voids & & & & MS \\
Factor & DF & SS & 0.003 & 2.605 \\
\hline Binder & 1 & 0.003 & 0.000 & 0.309 \\
NMAS & 2 & 0.001 & 0.737 \\
Binder x NMAS & 2 & 0.001 & 0.001 & 0.001 \\
Residuals & 24 & 0.024 & 0.001 & 0.506 \\
\hline
\end{tabular}

DF, degree of freedom; SS, sum of squares; MS, mean square (SS divided by DF); F, ratio of mean squares.

It is used to determine the P-value; $\mathrm{S}$, factor is significant. 


\section{Chapter 5 Conclusions and Recommendations}

\subsection{Conclusions}

From the analysis of the data collected the following can be concluded:

1. The volumetric and CoreLok method of measuring the air voids for the sample are significantly different for samples with a height of $150 \mathrm{~mm}$ and $48 \mathrm{~mm}$. When measuring the air voids for the two sample heights the dimensional method consistently found air voids higher than the CoreLok method. This also agrees with Crouch et al. (2007) who found that the dimensional method measures air voids greater than the CoreLok method. The dimensional method measures a larger volume than the CoreLok method, which computes a smaller bulk specific gravity and higher air void content for the sample in comparison to the CoreLok method.

2. The binder type for the mix does not affect the different measured air voids between the middle and ends of the specimen. The analyses found that when measuring the air voids in the middle of the sample in comparison to the ends of the sample, the binder type had no effect on the difference in air voids between the sections. It was also found that the binder type does not affect the difference in air void computations by the dimensional or CoreLok method.

3. The NMAS was found to not be significant in the air void distribution when measuring the air voids with the CoreLok method but was found to be significant when measuring the air voids with the dimensional method. Since each method had a different result, no conclusion can be made on the effect of the NMAS on the air void distribution within the sample. It was found that the interaction of NMAS and $\mathrm{G}_{\mathrm{mb}}$ method does not affect the air voids computed. This suggests that the different results for the relationship between the NMAS and air void distribution are not due to computational errors.

4. Samples produced with the SGC do not have a uniform distribution within the sample. The air voids in the middle of the sample was found to be significantly different from the air voids in the ends of the sample and the air voids in the middle of the sample was found to be consistently greater than the air voids in the ends of the sample. This agrees with the literature review. Thyagarajan et al. (2010) found that samples did not receive 
as much compaction in the middle of the specimen due to the compaction energy cones from the top and bottom of the sample not intersecting. On average, the air voids were $1.15 \%$ and $1.23 \%$ greater in the middle of the specimen than the ends of the specimen for the CoreLok and dimensional method respectively.

5. The heterogeneity index (HI) does not show potential in determining the air void distribution within HMA samples. The heterogeneity index can be used for comparing experimental factors to the air void distribution within HMA samples but still does not create reliable results. The HI may not detect high variances of air voids within HMA samples. T tests and ANOVAs are much more viable options for analyzing the air void distribution within HMA samples.

\subsection{Recommendations}

Judging from the results of this report the following is recommended:

1. Determine the effect of air void distribution on dynamic modulus testing.

2. Perform additional testing for sample uniformity following AASHTO PP 60 procedure.

3. Create a larger database to verify the effect of experimental factors on the air void distribution within an HMA sample.

4. Repeat testing with SGCs from different manufacturers.

It is recommended that the effect of the air void distribution on dynamic modulus testing be explored. Dynamic modulus testing should be performed on samples and then they should be cut into sections to determine the air void distribution. Chapter 2 explains that dynamic modulus testing has no effect on the air void distribution within an HMA sample, which will allow dynamic modulus testing to be performed on the sample before an air void distribution analysis is performed.

Determine if the sample uniformity or heterogeneity index may be utilized to establish a relationship between dynamic modulus testing repeatability and the air void variability of samples. If there is a relationship, a threshold can be established. This will allow an approach to determining if results obtained from performance testing should be used or not. If the sample does not meet the threshold than the results from performance testing with those samples should be rejected. 
A larger database should be created to determine the effect of the mix properties on the air void distribution within a sample. The data found that the binder type does not have an effect on the air void distribution within the sample, but it was found that the NMAS does have an effect on the air void distribution within the sample when using data from the dimensional method. The reliability of the results can only be improved with a greater sample size of NMAS and binder types. If the analysis of the updated database confirms that the mix properties do not have an effect on the air void distribution within a sample, it is recommended that a new compaction procedure or compaction equipment be explored that will create specimens with a uniform distribution of air voids.

It should be confirmed that the SGC prepared samples with a non-uniform air void distribution is not unique to the SGC at the WVU Asphalt Technology Laboratory. The WVU laboratory has a Pine AFGC125X SGC. Pine has developed new models since the SGC at the WVU laboratory was acquired such as the AFG2 and AFGB1. Samples should be prepared by SGCs from other manufacturers to determine if the SGC can provide adequate compaction for $180 \mathrm{~mm}$ tall specimens. 


\section{References}

Bonaquist, R. F., D. W. Christensen, and W. Stump, NCHRP 513: Simple Performance Tester for Superpave Mix Design, National Cooperative Highway Research Program. Transportation Research Board. Washington, DC, 2003.

Brown, R., P. Khandal, F. Roberts, Y. Kim, D. Lee, and T. Kennedy, Hot Mix Asphalt Materials, Mixture Design, and Construction, NAPA Research and Education Foundation. Lanham, MD, 2009.

Chen, J., B. Huang, and X. Shu, “Air-Void Distribution Analysis of Asphalt Mixture Using Discrete Element Method", ASCE: Journal of Materials in Civil Engineering. Vol. 25, Issue 10, October, 2013.

Cooley, L., B. Prowell, M. Hainin, M. Buchanan, and J. Harrington, Bulk Specific Gravity Round-Robin Using the CoreLok Vacuum Sealing Device, National Center for Asphalt Technology. Federal Highway Administration. FHWA-IF-02-044. Washington, DC. 2002.

Copple, F., Compaction - The Only Way to Quality Asphalt Pavements, Materials and Technology Engineering and Science. Michigan Department of Transportation. Lansing, MI. 1998.

Crouch, L., D. Badoe, M. Cates, T. Borden, A. Copeland, C. Walker, T. Durn, R. Maxwell, and W. Goodwin, Bulk Specific Gravity of Compacted Bituminous Mixtures: Finding a More Widely Applicable Method, Tennessee Department of Transportation. Federal Highway Administration. Nashville, TN. 2003.

Crouch, L., A. Copeland, C. Walker, R. Maxwell, G. Duncan, W. Goodwin, D. Badoe, and H. Leimer, "Determining Air Void Content of Compacted Hot-Mix Asphalt Mixtures", Transportation Research Record 1813: Journal of the Transportation Research Board. 2007.

Dubois, V., C. De La Roche, and O. Burban, "Influence of the Compaction Process on the Air Void Homogeneity of Asphalt Mixture Samples", Construction and Building Materials. Vol. 24, Issue 6, 2010. 
Encyclopedia Brittanica Online, “Archimedes Principle”, Encyclopedia Brittanica Inc. Web. 2015. $<$ http://www.britannica.com.www.libproxy.wvu.edu/science/Archimedes-principle>.

Hall, K., E. Dukatz, T. Lynn, R. Pyle, T. Brovold, K. Brown, and R. West, Superpave Gyratory Compactor, Office of Pavement Technology. Federal Highway Administration. FHWA-HIF11-032. Washington, DC. 2010.

Hall, K., S. Williams, and F. Griffith, An Examination of Gamma Ray Methods for Measuring Bulk Specific Gravity of Hot-Mix Asphalt Concrete, Paper Prepared for the Annual Meeting of the Association of Paving Technologists. Transportation Research Board. Fayetteville, AR. 2002.

Instrotek, “CoreLok Manual”, 2011.

$<$ http://www.instrotek.com/pdfs/CoreLok_Manual.pdf $>$

Instrotek, “AMPT Brochure”, 2012. $<\mathrm{http}$ //instrotek.com/wordpress/wp-content/uploads/IPC_AMPT_EN_WEB_1112.pdf>

Mamlouk, M. and J. Zaniewski, Materials for Civil and Construction Engineers ( ${ }^{\text {rd }}$ ed.), Upper Saddle River: Pearson Education. 2011.

McGennis, R., Anderson R., Kennedy, T., and M. Solaimanian, Background of Superpave Asphalt Mixture Design \& Analysis, Asphalt Institute. Federal Highway Administration. FHWA-SA-95-003. Lexington, KY. 1995.

Pavement Interactive. Compaction Importance. December 2010. $<$ pavementinteractive.org $>$.

Pavement Interactive. Bulk Specific Gravity Testing. April 2011. $<$ pavementinteractive.org $>$ 
Sholar, G., G. Page, J. Musselman, P. Upshaw, and H. Moseley, Investigation of the CoreLok for Maximum, Aggregate and Bulk Specific Gravity Tests, State of Florida Materials Office. Florida Department of Transportation. FL/DOT/SMO/03-462. Gainesville, FL. 2003.

Solaimanian, M., Y. Yildirim, R. McGennis, and T. Kennedy, Evaluation of Superpave Gyratory Compactors, Texas Center for Transportation Research. Federal Highway Administration. Report No. 1250-3. Austin, TX. 1999.

Tashman, L., E. Masada, and J. D’Angelo, “X-ray Tomography to Characterize Air Void Distribution in Superpave Gyratory Compacted Specimens.", International Journal of Pavement Engineering. Vol. 3, Issue 1, 2002.

Taylor, A., and N. Tran, Results of Inter-Laboratory Study for AMPT Pooled Fund Study, National Center for Asphalt Technology at Auburn University. Federal Highway Administration. DTFH61-11-H-00032. Washington, DC. 2013.

Thyagarajan, S., L. Tashman, E. Masad, and F. Bayomy, “The Heterogeneity and Mechanical Response of Hot Mix Asphalt Laboratory Specimens”, International Journal of Pavement Engineering. Vol. 11, No. 2, April 2010.

West, R., E. Dukatz, J. Haddock, K. Hall, J. Kliewer, C. Marek, J. Musselman, and A. Regimand, A Review of Aggregate and Asphalt Mixture Specific Gravity and their Impacts on Asphalt Mix Design Properties and Mix Acceptance, Office of Pavement Technology. Federal Highway Administration. FHWA-HIF-11-033. Washington, DC. 2010.

Williams, S., "Bulk Specific Gravity Measurements of 25.0-mm and 37.5-mm Coarse-Graded Superpave Mixes.”, Journal of the Transportation Research Board. Vol. 2001. 2007.

Witczak, M., R. Bonaquist, H. Von Quintus, and K. Kaloush, "Specimen Geometry and Aggregate Size Effects in Uniaxial Compression and Constant Height Shear Tests.”, Journal of the Association of Asphalt Paving Technologists. Vol. 69. 2000.

WVDOH, Guide to Designing Hot-Mix Asphalt Using the Superpave Volumetric Design Method, West Virginia Department of Transportation Division of Highways. Materials Procedure 401.02.28. Charleston, WV. 2011. 
WVDOH, Guide for Quality Control and Acceptance Requirements for Superpave Hot-Mix Asphalt, West Virginia Department of Transportation Division of Highways. Materials Procedure 401.02.29. Charleston, WV. 2000.

$\mathrm{Yu}, \mathrm{H}$., and S. Shen, An Investigation of Dynamic Modulus and Flow Number Properties of Asphalt Mixtures in Washington State, Washington State Transportation Center. Federal Highway Administration. Report No. TNW2012-02. Pullman, WA. 2012. 
Appendix A

Sample Information 


\begin{tabular}{|r|r|l|r|}
\hline \multicolumn{4}{|c|}{ Specimen Information } \\
\hline Sample ID & NMAS & Binder & Gmm \\
\hline 1 & 12.5 & $76-22 \mathrm{PM}$ & 2.492 \\
\hline 2 & 12.5 & $70-22 \mathrm{PM}$ & 2.495 \\
\hline 3 & 9.5 & $70-22 \mathrm{PM}$ & 2.462 \\
\hline 4 & 9.5 & $76-22 \mathrm{PM}$ & 2.469 \\
\hline 5 & 9.5 & $70-22$ & 2.451 \\
\hline 6 & 12.5 & $76-22 \mathrm{PM}$ & 2.492 \\
\hline 7 & 12.5 & $70-22 \mathrm{PM}$ & 2.495 \\
\hline 8 & 9.5 & $76-22 \mathrm{PM}$ & 2.469 \\
\hline 9 & 9.5 & $70-22 \mathrm{PM}$ & 2.462 \\
\hline 10 & 12.5 & $70-22$ & 2.486 \\
\hline 11 & 9.5 & $70-22$ & 2.451 \\
\hline 12 & 9.5 & $70-22$ & 2.451 \\
\hline 13 & 12.5 & $70-22$ & 2.486 \\
\hline 14 & 12.5 & $70-22 \mathrm{PM}$ & 2.495 \\
\hline 15 & 12.5 & $70-22$ & 2.486 \\
\hline 16 & 12.5 & $70-22$ & 2.486 \\
\hline 17 & 9.5 & $70-22 \mathrm{PM}$ & 2.462 \\
\hline 18 & 12.5 & $76-22 \mathrm{PM}$ & 2.492 \\
\hline 19 & 9.5 & $76-22 \mathrm{PM}$ & 2.469 \\
\hline 20 & 9.5 & $70-22$ & 2.451 \\
\hline 21 & 12.5 & $70-22$ & 2.486 \\
\hline 22 & 9.5 & $70-22$ & 2.451 \\
\hline 23 & 9.5 & $70-22 \mathrm{PM}$ & 2.462 \\
\hline 24 & 9.5 & $76-22 \mathrm{PM}$ & 2.469 \\
\hline 25 & 12.5 & $76-22 \mathrm{PM}$ & 2.492 \\
\hline 26 & 9.5 & $76-22 \mathrm{PM}$ & 2.469 \\
\hline 27 & 12.5 & $70-22 \mathrm{PM}$ & 2.495 \\
\hline 28 & 9.5 & $70-22 \mathrm{PM}$ & 2.462 \\
\hline 29 & 12.5 & $76-22 \mathrm{PM}$ & 2.492 \\
\hline 30 & 12.5 & $70-22 \mathrm{PM}$ & 2.495 \\
\hline & & & \\
\hline
\end{tabular}


Appendix B

Saturated Surface Dry Method Data 


\begin{tabular}{|c|c|c|c|c|c|c|c|}
\hline \multicolumn{8}{|c|}{ Summary of SSD Data } \\
\hline Sample & $\mathrm{Gmm}$ & $\begin{array}{l}\text { Dry Mass } \\
(\mathrm{g})\end{array}$ & $\begin{array}{l}\text { SSD Mass } \\
(\mathrm{g})\end{array}$ & $\begin{array}{c}\text { Submerged } \\
\text { Mass (g) }\end{array}$ & $\mathrm{G}_{\mathrm{mb}}$ & $\begin{array}{l}\text { Air } \\
\text { Voids } \\
(\%)\end{array}$ & $\begin{array}{c}\text { Absorption } \\
(\%)\end{array}$ \\
\hline 1 & 2.492 & 2747.5 & 2819.5 & 1631.8 & 2.313 & 7.17 & $\overline{6.06}$ \\
\hline 2 & 2.495 & 2756.1 & 2826.4 & 1633.0 & 2.309 & 7.44 & 5.89 \\
\hline 3 & 2.462 & 2719.6 & 2787.2 & 1600.1 & 2.291 & 6.95 & 5.69 \\
\hline 4 & 2.469 & 2745.5 & 2810.3 & 1616.6 & 2.300 & 6.85 & 5.43 \\
\hline 5 & 2.451 & 2720.2 & 2792.0 & 1596.8 & 2.276 & 7.14 & 6.01 \\
\hline 6 & 2.492 & 2756.4 & 2829.1 & 1634.8 & 2.308 & 7.39 & 6.09 \\
\hline 7 & 2.495 & 2727.2 & 2795.4 & 1614.4 & 2.309 & 7.45 & 5.77 \\
\hline 8 & 2.469 & 2720.0 & 2798.0 & 1605.6 & 2.281 & 7.61 & 6.54 \\
\hline 9 & 2.462 & 2671.6 & 2746.1 & 1574.6 & 2.280 & 7.37 & 6.36 \\
\hline 10 & 2.486 & 2725.4 & 2793.6 & 1612.7 & 2.308 & 7.16 & 5.78 \\
\hline 11 & 2.451 & 2694.4 & 2770.0 & 1584.5 & 2.273 & 7.27 & 6.38 \\
\hline 12 & 2.451 & 2701.3 & 2776.6 & 1586.9 & 2.271 & 7.36 & 6.33 \\
\hline 13 & 2.486 & 2739.3 & 2806.6 & 1619.4 & 2.307 & 7.19 & 5.67 \\
\hline 14 & 2.495 & 2748.4 & 2810.0 & 1626.1 & 2.321 & 6.95 & 5.20 \\
\hline 15 & 2.486 & 2742.0 & 2803.5 & 1620.6 & 2.318 & 6.76 & 5.20 \\
\hline 16 & 2.486 & 2718.7 & 2785.0 & 1605.5 & 2.305 & 7.28 & 5.62 \\
\hline 17 & 2.462 & 2686.0 & 2750.6 & 1575.9 & 2.287 & 7.13 & 5.50 \\
\hline 18 & 2.492 & 2730.8 & 2801.0 & 1617.8 & 2.308 & 7.38 & 5.93 \\
\hline 19 & 2.469 & 2701.3 & 2766.0 & 1589.3 & 2.296 & 7.02 & 5.50 \\
\hline 20 & 2.451 & 2668.0 & 2745.3 & 1567.1 & 2.264 & 7.61 & 6.56 \\
\hline 21 & 2.486 & 2739.5 & 2808.8 & 1622.6 & 2.309 & 7.10 & 5.84 \\
\hline 22 & 2.451 & 2672.3 & 2746.0 & 1571.9 & 2.276 & 7.14 & 6.28 \\
\hline 23 & 2.462 & 2692.0 & 2758.5 & 1582.2 & 2.289 & 7.05 & 5.65 \\
\hline 24 & 2.469 & 2701.4 & 2767.2 & 1588.8 & 2.292 & 7.15 & 5.58 \\
\hline 25 & 2.492 & 2744.4 & 2810.8 & 1627.0 & 2.318 & 6.97 & 5.61 \\
\hline 26 & 2.469 & 2705.5 & 2773.2 & 1594.0 & 2.294 & 7.07 & 5.74 \\
\hline 27 & 2.495 & 2734.1 & 2800.8 & 1619.6 & 2.315 & 7.23 & 5.65 \\
\hline 28 & 2.462 & 2652.6 & 2734.4 & 1560.4 & 2.259 & 8.23 & 6.97 \\
\hline 29 & 2.492 & 2730.1 & 2792.6 & 1618.3 & 2.325 & 6.71 & 5.32 \\
\hline 30 & 2.495 & 2723.4 & 2787.6 & 1611.3 & 2.315 & 7.21 & 5.46 \\
\hline
\end{tabular}


Appendix C

CoreLok Method Data 


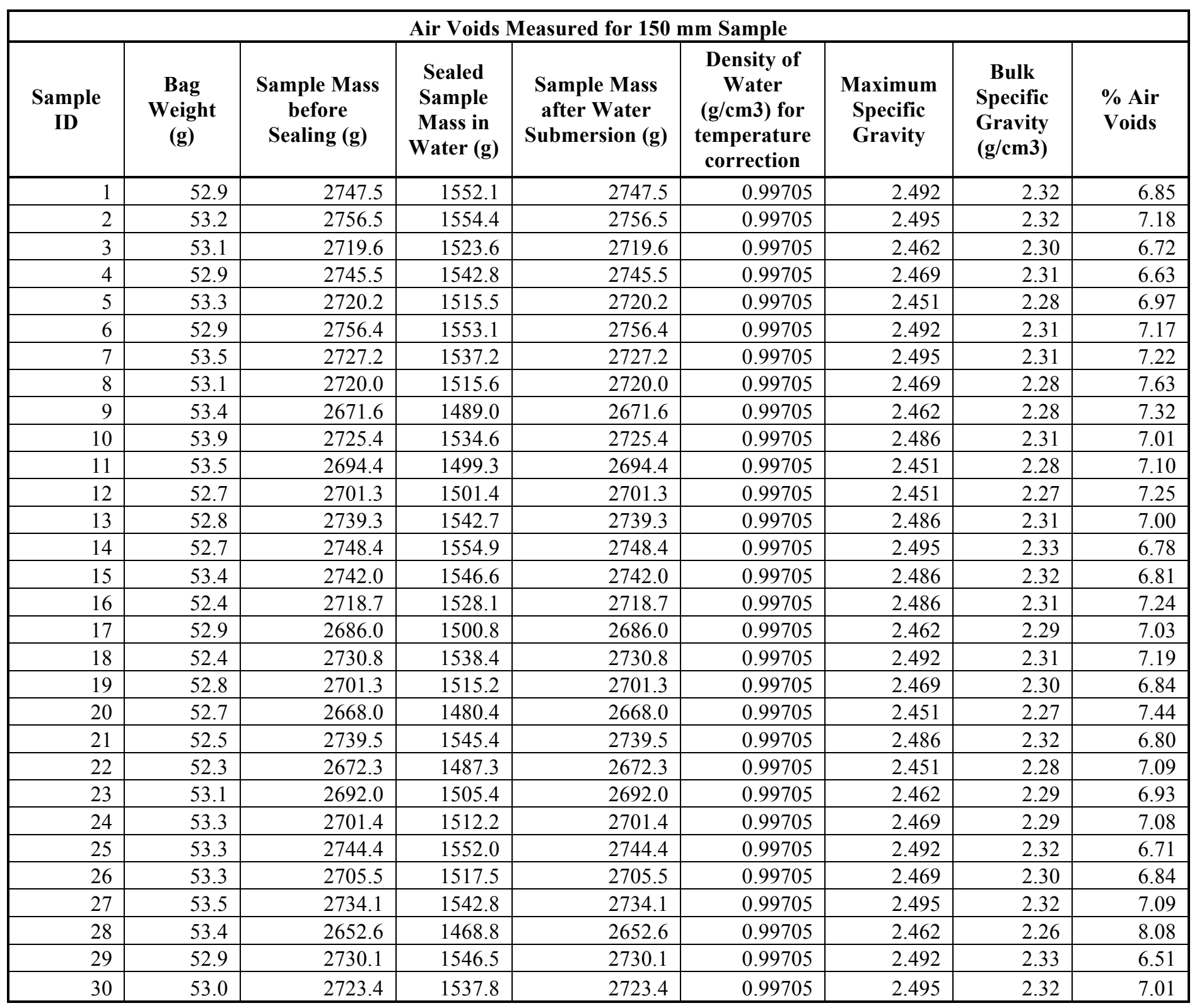




\begin{tabular}{|c|c|c|c|c|c|c|c|c|}
\hline \multicolumn{9}{|c|}{ Air Voids for End 1 of Sample } \\
\hline Sample ID & $\begin{array}{l}\text { Bag } \\
\text { Weight } \\
\text { (g) }\end{array}$ & $\begin{array}{c}\text { Sample Mass } \\
\text { before } \\
\text { Sealing (g) }\end{array}$ & $\begin{array}{c}\text { Sealed } \\
\text { Sample } \\
\text { Mass in } \\
\text { Water (g) }\end{array}$ & $\begin{array}{l}\text { Sample Mass } \\
\text { after Water } \\
\text { Submersion (g) }\end{array}$ & $\begin{array}{l}\text { Density of } \\
\text { Water } \\
\text { (g/cm3) for } \\
\text { temperature } \\
\text { correction }\end{array}$ & $\begin{array}{l}\text { Maximum } \\
\text { Specific } \\
\text { Gravity }\end{array}$ & $\begin{array}{c}\text { Bulk } \\
\text { Specific } \\
\text { Gravity } \\
(\mathrm{g} / \mathrm{cm} 3)\end{array}$ & $\begin{array}{l}\text { \% Air } \\
\text { Voids }\end{array}$ \\
\hline 1 & 27.5 & 900.5 & 507.1 & 900.0 & 0.99705 & 2.492 & 2.33 & 6.62 \\
\hline 2 & 27.6 & 866.3 & 490.2 & 866.0 & 0.99705 & 2.495 & 2.34 & 6.12 \\
\hline 3 & 27.6 & 838.8 & 470.1 & 838.2 & 0.99705 & 2.462 & 2.32 & 5.92 \\
\hline 4 & 27.5 & 886.8 & 497.6 & 886.5 & 0.99705 & 2.469 & 2.32 & 6.22 \\
\hline 5 & 27.5 & 867.9 & 482.6 & 867.7 & 0.99705 & 2.451 & 2.29 & 6.62 \\
\hline 6 & 27.5 & 857.7 & 478.9 & 857.4 & 0.99705 & 2.492 & 2.30 & 7.62 \\
\hline 7 & 27.8 & 873.0 & 491.9 & 872.7 & 0.99705 & 2.495 & 2.33 & 6.65 \\
\hline 8 & 27.7 & 869.5 & 484.6 & 869.1 & 0.99705 & 2.469 & 2.30 & 6.97 \\
\hline 9 & 27.7 & 843.9 & 469.1 & 843.6 & 0.99705 & 2.462 & 2.29 & 6.99 \\
\hline 10 & 27.7 & 864.4 & 486.2 & 864.2 & 0.99705 & 2.486 & 2.32 & 6.54 \\
\hline 11 & 27.6 & 853.6 & 475.9 & 853.4 & 0.99705 & 2.451 & 2.30 & 6.27 \\
\hline 12 & 27.3 & 856.6 & 475.3 & 856.6 & 0.99705 & 2.451 & 2.28 & 6.91 \\
\hline 13 & 27.2 & 841.4 & 470.0 & 841.0 & 0.99705 & 2.486 & 2.30 & 7.31 \\
\hline 14 & 27.4 & 868.0 & 489.6 & 867.6 & 0.99705 & 2.495 & 2.33 & 6.50 \\
\hline 15 & 27.4 & 867.9 & 485.6 & 867.6 & 0.99705 & 2.486 & 2.31 & 7.18 \\
\hline 16 & 27.4 & 848.5 & 476.5 & 848.3 & 0.99705 & 2.486 & 2.32 & 6.72 \\
\hline 17 & 27.5 & 837.3 & 466.1 & 837.1 & 0.99705 & 2.462 & 2.29 & 6.85 \\
\hline 18 & 27.5 & 866.3 & 490.7 & 866.0 & 0.99705 & 2.492 & 2.35 & 5.88 \\
\hline 19 & 27.4 & 901.6 & 506.7 & 901.3 & 0.99705 & 2.469 & 2.32 & 6.06 \\
\hline 20 & 27.4 & 825.1 & 456.7 & 825.2 & 0.99705 & 2.451 & 2.28 & 7.16 \\
\hline 21 & 27.5 & 860.6 & 482.7 & 860.3 & 0.99705 & 2.486 & 2.32 & 6.86 \\
\hline 22 & 27.6 & 849.5 & 470.4 & 849.8 & 0.99705 & 2.451 & 2.27 & 7.20 \\
\hline 23 & 27.5 & 827.7 & 461.7 & 827.4 & 0.99705 & 2.462 & 2.30 & 6.56 \\
\hline 24 & 27.5 & 858.4 & 479.2 & 858.2 & 0.99705 & 2.469 & 2.30 & 6.81 \\
\hline 25 & 27.5 & 870.3 & 490.7 & 870.2 & 0.99705 & 2.492 & 2.33 & 6.52 \\
\hline 26 & 27.6 & 874.1 & 488.2 & 873.8 & 0.99705 & 2.469 & 2.30 & 6.75 \\
\hline 27 & 27.5 & 887.1 & 500.2 & 887.1 & 0.99705 & 2.495 & 2.33 & 6.68 \\
\hline 28 & 27.5 & 849.9 & 470.5 & 849.8 & 0.99705 & 2.462 & 2.28 & 7.55 \\
\hline 29 & 27.4 & 867.1 & 490.0 & 867.1 & 0.99705 & 2.492 & 2.34 & 6.26 \\
\hline 30 & 27.7 & 858.8 & 482.0 & 858.6 & 0.99705 & 2.495 & 2.32 & 7.13 \\
\hline
\end{tabular}




\begin{tabular}{|c|c|c|c|c|c|c|c|c|}
\hline \multicolumn{9}{|c|}{ Air Voids Measured for Middle of Sample } \\
\hline $\begin{array}{c}\text { Sample } \\
\text { ID }\end{array}$ & $\begin{array}{c}\text { Bag } \\
\text { Weight } \\
\text { (g) }\end{array}$ & $\begin{array}{c}\text { Sample Mass } \\
\text { before Sealing } \\
\text { (g) }\end{array}$ & $\begin{array}{c}\text { Sealed } \\
\text { Sample } \\
\text { Mass in } \\
\text { Water (g) }\end{array}$ & $\begin{array}{c}\text { Sample Mass } \\
\text { after Water } \\
\text { Submersion (g) }\end{array}$ & $\begin{array}{l}\text { Density of } \\
\text { Water } \\
(\mathrm{g} / \mathrm{cm} 3) \text { for } \\
\text { temperature } \\
\text { correction }\end{array}$ & $\begin{array}{c}\text { Maximum } \\
\text { Specific } \\
\text { Gravity }\end{array}$ & $\begin{array}{l}\text { Bulk } \\
\text { Specific } \\
\text { Gravity } \\
(\mathrm{g} / \mathrm{cm} 3)\end{array}$ & $\begin{array}{l}\text { \% Air } \\
\text { Voids }\end{array}$ \\
\hline 1 & 24.6 & 830.9 & 462.4 & 830.9 & 0.99705 & 2.492 & 2.29 & 8.21 \\
\hline 2 & 24.8 & 871.3 & 484.3 & 871.3 & 0.99705 & 2.495 & 2.28 & 8.51 \\
\hline 3 & 24.8 & 877.9 & 488.4 & 877.9 & 0.99705 & 2.462 & 2.28 & 7.19 \\
\hline 4 & 25.1 & 824.8 & 458.4 & 825.0 & 0.99705 & 2.469 & 2.28 & 7.52 \\
\hline 5 & 25.5 & 845.1 & 467.9 & 845.1 & 0.99705 & 2.451 & 2.27 & 7.25 \\
\hline 6 & 25.5 & 871.5 & 488.4 & 871.5 & 0.99705 & 2.492 & 2.31 & 7.39 \\
\hline 7 & 24.8 & 849.0 & 474.8 & 849.0 & 0.99705 & 2.495 & 2.30 & 7.76 \\
\hline 8 & 24.8 & 834.8 & 461.8 & 834.6 & 0.99705 & 2.469 & 2.27 & 8.00 \\
\hline 9 & 24.4 & 812.1 & 444.2 & 812.1 & 0.99705 & 2.462 & 2.24 & 9.06 \\
\hline 10 & 24.6 & 835.5 & 467.0 & 835.5 & 0.99705 & 2.486 & 2.30 & 7.48 \\
\hline 11 & 25.3 & 825.0 & 453.3 & 825.0 & 0.99705 & 2.451 & 2.25 & 8.11 \\
\hline 12 & 24.6 & 832.1 & 456.0 & 832.1 & 0.99705 & 2.451 & 2.24 & 8.46 \\
\hline 13 & 24.1 & 871.2 & 486.5 & 871.2 & 0.99705 & 2.486 & 2.30 & 7.67 \\
\hline 14 & 27.3 & 853.3 & 477.0 & 853.0 & 0.99705 & 2.495 & 2.31 & 7.60 \\
\hline 15 & 27.3 & 846.9 & 474.2 & 846.7 & 0.99705 & 2.486 & 2.31 & 7.08 \\
\hline 16 & 27.6 & 858.6 & 476.9 & 858.3 & 0.99705 & 2.486 & 2.29 & 8.02 \\
\hline 17 & 27.8 & 841.2 & 461.6 & 841.0 & 0.99705 & 2.462 & 2.25 & 8.51 \\
\hline 18 & 27.6 & 852.1 & 472.8 & 852.1 & 0.99705 & 2.492 & 2.28 & 8.42 \\
\hline 19 & 27.7 & 881.9 & 485.7 & 881.7 & 0.99705 & 2.469 & 2.26 & 8.43 \\
\hline 20 & 27.4 & 819.6 & 446.1 & 819.6 & 0.99705 & 2.451 & 2.23 & 9.04 \\
\hline 21 & 27.6 & 844.7 & 472.1 & 844.5 & 0.99705 & 2.486 & 2.31 & 7.28 \\
\hline 22 & 27.4 & 838.9 & 461.4 & 838.6 & 0.99705 & 2.451 & 2.26 & 7.82 \\
\hline 23 & 27.6 & 856.9 & 471.5 & 856.6 & 0.99705 & 2.462 & 2.26 & 8.21 \\
\hline 24 & 27.5 & 830.7 & 458.6 & 830.6 & 0.99705 & 2.469 & 2.27 & 8.10 \\
\hline 25 & 27.5 & 861.2 & 481.3 & 861.2 & 0.99705 & 2.492 & 2.30 & 7.59 \\
\hline 26 & 27.5 & 822.8 & 453.9 & 822.7 & 0.99705 & 2.469 & 2.27 & 8.17 \\
\hline 27 & 27.6 & 834.5 & 463.4 & 834.5 & 0.99705 & 2.495 & 2.29 & 8.41 \\
\hline 28 & 27.5 & 813.1 & 445.5 & 812.8 & 0.99705 & 2.462 & 2.25 & 8.61 \\
\hline 29 & 27.6 & 832.2 & 464.6 & 831.7 & 0.99705 & 2.492 & 2.30 & 7.53 \\
\hline 30 & 27.6 & 839.3 & 469.6 & 839.2 & 0.99705 & 2.495 & 2.31 & 7.50 \\
\hline
\end{tabular}




\begin{tabular}{|c|c|c|c|c|c|c|c|c|}
\hline \multicolumn{9}{|c|}{ Air Voids Measured for End 2 of Sample } \\
\hline $\begin{array}{c}\text { Sample } \\
\text { ID }\end{array}$ & $\begin{array}{c}\text { Bag } \\
\text { Weight } \\
\text { (g) }\end{array}$ & $\begin{array}{c}\text { Sample Mass } \\
\text { before } \\
\text { Sealing (g) }\end{array}$ & $\begin{array}{c}\text { Sealed } \\
\text { Sample } \\
\text { Mass in } \\
\text { Water (g) }\end{array}$ & $\begin{array}{c}\text { Sample Mass } \\
\text { after Water } \\
\text { Submersion } \\
\text { (g) }\end{array}$ & $\begin{array}{l}\text { Density of } \\
\text { Water } \\
\text { (g/cm3) for } \\
\text { temperature } \\
\text { correction }\end{array}$ & $\begin{array}{c}\text { Maximum } \\
\text { Specific } \\
\text { Gravity }\end{array}$ & $\begin{array}{c}\text { Bulk } \\
\text { Specific } \\
\text { Gravity } \\
(\text { g/cm3) }\end{array}$ & $\begin{array}{l}\text { \% Air } \\
\text { Voids }\end{array}$ \\
\hline 1 & 25.5 & 874.8 & 490.6 & 875.0 & 0.99705 & 2.492 & 2.31 & 7.36 \\
\hline 2 & 24.9 & 876.5 & 492.8 & 876.4 & 0.99705 & 2.495 & 2.32 & 7.13 \\
\hline 3 & 24.6 & 864.1 & 480.1 & 864.1 & 0.99705 & 2.462 & 2.28 & 7.34 \\
\hline 4 & 24.3 & 894.0 & 500.9 & 894.0 & 0.99705 & 2.469 & 2.30 & 6.66 \\
\hline 5 & 25.0 & 867.8 & 480.1 & 867.8 & 0.99705 & 2.451 & 2.27 & 7.40 \\
\hline 6 & 25.2 & 886.0 & 498.0 & 886.0 & 0.99705 & 2.492 & 2.32 & 7.08 \\
\hline 7 & 25.0 & 864.9 & 483.5 & 864.9 & 0.99705 & 2.495 & 2.30 & 7.82 \\
\hline 8 & 24.2 & 879.9 & 490.4 & 879.9 & 0.99705 & 2.469 & 2.29 & 7.28 \\
\hline 9 & 24.0 & 874.6 & 485.5 & 874.8 & 0.99705 & 2.462 & 2.28 & 7.54 \\
\hline 10 & 24.5 & 883.4 & 494.8 & 883.5 & 0.99705 & 2.486 & 2.30 & 7.33 \\
\hline 11 & 24.9 & 876.9 & 484.0 & 876.8 & 0.99705 & 2.451 & 2.26 & 7.67 \\
\hline 12 & 25.2 & 873.1 & 484.4 & 873.1 & 0.99705 & 2.451 & 2.28 & 7.07 \\
\hline 13 & 25.4 & 884.6 & 499.3 & 884.5 & 0.99705 & 2.486 & 2.33 & 6.30 \\
\hline 14 & 25.0 & 885.1 & 498.2 & 885.1 & 0.99705 & 2.495 & 2.32 & 7.03 \\
\hline 15 & 24.5 & 884.5 & 501.0 & 884.4 & 0.99705 & 2.486 & 2.34 & 5.91 \\
\hline 16 & 24.3 & 870.1 & 487.7 & 869.7 & 0.99705 & 2.486 & 2.31 & 7.12 \\
\hline 17 & 24.4 & 867.0 & 486.4 & 867.1 & 0.99705 & 2.462 & 2.31 & 6.22 \\
\hline 18 & 24.4 & 871.4 & 488.2 & 871.2 & 0.99705 & 2.492 & 2.31 & 7.44 \\
\hline 19 & 24.5 & 778.3 & 437.0 & 778.3 & 0.99705 & 2.469 & 2.32 & 6.19 \\
\hline 20 & 24.6 & 885.0 & 493.2 & 884.6 & 0.99705 & 2.451 & 2.29 & 6.50 \\
\hline 21 & 24.5 & 892.8 & 501.3 & 892.8 & 0.99705 & 2.486 & 2.31 & 7.03 \\
\hline 22 & 24.8 & 843.6 & 470.4 & 843.8 & 0.99705 & 2.451 & 2.29 & 6.50 \\
\hline 23 & 25.1 & 868.7 & 487.8 & 868.7 & 0.99705 & 2.462 & 2.31 & 6.04 \\
\hline 24 & 24.7 & 874.0 & 490.8 & 874.0 & 0.99705 & 2.469 & 2.31 & 6.33 \\
\hline 25 & 23.7 & 873.0 & 493.2 & 872.7 & 0.99705 & 2.492 & 2.33 & 6.44 \\
\hline 26 & 24.2 & 868.9 & 488.0 & 868.7 & 0.99705 & 2.469 & 2.31 & 6.29 \\
\hline 27 & 24.9 & 871.8 & 492.1 & 871.6 & 0.99705 & 2.495 & 2.33 & 6.61 \\
\hline 28 & 25.5 & 853.1 & 470.0 & 853.1 & 0.99705 & 2.462 & 2.26 & 8.25 \\
\hline 29 & 25.2 & 889.0 & 502.6 & 889.0 & 0.99705 & 2.492 & 2.33 & 6.37 \\
\hline 30 & 24.6 & 882.4 & 498.3 & 882.4 & 0.99705 & 2.495 & 2.33 & 6.64 \\
\hline
\end{tabular}


Appendix D

\section{Dimensional Method Data}

Note: Diameter measurements did not vary. 


\begin{tabular}{|c|c|c|c|c|c|c|c|c|c|}
\hline \multicolumn{10}{|c|}{ Specimen Measurements for $150 \mathrm{~mm}$ Sample } \\
\hline $\begin{array}{c}\text { Sample } \\
\text { ID }\end{array}$ & $\begin{array}{c}\text { Average } \\
\text { Diameter } \\
(\mathrm{mm})\end{array}$ & $\begin{array}{l}\text { Height } 1 \\
\quad(\mathbf{m m})\end{array}$ & $\begin{array}{c}\text { Height } 2 \\
\quad(\mathbf{m m})\end{array}$ & $\begin{array}{c}\text { Height } 3 \\
(\mathbf{m m})\end{array}$ & $\begin{array}{c}\text { Height } 4 \\
(\mathbf{m m})\end{array}$ & $\begin{array}{c}\text { Height } 5 \\
(\mathrm{~mm})\end{array}$ & $\begin{array}{c}\text { Height } 6 \\
(\mathbf{m m})\end{array}$ & $\begin{array}{c}\text { Average } \\
\text { Height } \\
(\mathrm{mm}) \\
\end{array}$ & $\begin{array}{c}\text { Volume } \\
\text { (mm3) }\end{array}$ \\
\hline 1 & 100.5 & 151.2 & 151.2 & 151.3 & 151.3 & 151.2 & 151.2 & 151.2 & 1199691.4 \\
\hline 2 & 100.5 & 151.4 & 151.4 & 151.4 & 151.6 & 151.6 & 151.6 & 151.4 & 1201013.5 \\
\hline 3 & 100.5 & 150.6 & 150.7 & 150.8 & 150.6 & 150.6 & 150.6 & 150.7 & 1195063.9 \\
\hline 4 & 100.5 & 151.4 & 151.6 & 151.7 & 151.4 & 151.6 & 151.7 & 151.6 & 1202335.6 \\
\hline 5 & 100.5 & 151.9 & 152.1 & 151.9 & 151.5 & 151.9 & 152.1 & 151.9 & 1204979.8 \\
\hline 6 & 100.5 & 151.6 & 151.6 & 151.7 & 151.8 & 151.6 & 151.6 & 151.7 & 1202996.7 \\
\hline 7 & 100.5 & 150.0 & 149.8 & 150.0 & 149.9 & 150.0 & 149.8 & 149.9 & 1189246.6 \\
\hline 8 & 100.5 & 151.5 & 151.7 & 151.5 & 151.7 & 151.3 & 151.4 & 151.5 & 1201939.0 \\
\hline 9 & 100.5 & 149.0 & 149.3 & 149.3 & 149.3 & 149.5 & 149.5 & 149.3 & 1184487.0 \\
\hline 10 & 100.5 & 150.0 & 150.0 & 150.0 & 150.0 & 150.0 & 150.0 & 150.0 & 1189907.7 \\
\hline 11 & 100.5 & 150.4 & 150.4 & 150.4 & 150.4 & 150.6 & 150.6 & 150.5 & 1193609.6 \\
\hline 12 & 100.5 & 151.6 & 151.5 & 151.6 & 151.1 & 151.6 & 151.3 & 151.5 & 1201410.1 \\
\hline 13 & 100.5 & 151.2 & 151.1 & 150.7 & 150.8 & 151.1 & 151.2 & 151.0 & 1197972.6 \\
\hline 14 & 100.5 & 150.6 & 150.3 & 150.5 & 150.5 & 150.5 & 150.5 & 150.5 & 1193741.8 \\
\hline 15 & 100.5 & 150.4 & 150.3 & 150.3 & 150.3 & 150.3 & 150.3 & 150.3 & 1192419.7 \\
\hline 16 & 100.5 & 150.0 & 150.0 & 150.0 & 150.0 & 149.9 & 149.7 & 149.9 & 1189378.8 \\
\hline 17 & 100.5 & 149.6 & 149.7 & 149.8 & 149.6 & 149.6 & 149.7 & 149.7 & 1187263.4 \\
\hline 18 & 100.5 & 150.6 & 150.6 & 149.9 & 150.4 & 150.5 & 150.6 & 150.4 & 1193345.2 \\
\hline 19 & 100.5 & 149.7 & 149.6 & 149.7 & 149.6 & 149.7 & 149.6 & 149.7 & 1187131.2 \\
\hline 20 & 100.5 & 150.4 & 150.3 & 150.1 & 149.3 & 149.7 & 150.4 & 150.0 & 1190172.1 \\
\hline 21 & 100.5 & 150.8 & 150.7 & 150.6 & 150.7 & 150.8 & 150.7 & 150.7 & 1195592.8 \\
\hline 22 & 100.5 & 149.3 & 149.4 & 149.2 & 149.3 & 149.3 & 149.2 & 149.3 & 1184222.6 \\
\hline 23 & 100.5 & 149.5 & 149.4 & 149.5 & 149.4 & 149.5 & 149.4 & 149.5 & 1185544.7 \\
\hline 24 & 100.5 & 149.7 & 149.6 & 149.8 & 149.7 & 149.6 & 149.7 & 149.7 & 1187395.6 \\
\hline 25 & 100.5 & 150.2 & 150.1 & 150.1 & 150.3 & 150.2 & 150.2 & 150.2 & 1191362.0 \\
\hline 26 & 100.5 & 149.9 & 149.7 & 149.5 & 149.7 & 149.8 & 149.9 & 149.8 & 1187924.5 \\
\hline
\end{tabular}




\begin{tabular}{|r|c|c|c|r|r|r|r|r|r|}
\hline \multicolumn{10}{|c|}{ Specimen Measurements for 150 mm Sample } \\
\hline $\begin{array}{c}\text { Sample } \\
\text { ID }\end{array}$ & $\begin{array}{c}\text { Average } \\
\text { Diameter } \\
(\mathbf{m m})\end{array}$ & $\begin{array}{c}\text { Height 1 } \\
(\mathbf{m m})\end{array}$ & $\begin{array}{c}\text { Height 2 } \\
\mathbf{( m m})\end{array}$ & $\begin{array}{c}\text { Height 3 } \\
\mathbf{( m m})\end{array}$ & $\begin{array}{c}\text { Height 4 } \\
\mathbf{( m m})\end{array}$ & $\begin{array}{c}\text { Height 5 } \\
(\mathbf{m m})\end{array}$ & $\begin{array}{c}\text { Height 6 } \\
(\mathbf{m m})\end{array}$ & $\begin{array}{c}\text { Average } \\
\text { Height } \\
(\mathbf{m m})\end{array}$ & $\begin{array}{c}\text { Volume } \\
(\mathbf{m m})\end{array}$ \\
\hline 27 & 100.5 & 150.1 & 150.1 & 150.1 & 150.1 & 150.4 & 150.3 & 150.2 & 1191362.0 \\
\hline 28 & 100.5 & 149.3 & 149.5 & 149.6 & 149.6 & 149.3 & 149.3 & 149.4 & 1185412.5 \\
\hline 29 & 100.5 & 149.3 & 149.4 & 149.3 & 149.4 & 149.3 & 149.2 & 149.3 & 1184487.0 \\
\hline 30 & 100.5 & 149.3 & 149.4 & 149.5 & 149.4 & 149.5 & 149.6 & 149.5 & 1185544.7 \\
\hline
\end{tabular}




\begin{tabular}{|c|c|c|c|c|c|c|c|}
\hline \multicolumn{8}{|c|}{ Air Voids for $150 \mathrm{~mm}$ Sample } \\
\hline $\begin{array}{c}\text { Sample } \\
\text { ID }\end{array}$ & Volume (mm3) & Dry Mass (g) & $\begin{array}{c}\text { Volume } \\
\left(\mathrm{cm}^{3}\right)\end{array}$ & $\begin{array}{c}\text { Density } \\
\text { g/cm }\end{array}$ & Gmb & Gmm & Air Void (\%) \\
\hline 1 & 1199691.4 & 2747.8 & 1199.7 & 2.290 & 2.297 & 2.492 & 7.82 \\
\hline 2 & 1201013.5 & 2756.2 & 1201.0 & 2.295 & 2.302 & 2.495 & 7.75 \\
\hline 3 & 1195063.9 & 2753.9 & 1195.1 & 2.304 & 2.311 & 2.462 & 6.12 \\
\hline 4 & 1202335.6 & 2745.4 & 1202.3 & 2.283 & 2.290 & 2.469 & 7.24 \\
\hline 5 & 1204979.8 & 2720.0 & 1205.0 & 2.257 & 2.264 & 2.451 & 7.63 \\
\hline 6 & 1202996.7 & 2756.5 & 1203.0 & 2.291 & 2.298 & 2.492 & 7.78 \\
\hline 7 & 1189246.6 & 2727.0 & 1189.2 & 2.293 & 2.300 & 2.495 & 7.82 \\
\hline 8 & 1201939.0 & 2717.4 & 1201.9 & 2.261 & 2.268 & 2.469 & 8.16 \\
\hline 9 & 1184487.0 & 2668.1 & 1184.5 & 2.253 & 2.259 & 2.462 & 8.24 \\
\hline 10 & 1189907.7 & 2725.4 & 1189.9 & 2.290 & 2.297 & 2.486 & 7.59 \\
\hline 11 & 1193609.6 & 2694.4 & 1193.6 & 2.257 & 2.264 & 2.451 & 7.63 \\
\hline 12 & 1201410.1 & 2701.2 & 1201.4 & 2.248 & 2.255 & 2.451 & 8.00 \\
\hline 13 & 1197972.6 & 2739.4 & 1198.0 & 2.287 & 2.293 & 2.486 & 7.74 \\
\hline 14 & 1193741.8 & 2748.5 & 1193.7 & 2.302 & 2.309 & 2.495 & 7.45 \\
\hline 15 & 1192419.7 & 2742.2 & 1192.4 & 2.300 & 2.306 & 2.486 & 7.22 \\
\hline 16 & 1189378.8 & 2718.8 & 1189.4 & 2.286 & 2.293 & 2.486 & 7.78 \\
\hline 17 & 1187263.4 & 2686.1 & 1187.3 & 2.262 & 2.269 & 2.462 & 7.83 \\
\hline 18 & 1193345.2 & 2730.9 & 1193.3 & 2.288 & 2.295 & 2.492 & 7.90 \\
\hline 19 & 1187131.2 & 2701.3 & 1187.1 & 2.275 & 2.282 & 2.469 & 7.57 \\
\hline 20 & 1190172.1 & 2668.1 & 1190.2 & 2.242 & 2.248 & 2.451 & 8.27 \\
\hline 21 & 1195592.8 & 2739.5 & 1195.6 & 2.291 & 2.298 & 2.486 & 7.56 \\
\hline 22 & 1184222.6 & 2672.9 & 1184.2 & 2.257 & 2.264 & 2.451 & 7.64 \\
\hline 23 & 1185544.7 & 2691.8 & 1185.5 & 2.271 & 2.277 & 2.462 & 7.50 \\
\hline 24 & 1187395.6 & 2700.9 & 1187.4 & 2.275 & 2.281 & 2.469 & 7.60 \\
\hline 25 & 1191362.0 & 2744.4 & 1191.4 & 2.304 & 2.310 & 2.492 & 7.29 \\
\hline 26 & 1187924.5 & 2705.6 & 1187.9 & 2.278 & 2.284 & 2.469 & 7.48 \\
\hline 27 & 1191362.0 & 2734.1 & 1191.4 & 2.295 & 2.302 & 2.495 & 7.75 \\
\hline 28 & 1185412.5 & 2652.2 & 1185.4 & 2.237 & 2.244 & 2.462 & 8.86 \\
\hline
\end{tabular}




\begin{tabular}{|c|c|c|c|c|c|c|c|}
\hline \multicolumn{8}{|c|}{ Air Voids for $150 \mathrm{~mm}$ Sample } \\
\hline $\begin{array}{c}\text { Sample } \\
\text { ID }\end{array}$ & Volume (mm3) & Dry Mass (g) & $\begin{array}{c}\text { Volume } \\
\left(\mathrm{cm}^{3}\right)\end{array}$ & $\begin{array}{c}\text { Density } \\
\mathrm{g}^{\prime} \mathrm{cm}^{3}\end{array}$ & Gmb & Gmm & Air Void (\%) \\
\hline 29 & 1184487.0 & 2730.3 & 1184.5 & 2.305 & 2.312 & 2.492 & 7.23 \\
\hline 30 & 1185544.7 & 2723.3 & 1185.5 & 2.297 & 2.304 & 2.495 & 7.66 \\
\hline
\end{tabular}




\begin{tabular}{|r|r|r|r|r|r|r|r|}
\hline \multicolumn{1}{|c|}{$\begin{array}{c}\text { Sample } \\
\text { ID }\end{array}$} & $\begin{array}{c}\text { Avg. } \\
\text { Diameter } \\
(\mathbf{m m})\end{array}$ & $\begin{array}{c}\text { Height 1 } \\
(\mathbf{m m})\end{array}$ & $\begin{array}{c}\text { Height 2 } \\
\mathbf{( m m})\end{array}$ & $\begin{array}{c}\text { Height 3 } \\
\mathbf{( m m})\end{array}$ & $\begin{array}{c}\text { Height 4 } \\
\mathbf{( m m})\end{array}$ & $\begin{array}{c}\text { Average } \\
\text { Height } \\
(\mathbf{m m})\end{array}$ & $\begin{array}{c}\text { Volume } \\
\mathbf{( m m 3})\end{array}$ \\
\hline 1 & 100.5 & 49.6 & 49.6 & 49.5 & 49.5 & 49.6 & 393066.2 \\
\hline 2 & 100.5 & 47.6 & 47.4 & 47.4 & 47.2 & 47.4 & 376010.8 \\
\hline 3 & 100.5 & 46.5 & 46.4 & 46.3 & 46.2 & 46.4 & 367681.5 \\
\hline 4 & 100.5 & 49.1 & 49.1 & 48.8 & 48.8 & 49.0 & 388306.5 \\
\hline 5 & 100.5 & 48.8 & 48.5 & 48.6 & 48.3 & 48.6 & 385133.4 \\
\hline 6 & 100.5 & 48.0 & 47.8 & 47.7 & 47.6 & 47.8 & 378985.6 \\
\hline 7 & 100.5 & 47.8 & 47.7 & 47.7 & 47.6 & 47.7 & 378390.6 \\
\hline 8 & 100.5 & 48.7 & 48.4 & 48.2 & 48.2 & 48.4 & 383745.2 \\
\hline 9 & 100.5 & 47.1 & 47.0 & 46.9 & 46.8 & 47.0 & 372441.1 \\
\hline 10 & 100.5 & 48.0 & 47.7 & 47.6 & 47.6 & 47.7 & 378589.0 \\
\hline 11 & 100.5 & 47.6 & 47.6 & 47.6 & 47.2 & 47.5 & 376804.1 \\
\hline 12 & 100.5 & 48.0 & 47.9 & 47.9 & 47.8 & 47.9 & 379977.2 \\
\hline 13 & 100.5 & 46.9 & 46.8 & 46.8 & 46.5 & 46.8 & 370854.6 \\
\hline 14 & 100.5 & 47.6 & 47.4 & 47.4 & 47.2 & 47.4 & 376010.8 \\
\hline 15 & 100.5 & 48.2 & 48.1 & 48.0 & 47.9 & 48.1 & 381167.1 \\
\hline 16 & 100.5 & 46.8 & 46.7 & 46.7 & 46.6 & 46.7 & 370457.9 \\
\hline 17 & 100.5 & 46.9 & 46.9 & 46.8 & 46.7 & 46.8 & 371449.5 \\
\hline 18 & 100.5 & 47.5 & 47.4 & 47.4 & 47.2 & 47.4 & 375812.5 \\
\hline 19 & 100.5 & 49.8 & 49.7 & 49.7 & 49.6 & 49.7 & 394256.1 \\
\hline 20 & 100.5 & 46.3 & 46.4 & 46.7 & 46.5 & 46.5 & 368673.1 \\
\hline 21 & 100.5 & 47.5 & 47.5 & 47.4 & 47.3 & 47.4 & 376209.1 \\
\hline 22 & 100.5 & 47.7 & 47.6 & 47.6 & 47.6 & 47.6 & 377795.7 \\
\hline 23 & 100.5 & 46.4 & 46.3 & 46.1 & 46.1 & 46.2 & 366689.9 \\
\hline 24 & 100.5 & 47.7 & 47.6 & 47.5 & 47.4 & 47.6 & 377200.7 \\
\hline 25 & 100.5 & 47.8 & 47.7 & 47.7 & 47.6 & 47.7 & 378390.6 \\
\hline 26 & 100.5 & 48.5 & 48.5 & 48.4 & 48.3 & 48.4 & 384141.9 \\
\hline 27 & 100.5 & 48.8 & 48.7 & 48.7 & 48.5 & 48.7 & 386125.0 \\
\hline
\end{tabular}




\begin{tabular}{|r|c|r|r|r|r|r|r|}
\hline \multicolumn{7}{|c|}{ Specimen Measurements for End 1 of Sample } \\
\hline $\begin{array}{c}\text { Sample } \\
\text { ID }\end{array}$ & $\begin{array}{c}\text { Avg. } \\
\text { Diameter } \\
(\mathbf{m m})\end{array}$ & $\begin{array}{c}\text { Height 1 } \\
(\mathbf{m m})\end{array}$ & $\begin{array}{c}\text { Height 2 } \\
\mathbf{( m m})\end{array}$ & $\begin{array}{c}\text { Height 3 } \\
\mathbf{( m m})\end{array}$ & $\begin{array}{c}\text { Height 4 } \\
\mathbf{( m m})\end{array}$ & $\begin{array}{c}\text { Average } \\
\text { Height } \\
(\mathbf{m m})\end{array}$ & $\begin{array}{c}\text { Volume } \\
(\mathbf{m m})\end{array}$ \\
\hline 28 & 100.5 & 47.8 & 47.7 & 47.6 & 47.6 & 47.7 & 378192.3 \\
\hline 29 & 100.5 & 47.4 & 47.3 & 47.3 & 47.3 & 47.3 & 375415.9 \\
\hline 30 & 100.5 & 47.6 & 47.3 & 47.2 & 47.2 & 47.3 & 375415.9 \\
\hline
\end{tabular}




\begin{tabular}{|c|c|c|c|c|c|c|c|}
\hline \multicolumn{8}{|c|}{ Air Voids for End 1 of Sample } \\
\hline $\begin{array}{l}\text { Sample } \\
\text { ID }\end{array}$ & Volume $\left(\mathrm{mm}^{3}\right)$ & Dry Mass (g) & $\begin{array}{c}\text { Volume } \\
\left(\mathrm{cm}^{3}\right)\end{array}$ & $\begin{array}{c}\text { Density } \\
\mathrm{g}^{\prime} / \mathrm{cm}^{3}\end{array}$ & Gmb & Gmm & $\begin{array}{c}\text { Air Void } \\
(\%)\end{array}$ \\
\hline 1 & 393066.2 & 900.5 & 393.1 & 2.291 & 2.298 & 2.492 & 7.80 \\
\hline 2 & 376010.8 & 866.3 & 376.0 & 2.304 & 2.311 & 2.495 & 7.39 \\
\hline 3 & 367681.5 & 838.8 & 367.7 & 2.281 & 2.288 & 2.462 & 7.06 \\
\hline 4 & 388306.5 & 886.8 & 388.3 & 2.284 & 2.291 & 2.469 & 7.23 \\
\hline 5 & 385133.4 & 867.9 & 385.1 & 2.254 & 2.260 & 2.451 & 7.79 \\
\hline 6 & 378985.6 & 857.7 & 379.0 & 2.263 & 2.270 & 2.492 & 8.91 \\
\hline 7 & 378390.6 & 873.0 & 378.4 & 2.307 & 2.314 & 2.495 & 7.26 \\
\hline 8 & 383745.2 & 869.5 & 383.7 & 2.266 & 2.273 & 2.469 & 7.96 \\
\hline 9 & 372441.1 & 843.9 & 372.4 & 2.266 & 2.273 & 2.462 & 7.69 \\
\hline 10 & 378589.0 & 864.4 & 378.6 & 2.283 & 2.290 & 2.486 & 7.89 \\
\hline 11 & 376804.1 & 853.6 & 376.8 & 2.265 & 2.272 & 2.451 & 7.30 \\
\hline 12 & 379977.2 & 856.6 & 380.0 & 2.254 & 2.261 & 2.451 & 7.75 \\
\hline 13 & 370854.6 & 841.4 & 370.9 & 2.269 & 2.276 & 2.486 & 8.47 \\
\hline 14 & 376010.8 & 868.0 & 376.0 & 2.308 & 2.315 & 2.495 & 7.20 \\
\hline 15 & 381167.1 & 867.9 & 381.2 & 2.277 & 2.284 & 2.486 & 8.14 \\
\hline 16 & 370457.9 & 848.5 & 370.5 & 2.290 & 2.297 & 2.486 & 7.60 \\
\hline 17 & 371449.5 & 837.3 & 371.4 & 2.254 & 2.261 & 2.462 & 8.17 \\
\hline 18 & 375812.5 & 866.3 & 375.8 & 2.305 & 2.312 & 2.492 & 7.22 \\
\hline 19 & 394256.1 & 901.6 & 394.3 & 2.287 & 2.294 & 2.469 & 7.10 \\
\hline 20 & 368673.1 & 825.1 & 368.7 & 2.238 & 2.245 & 2.451 & 8.42 \\
\hline 21 & 376209.1 & 860.6 & 376.2 & 2.288 & 2.294 & 2.486 & 7.71 \\
\hline 22 & 377795.7 & 849.5 & 377.8 & 2.249 & 2.255 & 2.451 & 7.99 \\
\hline 23 & 366689.9 & 827.7 & 366.7 & 2.257 & 2.264 & 2.462 & 8.05 \\
\hline 24 & 377200.7 & 858.4 & 377.2 & 2.276 & 2.282 & 2.469 & 7.56 \\
\hline 25 & 378390.6 & 870.3 & 378.4 & 2.300 & 2.307 & 2.492 & 7.43 \\
\hline 26 & 384141.9 & 874.1 & 384.1 & 2.275 & 2.282 & 2.469 & 7.57 \\
\hline 27 & 386125.0 & 887.1 & 386.1 & 2.297 & 2.304 & 2.495 & 7.65 \\
\hline
\end{tabular}




\begin{tabular}{|c|c|c|c|c|c|c|c|}
\hline \multicolumn{8}{|c|}{ Air Voids for End 1 of Sample } \\
\hline $\begin{array}{c}\text { Sample } \\
\text { ID }\end{array}$ & Volume $\left(\mathrm{mm}^{3}\right)$ & Dry Mass (g) & $\begin{array}{c}\text { Volume } \\
\left(\mathrm{cm}^{3}\right)\end{array}$ & $\begin{array}{c}\text { Density } \\
\mathbf{g} / \mathrm{cm}^{3}\end{array}$ & Gmb & Gmm & $\begin{array}{c}\text { Air Void } \\
(\%)\end{array}$ \\
\hline 28 & 378192.3 & 849.9 & 378.2 & 2.247 & 2.254 & 2.462 & 8.45 \\
\hline 29 & 375415.9 & 867.1 & 375.4 & 2.310 & 2.317 & 2.492 & 7.04 \\
\hline 30 & 375415.9 & 858.8 & 375.4 & 2.288 & 2.294 & 2.495 & 8.04 \\
\hline
\end{tabular}




\begin{tabular}{|c|c|c|c|c|c|c|c|}
\hline \multicolumn{8}{|c|}{ Specimen Measurements for Middle of Sample } \\
\hline $\begin{array}{l}\text { Sample } \\
\text { ID }\end{array}$ & $\begin{array}{l}\text { Avg. } \\
\text { Diameter } \\
(\mathbf{m m})\end{array}$ & $\begin{array}{l}\text { Height } 1 \\
\quad(\mathbf{m m})\end{array}$ & $\begin{array}{c}\text { Height } 2 \\
\text { (mm) }\end{array}$ & $\begin{array}{c}\text { Height } 3 \\
(\mathbf{m m})\end{array}$ & $\begin{array}{c}\text { Height } 4 \\
(\mathbf{m m})\end{array}$ & $\begin{array}{c}\text { Average } \\
\text { Height }(\mathbf{m m})\end{array}$ & $\begin{array}{l}\text { Volume } \\
\text { (mm3) }\end{array}$ \\
\hline 1 & 100.5 & 45.9 & 45.9 & 46.1 & 46.0 & 46.0 & 364706.7 \\
\hline 2 & 100.5 & 48.7 & 48.7 & 48.8 & 48.8 & 48.8 & 386720.0 \\
\hline 3 & 100.5 & 49.0 & 49.0 & 48.9 & 49.2 & 49.0 & 388901.5 \\
\hline 4 & 100.5 & 46.4 & 46.3 & 46.2 & 46.1 & 46.3 & 366888.2 \\
\hline 5 & 100.5 & 47.5 & 47.5 & 47.4 & 47.4 & 47.5 & 376407.5 \\
\hline 6 & 100.5 & 48.3 & 48.1 & 48.1 & 48.0 & 48.1 & 381762.0 \\
\hline 7 & 100.5 & 47.1 & 47.1 & 47.1 & 47.2 & 47.1 & 373829.3 \\
\hline 8 & 100.5 & 47.0 & 47.0 & 47.1 & 46.8 & 47.0 & 372639.4 \\
\hline 9 & 100.5 & 46.3 & 46.3 & 46.2 & 46.0 & 46.2 & 366491.6 \\
\hline 10 & 100.5 & 46.5 & 46.5 & 46.4 & 46.3 & 46.4 & 368276.4 \\
\hline 11 & 100.5 & 46.6 & 46.7 & 47.0 & 47.4 & 46.9 & 372242.8 \\
\hline 12 & 100.5 & 47.7 & 47.3 & 47.2 & 47.2 & 47.4 & 375614.2 \\
\hline 13 & 100.5 & 48.8 & 48.7 & 48.6 & 48.4 & 48.6 & 385728.4 \\
\hline 14 & 100.5 & 47.4 & 47.2 & 47.1 & 47.1 & 47.2 & 374424.3 \\
\hline 15 & 100.5 & 47.0 & 46.8 & 46.8 & 46.7 & 46.8 & 371449.5 \\
\hline 16 & 100.5 & 47.8 & 47.9 & 48.0 & 48.1 & 48.0 & 380373.8 \\
\hline 17 & 100.5 & 47.8 & 47.7 & 47.6 & 47.5 & 47.7 & 377994.0 \\
\hline 18 & 100.5 & 47.7 & 47.6 & 47.6 & 47.5 & 47.6 & 377597.4 \\
\hline 19 & 100.5 & 49.8 & 49.8 & 49.7 & 49.6 & 49.7 & 394454.4 \\
\hline 20 & 100.5 & 47.0 & 46.9 & 46.9 & 46.8 & 46.9 & 372044.5 \\
\hline 21 & 100.5 & 46.8 & 46.8 & 46.8 & 46.8 & 46.8 & 371251.2 \\
\hline 22 & 100.5 & 47.3 & 47.3 & 47.4 & 47.4 & 47.4 & 375614.2 \\
\hline 23 & 100.5 & 48.8 & 48.5 & 48.4 & 48.4 & 48.5 & 384935.1 \\
\hline 24 & 100.5 & 46.9 & 46.8 & 46.7 & 46.6 & 46.8 & 370854.6 \\
\hline 25 & 100.5 & 47.7 & 47.6 & 47.6 & 47.6 & 47.6 & 377795.7 \\
\hline 26 & 100.5 & 46.2 & 46.1 & 46.1 & 46.0 & 46.1 & 365698.3 \\
\hline 27 & 100.5 & 46.6 & 46.5 & 46.5 & 46.3 & 46.5 & 368673.1 \\
\hline
\end{tabular}




\begin{tabular}{|r|c|r|r|r|r|r|r|}
\hline \multicolumn{7}{|c|}{ Specimen Measurements for Middle of Sample } \\
\hline $\begin{array}{c}\text { Sample } \\
\text { ID }\end{array}$ & $\begin{array}{c}\text { Avg. } \\
\text { Diameter } \\
(\mathbf{m m})\end{array}$ & $\begin{array}{c}\text { Height 1 } \\
(\mathbf{m m})\end{array}$ & $\begin{array}{c}\text { Height 2 } \\
\mathbf{( m m})\end{array}$ & $\begin{array}{c}\text { Height 3 } \\
\mathbf{( m m})\end{array}$ & $\begin{array}{c}\text { Height 4 } \\
\mathbf{( m m})\end{array}$ & $\begin{array}{c}\text { Average } \\
\text { Height (mm) }\end{array}$ & $\begin{array}{c}\text { Volume } \\
(\mathbf{m m} \mathbf{)})\end{array}$ \\
\hline 28 & 100.5 & 46.3 & 46.1 & 46.1 & 45.9 & 46.1 & 365698.3 \\
\hline 29 & 100.5 & 46.1 & 46.0 & 46.0 & 45.9 & 46.0 & 364905.0 \\
\hline 30 & 100.5 & 46.3 & 46.3 & 46.3 & 46.2 & 46.3 & 367086.5 \\
\hline
\end{tabular}




\begin{tabular}{|c|c|c|c|c|c|c|c|}
\hline \multicolumn{8}{|c|}{ Air Voids for Middle of Sample } \\
\hline $\begin{array}{c}\text { Sample } \\
\text { ID }\end{array}$ & $\begin{array}{l}\text { Volume } \\
\left(\mathrm{mm}^{3}\right)\end{array}$ & Dry Mass (g) & $\begin{array}{c}\text { Volume } \\
\left(\mathrm{cm}^{3}\right)\end{array}$ & $\begin{array}{c}\text { Density } \\
\mathrm{g} / \mathrm{cm}^{3}\end{array}$ & Gmb & Gmm & $\begin{array}{c}\text { Air Void } \\
(\%)\end{array}$ \\
\hline 1 & 364706.7 & 830.9 & 364.7 & 2.278 & 2.285 & 2.492 & 8.31 \\
\hline 2 & 386720.0 & 871.3 & 386.7 & 2.253 & 2.260 & 2.495 & 9.43 \\
\hline 3 & 388901.5 & 877.9 & 388.9 & 2.257 & 2.264 & 2.462 & 8.04 \\
\hline 4 & 366888.2 & 824.8 & 366.9 & 2.248 & 2.255 & 2.469 & 8.68 \\
\hline 5 & 376407.5 & 845.1 & 376.4 & 2.245 & 2.252 & 2.451 & 8.13 \\
\hline 6 & 381762.0 & 871.5 & 381.8 & 2.283 & 2.290 & 2.492 & 8.12 \\
\hline 7 & 373829.3 & 849.0 & 373.8 & 2.271 & 2.278 & 2.495 & 8.71 \\
\hline 8 & 372639.4 & 834.8 & 372.6 & 2.240 & 2.247 & 2.469 & 9.00 \\
\hline 9 & 366491.6 & 812.1 & 366.5 & 2.216 & 2.222 & 2.462 & 9.73 \\
\hline 10 & 368276.4 & 835.5 & 368.3 & 2.269 & 2.275 & 2.486 & 8.47 \\
\hline 11 & 372242.8 & 825.0 & 372.2 & 2.216 & 2.223 & 2.451 & 9.31 \\
\hline 12 & 375614.2 & 832.1 & 375.6 & 2.215 & 2.222 & 2.451 & 9.35 \\
\hline 13 & 385728.4 & 871.2 & 385.7 & 2.259 & 2.265 & 2.486 & 8.88 \\
\hline 14 & 374424.3 & 853.3 & 374.4 & 2.279 & 2.286 & 2.495 & 8.39 \\
\hline 15 & 371449.5 & 846.9 & 371.4 & 2.280 & 2.287 & 2.486 & 8.02 \\
\hline 16 & 380373.8 & 858.6 & 380.4 & 2.257 & 2.264 & 2.486 & 8.93 \\
\hline 17 & 377994.0 & 841.2 & 378.0 & 2.225 & 2.232 & 2.462 & 9.34 \\
\hline 18 & 377597.4 & 852.1 & 377.6 & 2.257 & 2.263 & 2.492 & 9.18 \\
\hline 19 & 394454.4 & 881.9 & 394.5 & 2.236 & 2.242 & 2.469 & 9.18 \\
\hline 20 & 372044.5 & 819.6 & 372.0 & 2.203 & 2.209 & 2.451 & 9.85 \\
\hline 21 & 371251.2 & 844.7 & 371.3 & 2.275 & 2.282 & 2.486 & 8.21 \\
\hline 22 & 375614.2 & 838.9 & 375.6 & 2.233 & 2.240 & 2.451 & 8.61 \\
\hline 23 & 384935.1 & 856.9 & 384.9 & 2.226 & 2.233 & 2.462 & 9.31 \\
\hline 24 & 370854.6 & 830.7 & 370.9 & 2.240 & 2.247 & 2.469 & 9.01 \\
\hline 25 & 377795.7 & 861.2 & 377.8 & 2.280 & 2.286 & 2.492 & 8.26 \\
\hline 26 & 365698.3 & 822.8 & 365.7 & 2.250 & 2.257 & 2.469 & 8.60 \\
\hline 27 & 368673.1 & 834.5 & 368.7 & 2.264 & 2.270 & 2.495 & 9.01 \\
\hline
\end{tabular}




\begin{tabular}{|c|c|c|c|c|c|c|c|}
\hline \multicolumn{8}{|c|}{ Air Voids for Middle of Sample } \\
\hline $\begin{array}{l}\text { Sample } \\
\text { ID }\end{array}$ & $\underset{\left(\mathbf{m m}^{3}\right)}{\text { Volume }}$ & Dry Mass (g) & $\underset{\left(\mathrm{cm}^{3}\right)}{\text { Volume }}$ & $\begin{array}{c}\text { Density } \\
\mathrm{g} / \mathrm{cm}^{3}\end{array}$ & Gmb & Gmm & $\begin{array}{c}\text { Air Void } \\
(\%)\end{array}$ \\
\hline 28 & 365698.3 & 813.1 & 365.7 & 2.223 & 2.230 & 2.462 & 9.42 \\
\hline 29 & 364905.0 & 832.2 & 364.9 & 2.281 & 2.287 & 2.492 & 8.21 \\
\hline 30 & 367086.5 & 839.3 & 367.1 & 2.286 & 2.293 & 2.495 & 8.09 \\
\hline
\end{tabular}




\begin{tabular}{|c|c|c|c|c|c|c|c|}
\hline \multicolumn{8}{|c|}{ Specimen Measurements for End 2 of Sample } \\
\hline $\begin{array}{l}\text { Sample } \\
\text { ID }\end{array}$ & $\begin{array}{c}\text { Avg. } \\
\text { Diameter } \\
(\mathbf{m m})\end{array}$ & $\begin{array}{c}\text { Height } 1 \\
(\mathbf{m m})\end{array}$ & $\begin{array}{c}\text { Height } 2 \\
(\mathbf{m m})\end{array}$ & $\begin{array}{c}\text { Height } 3 \\
(\mathbf{m m})\end{array}$ & $\begin{array}{c}\text { Height } 4 \\
(\mathbf{m m})\end{array}$ & $\begin{array}{c}\text { Average } \\
\text { Height } \\
(\mathrm{mm})\end{array}$ & $\begin{array}{l}\text { Volume } \\
\text { (mm3) }\end{array}$ \\
\hline 1 & 100.5 & 47.8 & 47.8 & 48.3 & 48.3 & 48.1 & 381167.1 \\
\hline 2 & 100.5 & 48.3 & 48.2 & 48.3 & 48.0 & 48.2 & 382357.0 \\
\hline 3 & 100.5 & 48.3 & 48.2 & 47.9 & 48.1 & 48.1 & 381762.0 \\
\hline 4 & 100.5 & 49.4 & 49.3 & 49.4 & 49.2 & 49.3 & 391281.3 \\
\hline 5 & 100.5 & 48.6 & 48.5 & 48.5 & 48.3 & 48.5 & 384538.5 \\
\hline 6 & 100.5 & 48.4 & 48.5 & 48.6 & 48.7 & 48.6 & 385133.4 \\
\hline 7 & 100.5 & 47.9 & 47.7 & 47.6 & 47.7 & 47.7 & 378589.0 \\
\hline 8 & 100.5 & 48.8 & 48.9 & 48.9 & 49.0 & 48.9 & 387909.9 \\
\hline 9 & 100.5 & 48.9 & 48.9 & 48.5 & 48.6 & 48.7 & 386521.7 \\
\hline 10 & 100.5 & 48.7 & 48.9 & 49.0 & 48.5 & 48.8 & 386918.3 \\
\hline 11 & 100.5 & 49.0 & 49.0 & 49.1 & 49.1 & 49.1 & 389099.8 \\
\hline 12 & 100.5 & 48.8 & 48.7 & 48.8 & 48.7 & 48.8 & 386720.0 \\
\hline 13 & 100.5 & 48.0 & 48.1 & 48.4 & 48.5 & 48.3 & 382753.6 \\
\hline 14 & 100.5 & 48.4 & 48.4 & 48.3 & 48.3 & 48.4 & 383546.9 \\
\hline 15 & 100.5 & 47.8 & 48.5 & 48.4 & 47.8 & 48.1 & 381762.0 \\
\hline 16 & 100.5 & 48.1 & 48.4 & 48.5 & 47.8 & 48.2 & 382357.0 \\
\hline 17 & 100.5 & 47.3 & 47.6 & 47.9 & 47.7 & 47.6 & 377795.7 \\
\hline 18 & 100.5 & 47.9 & 48.0 & 48.1 & 48.2 & 48.1 & 381167.1 \\
\hline 19 & 100.5 & 42.8 & 42.7 & 42.7 & 42.6 & 42.7 & 338727.1 \\
\hline 20 & 100.5 & 49.4 & 49.5 & 49.4 & 49.1 & 49.4 & 391479.6 \\
\hline 21 & 100.5 & 49.0 & 49.0 & 49.1 & 49.1 & 49.1 & 389099.8 \\
\hline 22 & 100.5 & 46.9 & 46.9 & 46.8 & 47.0 & 46.9 & 372044.5 \\
\hline 23 & 100.5 & 47.7 & 47.8 & 47.9 & 48.2 & 47.9 & 379977.2 \\
\hline 24 & 100.5 & 47.5 & 47.4 & 47.6 & 47.6 & 47.5 & 377002.4 \\
\hline 25 & 100.5 & 47.8 & 47.9 & 47.5 & 47.7 & 47.7 & 378589.0 \\
\hline 26 & 100.5 & 47.8 & 47.9 & 47.5 & 47.7 & 47.7 & 378589.0 \\
\hline 27 & 100.5 & 47.6 & 47.6 & 47.8 & 47.8 & 47.7 & 378390.6 \\
\hline
\end{tabular}




\begin{tabular}{|r|c|r|r|r|r|r|r|}
\hline \multicolumn{7}{|c|}{ Specimen Measurements for End 2 of Sample } \\
\hline $\begin{array}{c}\text { Sample } \\
\text { ID }\end{array}$ & $\begin{array}{c}\text { Avg. } \\
\text { Diameter } \\
(\mathbf{m m})\end{array}$ & $\begin{array}{c}\text { Height 1 } \\
(\mathbf{m m})\end{array}$ & $\begin{array}{c}\text { Height 2 } \\
\mathbf{( m m})\end{array}$ & $\begin{array}{c}\text { Height 3 } \\
(\mathbf{m m})\end{array}$ & $\begin{array}{c}\text { Height 4 } \\
\mathbf{( m m})\end{array}$ & $\begin{array}{c}\text { Average } \\
\text { Height } \\
(\mathbf{m m})\end{array}$ & $\begin{array}{c}\text { Volume } \\
(\mathbf{m m} \mathbf{)})\end{array}$ \\
\hline 28 & 100.5 & 48.2 & 48.5 & 48.2 & 48.0 & 48.2 & 382555.3 \\
\hline 29 & 100.5 & 48.4 & 48.5 & 48.5 & 48.2 & 48.4 & 383943.5 \\
\hline 30 & 100.5 & 48.1 & 48.2 & 48.3 & 48.5 & 48.3 & 382952.0 \\
\hline
\end{tabular}




\begin{tabular}{|c|c|c|c|c|c|c|c|}
\hline \multicolumn{8}{|c|}{ Air Voids for End 2 of Sample } \\
\hline $\begin{array}{l}\text { Sample } \\
\text { ID }\end{array}$ & $\begin{array}{c}\text { Volume } \\
\left(\mathrm{mm}^{3}\right)\end{array}$ & $\begin{array}{l}\text { Dry Mass } \\
\text { (g) }\end{array}$ & $\begin{array}{c}\text { Volume } \\
\left(\mathrm{cm}^{3}\right)\end{array}$ & $\begin{array}{c}\text { Density } \\
\mathrm{g} / \mathrm{cm}^{3}\end{array}$ & Gmb & Gmm & $\begin{array}{c}\text { Air Void } \\
(\%)\end{array}$ \\
\hline 1 & 381167.1 & 874.8 & 381.2 & 2.295 & 2.302 & 2.492 & 7.63 \\
\hline 2 & 382357.0 & 876.5 & 382.4 & 2.292 & 2.299 & 2.495 & 7.85 \\
\hline 3 & 381762.0 & 864.1 & 381.8 & 2.263 & 2.270 & 2.462 & 7.79 \\
\hline 4 & 391281.3 & 894.0 & 391.3 & 2.285 & 2.292 & 2.469 & 7.19 \\
\hline 5 & 384538.5 & 867.8 & 384.5 & 2.257 & 2.263 & 2.451 & 7.65 \\
\hline 6 & 385133.4 & 886.0 & 385.1 & 2.301 & 2.307 & 2.492 & 7.41 \\
\hline 7 & 378589.0 & 864.9 & 378.6 & 2.285 & 2.291 & 2.495 & 8.16 \\
\hline 8 & 387909.9 & 879.9 & 387.9 & 2.268 & 2.275 & 2.469 & 7.86 \\
\hline 9 & 386521.7 & 874.6 & 386.5 & 2.263 & 2.269 & 2.462 & 7.82 \\
\hline 10 & 386918.3 & 883.4 & 386.9 & 2.283 & 2.290 & 2.486 & 7.89 \\
\hline 11 & 389099.8 & 876.9 & 389.1 & 2.254 & 2.260 & 2.451 & 7.78 \\
\hline 12 & 386720.0 & 873.1 & 386.7 & 2.258 & 2.264 & 2.451 & 7.61 \\
\hline 13 & 382753.6 & 884.6 & 382.8 & 2.311 & 2.318 & 2.486 & 6.76 \\
\hline 14 & 383546.9 & 885.1 & 383.5 & 2.308 & 2.314 & 2.495 & 7.23 \\
\hline 15 & 381762.0 & 884.5 & 381.8 & 2.317 & 2.324 & 2.486 & 6.53 \\
\hline 16 & 382357.0 & 870.1 & 382.4 & 2.276 & 2.282 & 2.486 & 8.19 \\
\hline 17 & 377795.7 & 867.0 & 377.8 & 2.295 & 2.302 & 2.462 & 6.51 \\
\hline 18 & 381167.1 & 871.4 & 381.2 & 2.286 & 2.293 & 2.492 & 7.99 \\
\hline 19 & 338727.1 & 778.3 & 338.7 & 2.298 & 2.305 & 2.469 & 6.66 \\
\hline 20 & 391479.6 & 885.0 & 391.5 & 2.261 & 2.267 & 2.451 & 7.49 \\
\hline 21 & 389099.8 & 892.8 & 389.1 & 2.295 & 2.301 & 2.486 & 7.43 \\
\hline 22 & 372044.5 & 843.6 & 372.0 & 2.267 & 2.274 & 2.451 & 7.21 \\
\hline 23 & 379977.2 & 868.7 & 380.0 & 2.286 & 2.293 & 2.462 & 6.87 \\
\hline 24 & 377002.4 & 874.0 & 377.0 & 2.318 & 2.325 & 2.469 & 5.83 \\
\hline 25 & 378589.0 & 873.0 & 378.6 & 2.306 & 2.313 & 2.492 & 7.19 \\
\hline 26 & 378589.0 & 868.9 & 378.6 & 2.295 & 2.302 & 2.469 & 6.77 \\
\hline 27 & 378390.6 & 871.8 & 378.4 & 2.304 & 2.311 & 2.495 & 7.38 \\
\hline
\end{tabular}




\begin{tabular}{|r|c|r|r|r|r|r|r|}
\hline \multicolumn{7}{|c|}{ Air Voids for End 2 of Sample } \\
\hline $\begin{array}{c}\text { Sample } \\
\text { ID }\end{array}$ & $\begin{array}{c}\text { Volume } \\
\left(\mathbf{m m}^{\mathbf{3}}\right)\end{array}$ & $\begin{array}{c}\text { Dry Mass } \\
\mathbf{( g )}\end{array}$ & $\begin{array}{c}\text { Volume } \\
\left(\mathbf{c m}^{\mathbf{3}}\right)\end{array}$ & $\begin{array}{c}\text { Density } \\
\mathbf{g} / \mathbf{c m}^{\mathbf{3}}\end{array}$ & $\mathbf{G m b}$ & $\mathbf{G m m}$ & $\begin{array}{c}\text { Air Void } \\
(\mathbf{\%})\end{array}$ \\
\hline 28 & 382555.3 & 853.1 & 382.6 & 2.230 & 2.237 & 2.462 & 9.16 \\
\hline 29 & 383943.5 & 889.0 & 383.9 & 2.315 & 2.322 & 2.492 & 6.81 \\
\hline 30 & 382952.0 & 882.4 & 383.0 & 2.304 & 2.311 & 2.495 & 7.37 \\
\hline
\end{tabular}


Appendix E

Statistical Analyses 
- $t$ test CoreLok vs Dimensional Method for $150 \mathrm{~mm}$ samples

$>$ t.test(NTAV\$Air.Voids NTAV\$Gmb.Method)

Welch Two Sample t-test

data: NTAV\$Air.Voids by NTAV\$Gmb. Method

$\mathrm{t}=-6.1897, \mathrm{df}=51.607, \mathrm{p}$-value $=9.91 \mathrm{e}-08$

alternative hypothesis: true difference in means is not equal to 0 95 percent confidence interval:

$-0.8205946-0.4187387$

sample estimates:

mean in group Corelok mean in group Dimensional 7.050667

7.670333

- ANOVA of Air Voids in Whole Sample

$>\operatorname{aov}($ Air.Voids Gmb.Method*NMAS*Binder, NTAV)

Call:

$\operatorname{aov}($ formula $=$ Air. Voids $\sim$ Gmb. Method * NMAS * Binder, data $=$ NTAV)

Terms:

\begin{tabular}{|c|c|c|c|c|c|}
\hline & Gmb. Method & Binder & Gmb.Method: NMAS & Gmb. Method:Binder & NMAS:Binder \\
\hline Sum of Squares & 5.7598020 .241935 & 0.222330 & 0.015042 & 0.026763 & 0.077250 \\
\hline Deg. of Freedom & $\begin{array}{lll}1 & 1\end{array}$ & 2 & 1 & 2 & \\
\hline & \multicolumn{5}{|c|}{ Gmb.Method:NMAS:Binder Residuals } \\
\hline Sum of Squares & 0.0279 & 638.108 & 3400 & & \\
\hline Deg. of Freedom & & 2 & 48 & & \\
\hline
\end{tabular}

Residual standard error: 0.4110049

Estimated effects may be unbalanced

$>\operatorname{summary}(\operatorname{aov}(A i r$. Voids Gmb. Method*NMAS*Binder, NTAV))

Gmb. Method

Df Sum Sq Mean Sq F value $\operatorname{Pr}(>\mathrm{F})$

NMAS

15.760

5.760

$34.0974 .41 \mathrm{e}-07$

Binder

0.242

0.242

1.432

0.237

Gmb.Method:NMAS

20.222

Gmb. Method:Binder

10.015

0.111

0.658

0.015

0.089

0.522

20.027

0.013

0.079

0.767

NMAS:Binder

0.077

0.039

0.229

0.924

Gmb. Method:NMAS:Binder

0.028

Residuals

$\begin{array}{ll}48 & 8.108\end{array}$

0.014

0.169

0.083

0.796

---

Signif. codes: 0 “***, 0.001 “**, 0.01 “*, 0.05 ', 0.1 ‘, 1 
- $t$ test Comparing Air Voids in Middle and Ends of Sample with CoreLok Method Data

$>$ t.test(CSA\$Air CSA\$Section)

Welch Two Sample t-test

data: CSA\$Air by CSA\$Section

$t=-9.7128, \mathrm{df}=56.836, \mathrm{p}$-value $=1.115 \mathrm{e}-13$

alternative hypothesis: true difference in means is not equal to 0 95 percent confidence interval:

$-1.397963-0.920037$

sample estimates:

mean in group End mean in group Middle

6.805333

7.964333

- $t$ test Comparing Air Voids in Middle and Ends of Sample with Dimensional Method Data

$$
\text { Welch Two Sample t-test }
$$

data: DSA\$Air by DSA\$Section

$t=-9.8754, d f=62.235, p$-value $=2.322 \mathrm{e}-14$

alternative hypothesis: true difference in means is not equal to 0 95 percent confidence interval:

$-1.4769543-0.9797124$

sample estimates:

mean in group End mean in group Middle
7.564333
8.792667 
- ANOVA of Air Voids within Sample with CoreLok Method Data

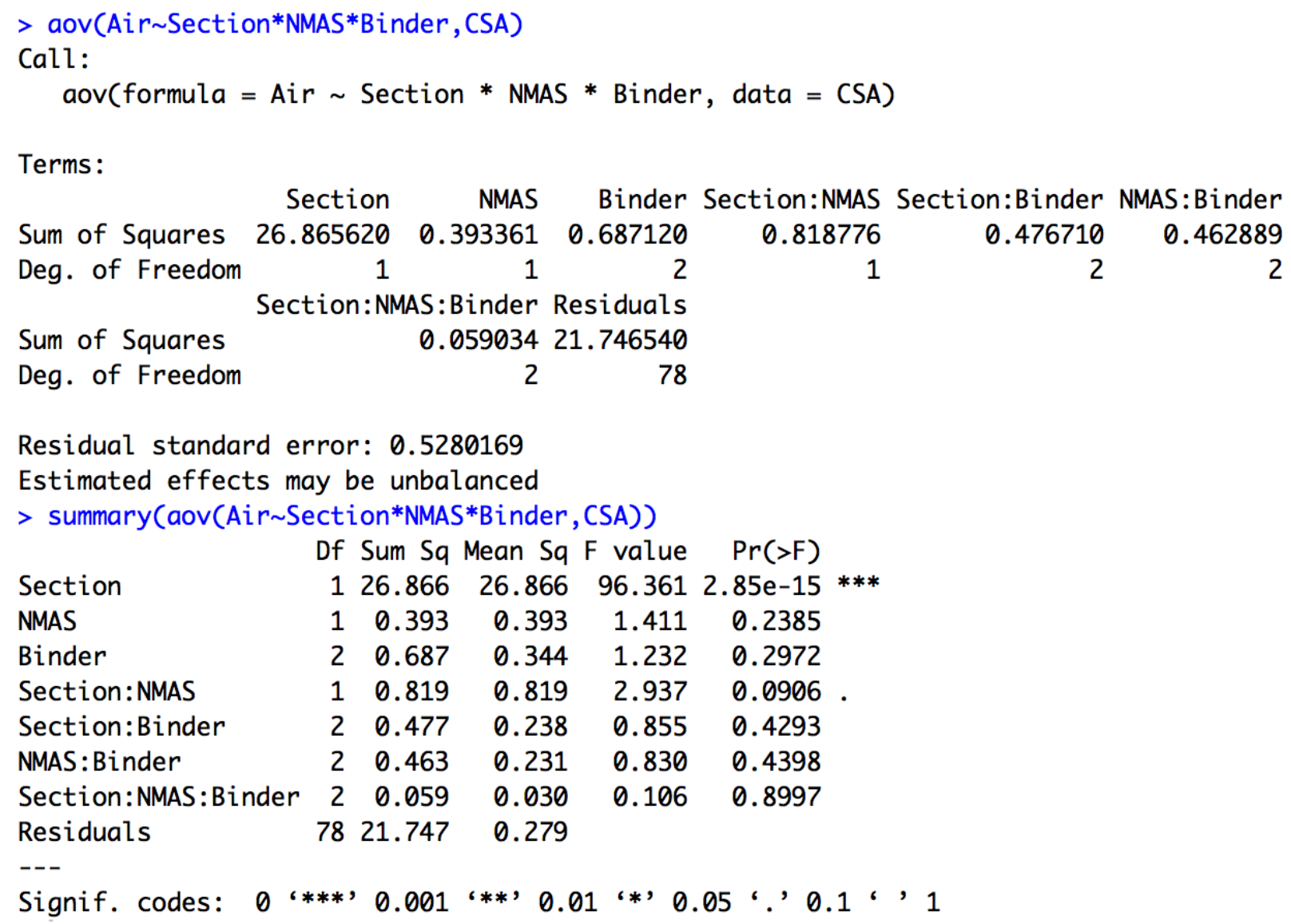


- ANOVA of Air Voids within Sample with Dimensional Method Data

$>\operatorname{aov}($ Air. Voids Section*NMAS*Binder,DSA)

Call:

$\operatorname{aov}($ formula $=$ Air. Voids $\sim$ Section * NMAS * Binder, data $=$ DSA $)$

Terms :

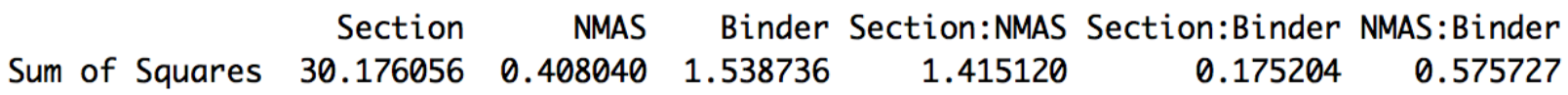

Deg. of Freedom

Section:NMAS:Binder Residuals

Sum of Squares $\quad 0.31129324 .237940$

Deg. of Freedom

2

78

Residual standard error: 0.5574431

Estimated effects may be unbalanced

> summary(aov(Air.Voids Section*NMAS*Binder, DSA))

Df Sum Sq Mean Sq F value $\operatorname{Pr}(>\mathrm{F})$

Section $\quad 130.176 \quad 30.176 \quad 97.1092 .4 \mathrm{e}-15$

$\begin{array}{llllll}\text { NMAS } & 1 & 0.408 & 0.408 & 1.313 & 0.2553\end{array}$

$\begin{array}{llllll}\text { Binder } & 2 & 1.539 & 0.769 & 2.476 & 0.0907 .\end{array}$

$\begin{array}{llllll}\text { Section:NMAS } & 1 & 1.415 & 1.415 & 4.554 & 0.0360^{*}\end{array}$

$\begin{array}{llllll}\text { Section:Binder } & 2 & 0.175 & 0.088 & 0.282 & 0.7551\end{array}$

$\begin{array}{llllll}\text { NMAS:Binder } & 2 & 0.576 & 0.288 & 0.926 & 0.4003\end{array}$

$\begin{array}{llllll}\text { Section:NMAS:Binder } & 2 & 0.311 & 0.156 & 0.501 & 0.6079\end{array}$

$\begin{array}{llll}\text { Residuals } & 78 & 24.238 & 0.311\end{array}$

---

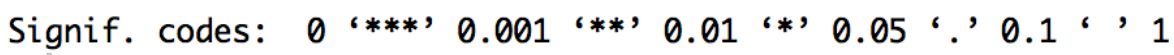


- ANOVA of Heterogeneity Index with CoreLok Data

$>\operatorname{aov}(\mathrm{HI}$. Avg NMAS*Binder, NCSA.HI)

Call:

$$
\operatorname{aov}(\text { formula }=\text { HI.Avg } \sim \text { NMAS } * \text { Binder, data }=\text { NCSA.HI) }
$$

Terms:

NMAS Binder NMAS:Binder Residuals

Sum of Squares 0.0032033330 .0015200000 .0001066670 .026440000

$\begin{array}{lllll}\text { Deg. of Freedom } & 1 & 2 & 2 & 24\end{array}$

Residual standard error: 0.03319136

Estimated effects may be unbalanced

$>$ summary(aov(HI.Avg NMAS*Binder, NCSA.HI))

Df Sum Sq Mean Sq $F$ value $\operatorname{Pr}(>F)$

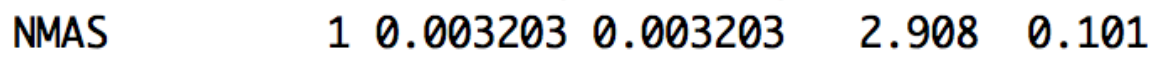

Binder $\quad 20.0015200 .000760 \quad 0.690 \quad 0.511$

NMAS:Binder $20.000107 \quad 0.000053 \quad 0.048 \quad 0.953$

Residuals 240.0264400 .001102

- ANOVA of Heterogeneity Index with Dimensional Method Data

$>\operatorname{aov}(\mathrm{HI}$. Avg NMAS*Binder, NVSA.HI)

Call:

$\operatorname{aov}($ formula $=$ HI.Avg $\sim$ NMAS $*$ Binder, data $=$ NVSA.HI)

Terms :

NMAS Binder NMAS:Binder Residuals

Sum of Squares $0.0026133330 .000620000 \quad 0.001406667 \quad 0.024080000$

Deg. of Freedom $\quad 1 \quad 24$

Residual standard error: 0.03167544

Estimated effects may be unbalanced

$>$ summary (aov(HI.Avg NMAS*Binder, NVSA.HI))

Df Sum Sq Mean Sq $F$ value $\operatorname{Pr}(>F)$

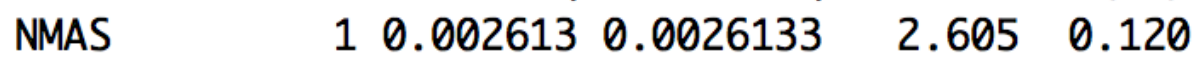

$\begin{array}{lllll}\text { Binder } \quad 2 & 0.000620 & 0.0003100 & 0.309 & 0.737\end{array}$

NMAS:Binder $20.001407 \quad 0.0007033 \quad 0.701 \quad 0.506$

Residuals 240.0240800 .0010033 